\title{
Synthesis, Characterization, and Reactivity Studies of para- Substituted Triaryltin Cobaloximes
}

\author{
Elizabeth Marie Ward
}

Follow this and additional works at: https://researchrepository.wvu.edu/etd

\section{Recommended Citation}

Ward, Elizabeth Marie, "Synthesis, Characterization, and Reactivity Studies of para-Substituted Triaryltin Cobaloximes" (2017). Graduate Theses, Dissertations, and Problem Reports. 6914.

https://researchrepository.wvu.edu/etd/6914

This Thesis is protected by copyright and/or related rights. It has been brought to you by the The Research Repository @ WVU with permission from the rights-holder(s). You are free to use this Thesis in any way that is permitted by the copyright and related rights legislation that applies to your use. For other uses you must obtain permission from the rights-holder(s) directly, unless additional rights are indicated by a Creative Commons license in the record and/ or on the work itself. This Thesis has been accepted for inclusion in WVU Graduate Theses, Dissertations, and Problem Reports collection by an authorized administrator of The Research Repository @ WVU. For more information, please contact researchrepository@mail.wvu.edu. 
SYNTHESIS, CHARACTERIZATION, AND REACTIVITY STUDIES OF PARA-SUBSTITUTED TRIARYLTIN COBALOXIMES

\author{
Elizabeth Marie Ward
}
Thesis submitted to the Eberly College of Arts and Sciences at West Virginia University
in partial fulfillment of the requirements
for the degree of
Master of Science
in
Chemistry
Jeffrey Petersen, Ph.D., Committee Chairperson
Björn Söderberg, Ph.D.
Kung Wang, Ph.D.

C. Eugene Bennett Department of Chemistry

Morgantown, West Virginia

2017

Keywords: cobaloxime, Vitamin $\mathrm{B}_{12}$ models, Co-Sn bond, halogen cleavage reactions, aryltin cobaloxime

Copyright 2017 Elizabeth Marie Ward 


\section{Abstract \\ Synthesis, Characterization, and Reactivity Studies of para-Substituted Triaryltin Cobaloximes}

\section{Elizabeth Marie Ward}

Several six-coordinate cobaloxime compounds containing a triaryltin ligand were synthesized and characterized. These cobaloximes include (4-t-BuPy) $\mathrm{Co}(\mathrm{DH})_{2} \mathrm{Sn}\left(\mathrm{C}_{6} \mathrm{H}_{4}-p\right.$ tolyl $)_{3}$, (4-t-BuPy)Co(DH $)_{2} \mathrm{Sn}\left(\mathrm{C}_{6} \mathrm{H}_{4}-p-t-\mathrm{Bu}\right)_{3},\left(\mathrm{NH}_{3}\right) \mathrm{Co}(\mathrm{DH})_{2} \mathrm{SnPh}_{3}$, and (4-tBuPy)Co(DH $)_{2} \mathrm{Bn}$. (4-t-BuPy)Co(DH $)_{2} \mathrm{Sn}\left(\mathrm{C}_{6} \mathrm{H}_{4}-p \text {-tolyl }\right)_{3}$ crystallized in the centrosymmetric triclinic space group $P-1(\mathrm{Z}=4)$ with unit cell dimensions a $=13.2949$ (5) $\AA, b=17.7508(7) \AA, c=18.2240(7) \AA, \alpha=107.1983(13)^{\circ}, \beta=91.6597(13)^{\circ}, \gamma=$ 107.6992(12) $)^{\circ}$, and Volume $=3880.5(3) \AA^{3}$. The structure was isostructural with other alkyl cobaloximes. Preliminary X-ray structure analysis determined that $\left(\mathrm{NH}_{3}\right) \mathrm{Co}(\mathrm{DH})_{2} \mathrm{SnPh}_{3}$ had a $\mathrm{NH}_{3}$ ligand bound to the six-coordinate octahedral cobalt center and trans to the triaryltin ligand. The para-substituted cobaloximes were synthesized through a Gringard reaction to obtain the tetraaryltin species, $\mathrm{SnAr}_{4}$, followed by an adapted Jolly redistribution procedure to obtain the triaryltin chloride species, ClSnAr3. The $\mathrm{SnAr}_{4}$ compounds synthesized were $\mathrm{Sn}\left(\mathrm{C}_{6} \mathrm{H}_{4}-p \text {-tolyl }\right)_{4}, \mathrm{Sn}\left(\mathrm{C}_{6} \mathrm{H}_{4}-p \text {-t-Bu }\right)_{4}$, and $\mathrm{Sn}\left(\mathrm{C}_{6} \mathrm{H}_{4}-p-\mathrm{OCH}_{3}\right)_{4}$. The $\mathrm{ClSnAr} 3$ complexes synthesized successfully were $\mathrm{ClSn}\left(\mathrm{C}_{6} \mathrm{H}_{4}-p\right.$ tolyl $)_{3}$ and $\mathrm{ClSn}\left(\mathrm{C}_{6} \mathrm{H}_{4}-p-t-\mathrm{Bu}\right)_{3}$. These $\mathrm{ClSnAr}_{3}$ complexes were used as the tin ligand to synthesize the corresponding cobaloxime compounds. Once synthesized, the cobaloximes underwent halogen cleavage titrations to investigate the effects of changes in the cobaloxime coordination environment and to compare their reactivity to that of the $\mathrm{Co}^{\mathrm{III}}(\mathrm{OEP}) \mathrm{SnPh}_{3}$. The multiple products formed through these halogen cleavage reactions indicates that the Co-Sn bond is not cleaved cleanly for these cobaloximes, unlike the porphyrins compounds. The cobaloximes react with the halogens to first cleave the Sn-C bonds through electrophilic aromatic substitution, indicating that cleavage of the Sn-C bond is more facile than cleavage of the Co-Sn bond in these compounds. 


\section{DEDICATION}

I would like to dedicate this thesis to my parents, Roger and Kathy Ward for their never ending support, encouragement and love. You always believed I could do this, even when I lost faith myself. 


\section{ACKNOWLEDGMENTS}

I would like to acknowledge and express my gratitude to the following individuals and groups:

Dr. Alan M. Stolzenberg, my research advisor, for all of your guidance, support, and invaluable ideas and suggestions.

Dr. Jeffrey Petersen for stepping in as my committee chair and pushing me to the finish line. I am extremely grateful for all you did to help me finish this thesis and prepare to move on to my next chapter. I also want to thank you for the X-ray structure analysis of my compounds.

My committee members, Dr. Jeffrey Petersen, Dr. Björn Söderberg, and Dr. Kung Wang for serving on my committee and for reviewing and providing your feedback on my document throughout this process.

I would like to thank all of my family and friends for their support, encouragement, love, and overall just keeping me sane during graduate school. This has been a long road and without you in my life I do not think this would have been possible. Although I cannot include everyone who deserves to be on this list, I want to give a special thank you to my parentsKathy and Roger Ward, my sister- Charlotte Ward, my Nanny and my late Grandpa Blevins, my very best friends and confidants- Michelle Montovio, Dr. Elizabeth Yates, Rachael Pickens, and Dr. Stephanie Martindale. I also want to thank my fur babies Daisy and her late brother Hank for being my constant companions, snuggle buddies, and sounding boards.

I would also like to thank West Virginia University and the C. Eugene Bennett Chemistry Department for their financial support during my time as a graduate student. 


\section{Table of Contents}

Abstract ........................................................................................... ii

Dedication ............................................................................................ iii

Acknowledgments ................................................................................ iv

Table of Contents .................................................................................. V

LIST OF TABLES .......................................................................................... vii

LIST OF FIGURES ................................................................................ viii

LIST OF SCHEMES ….......................................................................

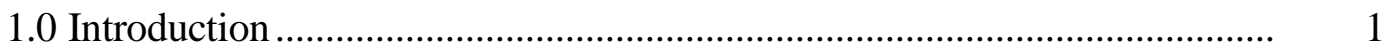

1.1 Thesis Overview ........................................................................... 1

1.2 Project Background .......................................................................... 1

1.3 Basis of Current Project ...................................................................... 7

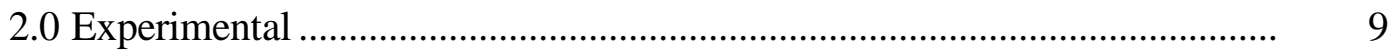

2.1 Materials and Methods .................................................................... 9

2.2 Syntheses ....................................................................................... 10

2.2.1 Synthesis of tetraaryltin complexes, $\mathrm{SnAr}_{4} \ldots \ldots \ldots \ldots \ldots \ldots . . . . . . . . .10$

2.2.2 Synthesis of chlorotriaryltin complexes, $\mathrm{ClSnAr}_{3} \ldots \ldots \ldots . . \quad 12$

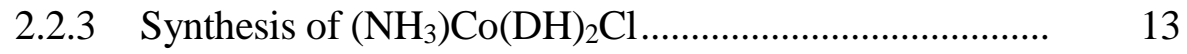

2.2.4 Synthesis of Cobaloximes Using One-Step Synthesis .... 13

2.2.5 Synthesis of Cobaloximes Using Regular Synthesis ...... 14

2.3 X-ray Structure Analysis...................................................................... 14 
2.3.1 Analysis for (4-t-BuPy) $\mathrm{Co}(\mathrm{DH})_{2} \mathrm{Sn}\left(\mathrm{C}_{6} \mathrm{H}_{4}-p \text {-tolyl }\right)_{3} \ldots \ldots \ldots . \quad 14$

2.3.2 Preliminary X-ray Analysis for $\left(\mathrm{NH}_{3}\right) \mathrm{Co}(\mathrm{DH})_{2} \mathrm{SnPh}_{3} \ldots . \quad 17$

2.4 Halogen Cleavage Titrations................................................................... 17

3.0 Results and Discussion .............................................................................. 18

3.1 Synthesis and Characterization of Compounds........................................ 19

3.1.1 Synthesis of Cobaloximes.................................................. 19

3.1.2 Synthesis of Tetraaryltin Compounds ............................. 24

3.1.3 Synthesis of TriaryltinCl Compounds .............................. 26

3.2 X-ray Structure Analysis of Cobaloxime Tin Complexes ........................ 32

3.2.1 X-ray Analysis of (4-t-BuPy) $\mathrm{Co}(\mathrm{DH})_{2} \mathrm{Sn}\left(\mathrm{C}_{6} \mathrm{H}_{4}-p \text {-tolyl }\right)_{3} \quad 32$

3.2.2 Preliminary X-ray Analysis of $\left(\mathrm{NH}_{3}\right) \mathrm{Co}(\mathrm{DH})_{2} \mathrm{SnPh}_{3} \ldots . . \quad 35$

3.3 Halogen Cleavage Titrations................................................................... 37

4.0 Conclusions .......................................................................................

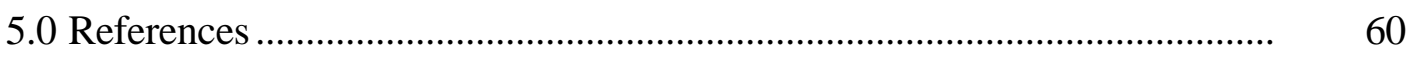




\section{LIST OF TABLES}

Table 1: Data collection details for (4-t-BuPy)Co(DH) ${ }_{2} \mathrm{Sn}\left(\mathrm{C}_{6} \mathrm{H}_{4}-p \text {-tolyl }\right)_{3} \ldots \ldots . . . .15$

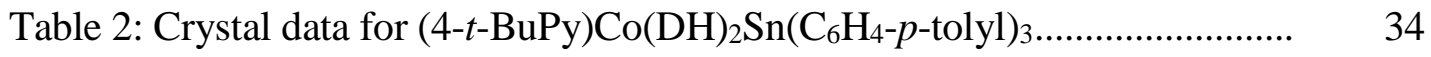

Table 3: Data Collection and structure refinement for

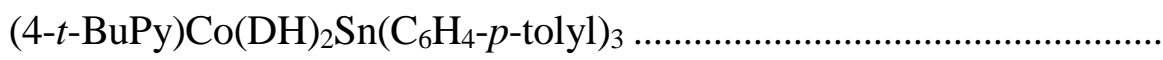

Table 4: Selected interatomic distances $(\AA)$ and bond angles $\left(^{\circ}\right)$ for (4-t-BuPy)Co(DH) ${ }_{2} \mathrm{Sn}\left(\mathrm{C}_{6} \mathrm{H}_{4}-p \text {-tolyl }\right)_{3}$

35 


\section{LIST OF FIGURES}

Figure 1: General Cobalamin Structure where R = 5'-deoxyadenosyl, CN, or Me 2

Figure 2: Corrin ring versus porphyrin ring...................................................

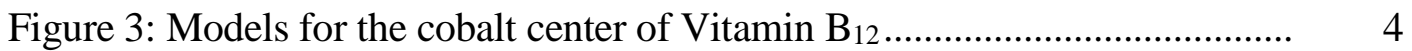

Figure 4: ORTEP drawing of (4-t-BuPy)Co(DH $)_{2} \mathrm{Sn}\left(\mathrm{C}_{6} \mathrm{H}_{4}-p \text {-tolyl }\right)_{3} \ldots \ldots \ldots \ldots \ldots \ldots . . . . . . . . \quad 32$

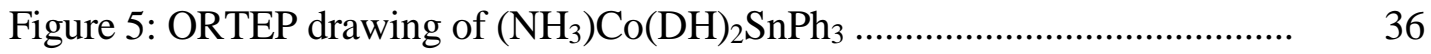

Figure 6: Initial ${ }^{1} \mathrm{H}$ NMR spectrum of (4-t-BuPy)Co(DH) $)_{2} \mathrm{Sn}\left(\mathrm{C}_{6} \mathrm{H}_{4}-p-t-\mathrm{Bu}\right)_{3}$ in $\mathrm{C}_{6} \mathrm{D}_{6}$

Figure 7: Bromine Cleavage of (4-t-BuPy)Co(DH $)_{2} \mathrm{Sn}\left(\mathrm{C}_{6} \mathrm{H}_{4}-p-t-\mathrm{Bu}\right)_{3}{ }^{1} \mathrm{H}$ NMR in $\mathrm{C}_{6} \mathrm{D}_{6}$. The $\mathrm{O}-\mathrm{H} \cdots \mathrm{O}$ bridging region for 0 and 0.25 equivalents of $\mathrm{Br}_{2}$

Figure 8: Bromine Cleavage of (4-t-BuPy)Co(DH $)_{2} \mathrm{Sn}\left(\mathrm{C}_{6} \mathrm{H}_{4}-p-t-\mathrm{Bu}\right)_{3}{ }^{1} \mathrm{H}$ NMR in $\mathrm{C}_{6} \mathrm{D}_{6}$. The $\mathrm{O}-\mathrm{H} \cdots \mathrm{O}$ bridging region for 0.5 and 0.75 equivalents of $\mathrm{Br}_{2}$

Figure 9: Bromine Cleavage of (4-t-BuPy)Co(DH $)_{2} \mathrm{Sn}\left(\mathrm{C}_{6} \mathrm{H}_{4}-p-t-\mathrm{Bu}\right)_{3}{ }^{1} \mathrm{H} N M R$ in $\mathrm{C}_{6} \mathrm{D}_{6}$. The $\mathrm{O}-\mathrm{H} \cdots \mathrm{O}$ bridging region for 1 and 2 equivalents of $\mathrm{Br}_{2}$

Figure 10: Bromine Cleavage of (4-t-BuPy)Co(DH) $)_{2} \mathrm{Sn}\left(\mathrm{C}_{6} \mathrm{H}_{4}-p-t-\mathrm{Bu}\right)_{3}{ }^{1} \mathrm{H}$ NMR in $\mathrm{C}_{6} \mathrm{D}_{6}$. The alkyl region for 0 equivalents of $\mathrm{Br}_{2}$

Figure 11: Bromine Cleavage of (4-t-BuPy)Co(DH) $)_{2} \mathrm{Sn}\left(\mathrm{C}_{6} \mathrm{H}_{4}-p-t-\mathrm{Bu}\right)_{3}{ }^{1} \mathrm{H}$ NMR in $\mathrm{C}_{6} \mathrm{D}_{6}$. The alkyl region for 0.25 equivalents of $\mathrm{Br}_{2}$ 
Figure 12: Bromine Cleavage of (4-t-BuPy)Co(DH) $)_{2} \mathrm{Sn}\left(\mathrm{C}_{6} \mathrm{H}_{4}-p-t-\mathrm{Bu}\right)_{3}{ }^{1} \mathrm{H}$ NMR in $\mathrm{C}_{6} \mathrm{D}_{6}$. The alkyl region for 0.5 equivalents of $\mathrm{Br}_{2}$

Figure 13: Bromine Cleavage of (4-t-BuPy)Co(DH $)_{2} \mathrm{Sn}\left(\mathrm{C}_{6} \mathrm{H}_{4}-p-t-\mathrm{Bu}\right)_{3}{ }^{1} \mathrm{H}$ NMR in $\mathrm{C}_{6} \mathrm{D}_{6}$. The alkyl region for 0.75 equivalents of $\mathrm{Br}$ 46

Figure 14: Bromine Cleavage of (4-t-BuPy)Co(DH) $)_{2} \mathrm{Sn}\left(\mathrm{C}_{6} \mathrm{H}_{4}-p-t-\mathrm{Bu}\right)_{3}{ }^{1} \mathrm{H}$ NMR in $\mathrm{C}_{6} \mathrm{D}_{6}$. The alkyl region for 1 equivalent of $\mathrm{Br}_{2}$

Figure 15: Bromine Cleavage of (4-t-BuPy)Co(DH) $)_{2} \mathrm{Sn}\left(\mathrm{C}_{6} \mathrm{H}_{4}-p-t-\mathrm{Bu}\right)_{3}{ }^{1} \mathrm{H}$ NMR in $\mathrm{C}_{6} \mathrm{D}_{6}$. The alkyl region for 2 equivalents of $\mathrm{Br}_{2}$

Figure 16: Bromine Cleavage of (4-t-BuPy)Co(DH $)_{2} \mathrm{Sn}\left(\mathrm{C}_{6} \mathrm{H}_{4}-p-t-\mathrm{Bu}\right)_{3}{ }^{1} \mathrm{H}$ NMR in $\mathrm{C}_{6} \mathrm{D}_{6}$. The aromatic region for 0 equivalents of $\mathrm{Br}_{2}$

Figure 17: Bromine Cleavage of (4-t-BuPy)Co(DH) $)_{2} \mathrm{Sn}\left(\mathrm{C}_{6} \mathrm{H}_{4}-p-t-\mathrm{Bu}\right)_{3}{ }^{1} \mathrm{H}$ NMR in $\mathrm{C}_{6} \mathrm{D}_{6}$. The aromatic region for 0.25 equivalents of $\mathrm{Br}_{2}$ 50

Figure 18: Bromine Cleavage of (4-t-BuPy)Co(DH) $)_{2} \mathrm{Sn}\left(\mathrm{C}_{6} \mathrm{H}_{4}-p-t-\mathrm{Bu}\right)_{3}{ }^{1} \mathrm{H}$ NMR in $\mathrm{C}_{6} \mathrm{D}_{6}$. The aromatic region for 0.5 equivalents of $\mathrm{Br}_{2}$

Figure 19: Bromine Cleavage of (4-t-BuPy)Co(DH) $)_{2} \mathrm{Sn}\left(\mathrm{C}_{6} \mathrm{H}_{4}-p-t-\mathrm{Bu}\right)_{3}{ }^{1} \mathrm{H}$ NMR in $\mathrm{C}_{6} \mathrm{D}_{6}$. The aromatic region for 0.75 equivalents of $\mathrm{Br}_{2}$ 52

Figure 20: Bromine Cleavage of (4-t-BuPy)Co(DH $)_{2} \mathrm{Sn}\left(\mathrm{C}_{6} \mathrm{H}_{4}-p-t-\mathrm{Bu}\right)_{3}{ }^{1} \mathrm{H}$ NMR in $\mathrm{C}_{6} \mathrm{D}_{6}$. The aromatic region for 1 equivalent of $\mathrm{Br}_{2}$ 
Figure 21: Bromine Cleavage of (4-t-BuPy)Co(DH $)_{2} \mathrm{Sn}_{2}\left(\mathrm{C}_{6} \mathrm{H}_{4}-p-t-\mathrm{Bu}\right)_{3}{ }^{1} \mathrm{H}$ NMR in $\mathrm{C}_{6} \mathrm{D}_{6}$.

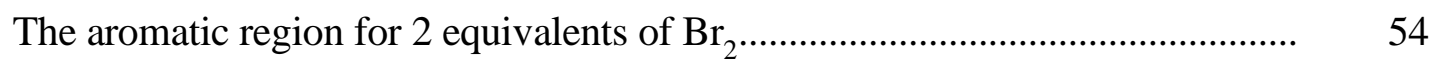




\section{LIST OF SCHEMES}

Scheme 1: Synthesis of $\mathrm{Co}^{\mathrm{III}}(\mathrm{OEP}) \mathrm{SnPh}_{3}$ and its oxidation with Iodine ............. 8

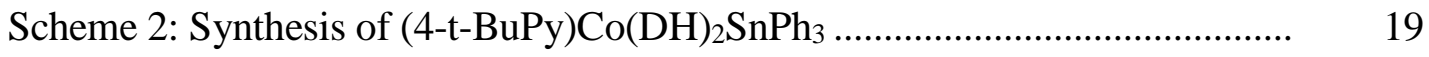

Scheme 3: Halogen Cleavage of $\mathrm{Co}(\mathrm{OEP}) \mathrm{SnPh}_{3}$ versus (base)Co(DH) $)_{2} \mathrm{SnPh}_{3} . . \quad 20$

Scheme 4: Synthesis of benzyl cobaloxime and synthetic attempt to synthesize

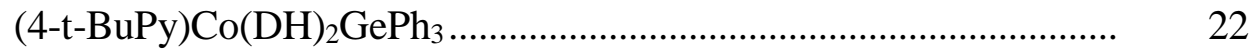

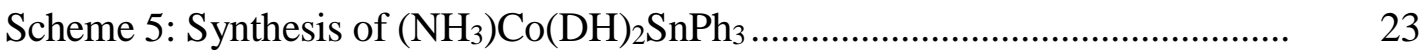

Scheme 6: Retrosynthesis of para-substituted chlorotriaryltin species ................ 24

Scheme 7: Synthesis of tetra-p-tolyl tin .............................................................. 25

Scheme 8: Kocheshkov redistribution synthesis attempt .................................. 27

Scheme 9: Chambers and Scherer redistribution synthetic attempt ...................... 28

Scheme 10: Krause method for redistribution synthetic attempt ........................ 29

Scheme 11: 3:1 Grignard in an attempt to synthesize ClSn( $\left(\mathrm{C}_{6} \mathrm{H}_{4}-p \text {-tolyl }\right)_{3} \ldots . . . . . \quad 30$

Scheme 12: Jolly procedure for the successful redistribution of $\mathrm{Sn}\left(\mathrm{C}_{6} \mathrm{H}_{4}-p \text {-tolyl }\right)_{4}$ to

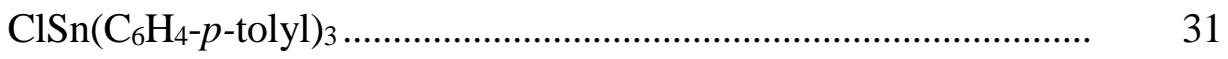

Scheme 13: Proposed Reaction of Halogen with Triaryltin Cobaloxime............ 56 


\subsection{Introduction}

\subsection{Thesis Overview}

The objective of this thesis project is to develop a cobaloxime with a Co-Sn bond that will exhibit clean cleavage through oxidation with halogen. The cobaloxime environment will be tuned in order to gain more insight into the structure and possibly the reactivity of the cobaloxime. This project involves changing the substituents on the phenyl ring of the triaryltin group of the cobaloxime and also work on modifying the Lewis base ligand and attempts to change the group 14 element bound to the cobalt center. The setup of this thesis begins with an introduction into the history of vitamin $\mathrm{B}_{12}$, its structure, work done to investigate factors affecting the Co-C bond, model compounds for vitamin $\mathrm{B}_{12}$, and work done by the Stolzenberg group that provides the basis for this project. Following the introduction, the experimental section will cover the synthesis of the compounds used in this project. Finally, the results and discussion and concluding remarks are presented.

\subsection{Project Background}

Vitamin $\mathrm{B}_{12}$ (cyanocobalamin), seen in Figure 1 with $\mathrm{R}=\mathrm{CN}$, is a bioinorganic naturally occurring molecule that has been investigated by many different disciplines such as medicine, agriculture, biochemistry, microbiology, organic and inorganic chemistry, X-ray crystallography, theoretical chemists, etc. ${ }^{1}$ The interest in vitamin $\mathrm{B}_{12}$ has its beginnings in medicine as a treatment for pernicious anemia in the 1920's using liver therapy. The use as a therapy preceded the isolation of the compound in 1948 by Folkers at Merck and by Smith and Parker at Glaxo Laboratories. ${ }^{2-4}$ Following this, the coenzyme was isolated in 1958 by Barker and associates. ${ }^{5}$ The majority of the structure was unknown, but the X-ray crystal structure was solved in 1961 by 
Dorothy Hodgkin. Her work revealed the presence of two structures that were previously unknown in nature: the corrin ring (seen in Figure 2) and the Co-C bond which was the first known naturally occurring organometallic compound. ${ }^{1}$ This relatively inert bond between cobalt and a primary alkyl ligand is especially interesting due to its stability under physiological conditions. ${ }^{6}$

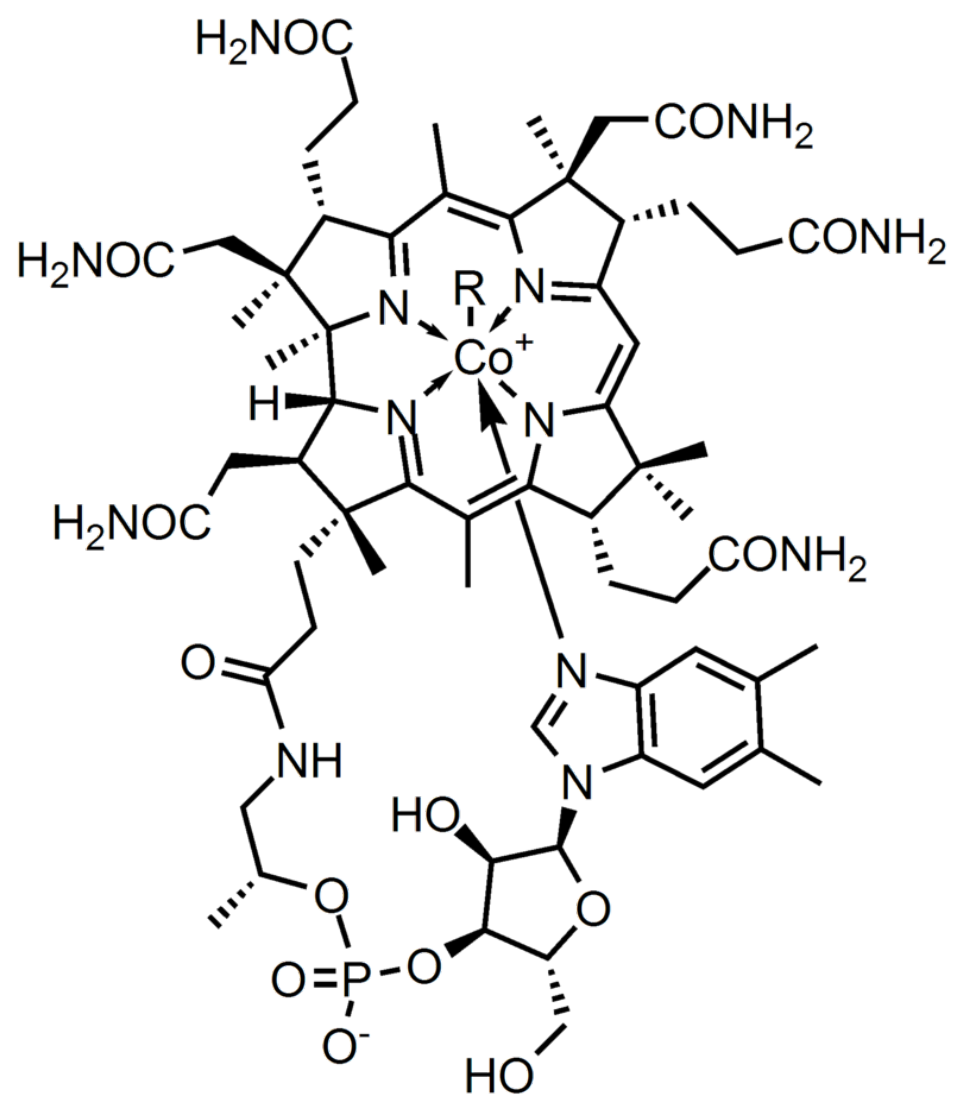

Figure 1: General Cobalamin Structure where R = 5'deoxyadenosyl, $\mathrm{CN}$, or $\mathrm{Me}$

Vitamin $\mathrm{B}_{12}$ belongs to a class of compounds called cobalamins, where the heterocyclic base is 5,6-dimethylbenzimidazole. Figure 1 above shows the structures of vitamin $\mathrm{B}_{12}$ also known as cyanocobalamin ( $\mathrm{CNCbl}, \mathrm{R}=\mathrm{CN}$ ), adenosylcobalamin (AdoCbl, R=5'-deoxyadenosyl), and methylcobalamin (MeCbl, $\mathrm{R}=\mathrm{Me}) .^{7-8}$ The six-coordinate cobalt atom exhibits an octahedral 
structure that is bound axially by the R group, nitrogen on the benzimidazole, and by four donor nitrogen atoms of the corrin ring in the equatorial plane. The six-coordinate arrangement exhibits a tetragonal distortion and the corresponding splitting pattern of the d-orbitals is observed. ${ }^{6}$ The corrin ring, conjugated system of double bonds, creates a strong ligand field resulting in low spin cobalt and differs slightly from the more widely known porphyrin ring by directly binding two of the rings, as seen in Figure 2. ${ }^{9-10}$ The four donor nitrogen atoms of the corrin ring are not coplanar with the cobalt atom, as is seen in the porphyrin complex. ${ }^{7}$ The Co-N bond to the benzimidazole is longer than the Co- $\mathrm{N}$ bonds in the equatorial plane. The cleavage of the Co-C bond is important in the enzymatic reactions of the coenzymes. The Co-C bond is stable towards hydrolysis, but still weak enough to be cleaved readily by enzymatic reactions. This interesting behavior led chemists to study these complexes and the reactivity of the metal-alkyl bond specifically. ${ }^{7,11-12}$
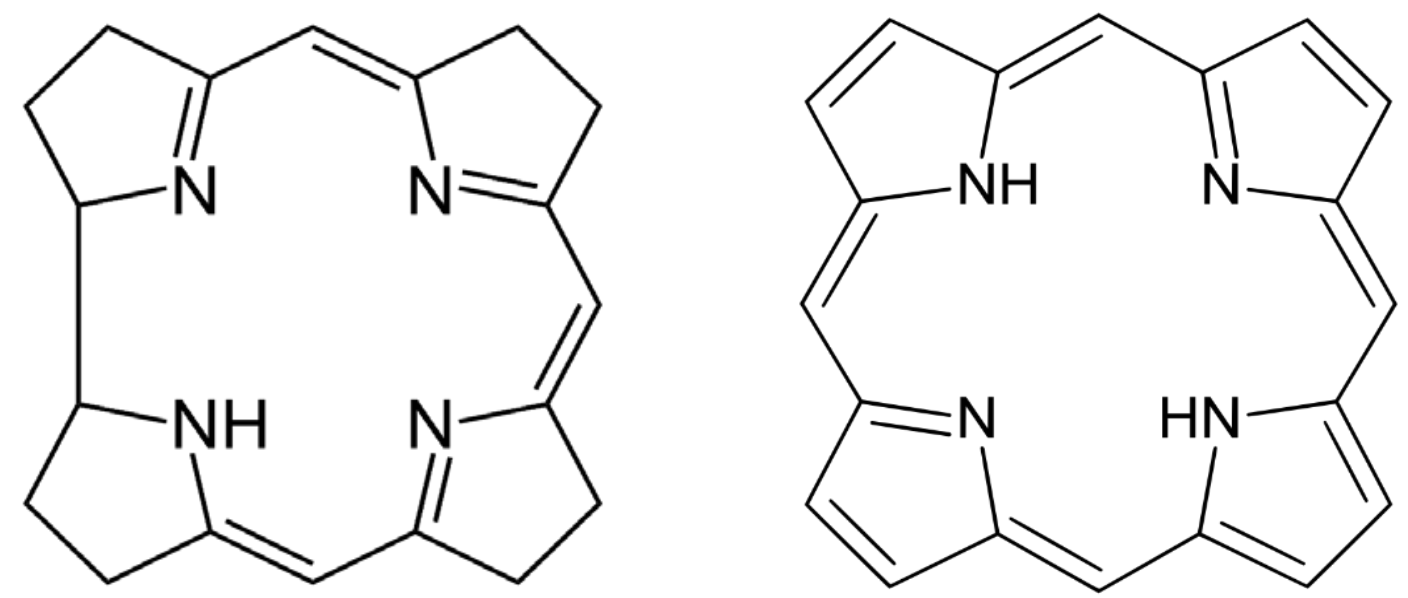

Figure 2: Corrin ring (left) versus porphyrin ring (right)

To understand the enzymatic reactions of the coenzymes, it is important to gain understanding into the Co-C bond and how readily it gets cleaved. This led to investigating the variability of the Co-C bond length and what factors affect it, such as the nature of the axial 
ligands trans to each other. In order to more easily probe the structure of the cobalamins, model compounds were developed and a sampling of those models including Schiff bases such as Co(Saloph)R and Co(Salen)R, alkyl cobalt porphyrins, and cobaloximes (seen in Figure 3).
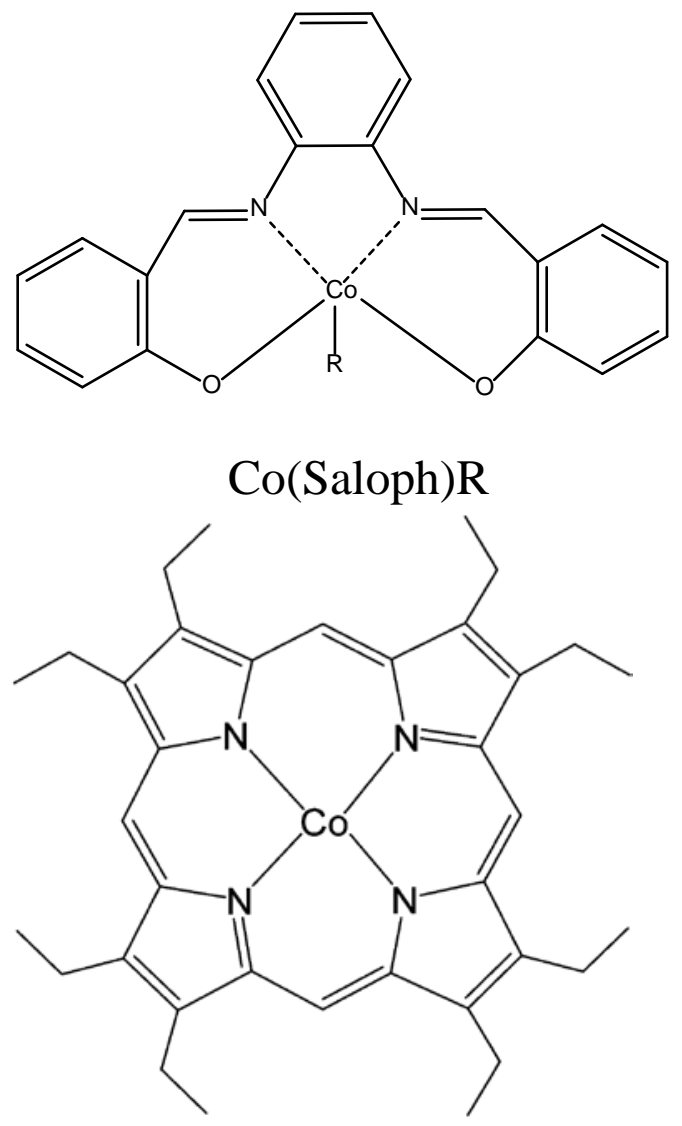

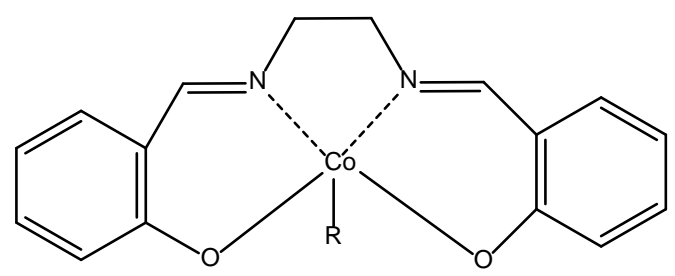

Co(Salen)R

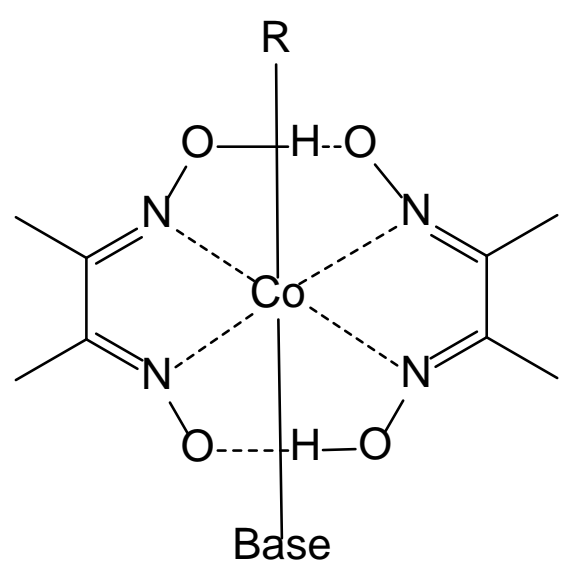

Figure 3: Models for the cobalt center of Vitamin $\mathrm{B}_{12}$

In 1964, Schrauzer and Kohnle introduced cobaloximes, named for their similarities to cobalamins with the general form (Base)Co(DH $)_{2} \mathrm{R}$, where $\mathrm{DH}$ is the dimethylglyoxime ligand (seen in Figure 3). ${ }^{13}$ These Co(III) complexes consist of two dimethylglyoxime ligands (abbreviated DMG) that are linked through $\mathrm{O}-\mathrm{H} \cdots \mathrm{O}$ hydrogen bonds. The axial positions include an alky group (R) and an electron donating Lewis base trans to it. The first alkyl 
cobaloxime was studied by Lenhert in 1967 and has the structure (Py)Co(DH) ${ }_{2} \mathrm{CH}_{2} \mathrm{COOCH}_{3}$. It was characterized by X-ray crystallography to confirm the structure of the cobaloxime and compare the bond distances and angles to the coenzyme. ${ }^{14}$ The four donor nitrogen atoms lie in the plane with the Co atom, as opposed to the slightly distorted plane of the cobalamins. The equatorial Co-N bond distances of the cobaloxime averaged $1.88 \AA$, very similar to the coenzyme (1.90 $\AA$ ). The axial bond lengths for the Co-N and Co-C in the cobaloxime are both $\sim 2.04 \AA$, whereas the Co-C and axial Co- $\mathrm{N}$ of the coenzyme are $2.03 \AA$ and $2.24 \AA$ respectively. The axial Co-N bond in the cobaloxime is significantly shorter than that of the coenzyme, resulting from the slightly more positive cobalt center in the cobaloxime. ${ }^{7}$ Among the series of synthesized cobaloximes, the DMG ligands and cobalt atom have similar bond lengths and angles with some variability in the bridging $\mathrm{H}$ location, but the lengths to the axial substituents will vary greatly.

The main reason for this variability in the axial bond lengths is the trans effect. ${ }^{15-17}$ This arises from the effect of the axial electron donating base on the axial alkyl group and resulting Co-C bond trans to it. This effect can be seen in the cobalamins and the changes in the axial Co$\mathrm{N}$ bond of the benzimidazole. When the group trans to benzimidazole is the $\mathrm{CN}$ group of vitamin $\mathrm{B}_{12}$ the bond length is $1.97-2.06 \AA$, but when the group trans to the benzimidazole is the adenosyl group of AdoCbl the Co-N bond length is $2.24 \AA$, indicating a weaker bond to the benzimidazole. This could indicate that when the bond from the cobalt center to the benzimidazole is replaced upon binding to the protein, the nature of the group (side chain on protein) that binds the cobalt could control the cleavage of the Co-C bond trans to it through its electron withdrawing properties. 
This trans effect was studied further through cobalamin models. Elder and coworkers investigated this effect first using pentammine cobalt complexes, $\left[\mathrm{Co}\left(\mathrm{NH}_{3}\right)_{5} \mathrm{X}\right]$ and found that the equatorial Co-N bonds were similar in length to the cobalamins, but the axial Co-N bond length depends on the nature of the X ligand trans to it. ${ }^{18-22}$ Elder and coworkers then extended their work to cobaloximes and found a correlation between the structural and kinetic trans effects indicating bond lengthening could correlate to reactivity. Randaccio and Marcilli analyzed several series of cobaloximes and their geometries. They found that for the same phosphine, $\left(\mathrm{PPh}_{3}\right) \mathrm{Co}(\mathrm{DH})_{2} \mathrm{X}$ for example, as the $\sigma$ donating ability of the trans ligand increases the Co-P bond will shorten with $\mathrm{X}$ being electron withdrawing and will lengthen with $\mathrm{X}$ being electron donating. ${ }^{23}$ They also found that the substituents on the $\mathrm{C}$ of the alkyl group attached to the cobalt can also have trans influencing effects, with an electron withdrawing substituent weakening the trans influence and an electron donating substituent strengthening the trans influence. Also they found that in the series of cobaloximes, the nature of the base will also effect the trans influence, with P-donor Lewis bases having a greater influence than the N-donor Lewis bases.

Sterics can also affect the bond lengths of the axial alkyl group and base to the cobalt center. In cobaloximes, non-bulky axial ligands will allow the Co atom to sit nearly coplanar with the four donor nitrogen atoms. Bulky axial ligands will displace the cobalt atom from the plane of the DMG ligands, moving the cobalt towards the bulky ligand and bending the DMG ligands away from the bulky axial ligand. ${ }^{7}$ In phosphine cobaloximes, for the same axial trans ligand, the length of the Co-P bond will fall between $2.165-2.418 \AA .^{24}$ The effects of increasing the bulk (cone angle) of the phosphine ligand were that the Co-P bond lengthens, the cobalt atom displaces toward the P, also the Co-C bond will lengthen with the increase in the bulk of the 
phosphine ligand trans to it. Marzilli, Randaccio and coworkers were able to demonstrate a linear relationship between the length of the Co-C bond and the number of non-hydrogen substituents on the $\mathrm{C}$ of the alkyl group bound to the cobalt center in $(\mathrm{Py}) \mathrm{Co}(\mathrm{DH})_{2} \mathrm{X}$ cobaloximes. ${ }^{23}$ Ohashi found similarly that this lengthening will also occur with substituents that are not simple alkyl groups, but the relationship will be exponential instead of linear. To summarize the effects of steric bulk on the alkyl-cobalt bond: small axial ligands will lead to a short Co-C and the cobalt ion being coplanar with the DMG ligands, a bulky base will cause the DMG ligands to bend towards the alkyl group and lengthen the Co-C slightly, and lastly a bulky substituent on the alkyl group bound to carbon leads to a lengthening of the Co-C bond and an increase in the CoC-R bond angle due to an increase in steric interactions between the R substituent and the DMG ligands. This increase in substituent bulk leading to the lengthening of the Co-C bond is also seen in the $\mathrm{Co}_{-}-\mathrm{CH}_{2}-\mathrm{C}$ bond angle in the coenzyme $\mathrm{B}_{12}$ with analogous steric interactions with the corrin ring. These steric interactions cause strain and therefore help promote the cleaving of the Co-C bond.

\subsection{Basis of Current Project}

Stolzenberg has done extensive research involving the synthesis, characterization, and reactivity studies of organocobalt porphyrins. ${ }^{25-29}$ These organocobalt porphyrins can also be used as models for vitamin $\mathrm{B}_{12}$. The reactivity of the Co-E bond, where $\mathrm{E}$ is a group 14 element, was investigated. In 2001, Cao and Stolzenberg synthesized $\mathrm{Co}^{\mathrm{III}}(\mathrm{OEP}) \mathrm{SnPh}_{3}$, where OEP is octaethylporphyrin, and found that it was unexpectedly inert when compared to the alkyl porphyrin. The synthesis of the porphyrin is seen in Scheme 1 . This stability of the $\mathrm{Co}^{\mathrm{III}}(\mathrm{OEP}) \mathrm{SnPh}_{3}$ raises questions about why the Co-Sn bond is stronger than the Co-C bond in this system. The $\mathrm{Co}^{\mathrm{III}}(\mathrm{OEP}) \mathrm{SnPh}_{3}$ has a slow rate of homolysis and is stable to thermal 
decomposition. The Co-Sn bond of the porphyrin can be readily cleaved by oxidation with a halogen or photolysis (Scheme 1).

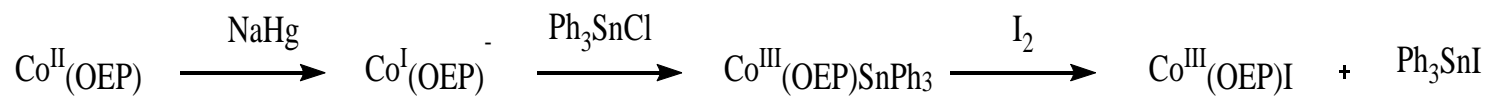

Scheme 1: Synthesis of ${ }^{\text {III }}(\mathrm{OEP}) \mathrm{SnPh}_{3}$ and its oxidation with Iodine

The interesting reactivity of the porphyrins prompted investigation into bond strengths of the group 14 analogues. With this in mind, a larger quantity of material would be needed to perform the necessary experiments and with the low yield syntheses of the organocobalt porphyrins, this was not feasible. The switch to cobaloximes, another vitamin $\mathrm{B}_{12}$ model came after finding a series of compounds synthesized by Schrauzer of the form (Py)Co(DH) $)_{2} \mathrm{EPh}_{3}$, where $\mathrm{E}=\mathrm{Si}, \mathrm{Ge}, \mathrm{Sn}$, and $\mathrm{Pb} \cdot{ }^{30-31}$ He reported the complexes to have good thermal and moderate air stability, for the tin and lead cobaloximes, but the reactivity of these compounds was not investigated. In 2007, Stolzenberg and co-workers. ${ }^{32}$ synthesized the 4-t-BuPy analogues of the $\mathrm{SnPh}_{3}$ and $\mathrm{PbPh}_{3}$ cobaloximes and were able to obtain crystal structures and some reactivity data for them. The 4-t-butylpyridine (4-t-BuPy) was used in placed of pyridine (Py) to improve solubility and simplify the ${ }^{1} \mathrm{H}$ NMR spectra of the synthesized compounds. ${ }^{33-35}$ The germanium and silicon analogues were unable to be synthesized due to poor solubility and other issues.

Halogen cleavage reactions were performed on the (4-t-BuPy)Co(DH) ${ }_{2} \mathrm{SnPh}_{3}$ and the (4$t$-BuPy)Co(DH $)_{2} \mathrm{PbPh}_{3}$ and found that clean cleavage of the Co-E bond did not occur. This outcome is very different from the reaction of the organocobalt porphyrin with halogen. This difference in reactivity of the porphyrin and cobaloxime complexes containing Co-Sn bonds is the basis for this project. The goal of this work is to find a cobaloxime system that, through tuning of the ligand environment, will exhibit clean Co-Sn bond cleavage and provide insight 
into the differences in reactivity of these two cobalamin model compounds. There are several ways to change the ligand environment to tune the reactivity: changing the size or strength of the base, changing the group 14 element (E) bound to the cobalt center, changing the substitution on the triaryltin ligand, or looking into another 5 coordinate system (like Schiff bases or a labile base that can be easily removed to form a 5 coordinate cobaloxime) to compare to the 5 coordinate porphyrin. The approach that is taken in this project is to change the substitution of the triaryltin ligand by adding a substituent to the para position of the phenyl ring. Our hypothesis is that the halogen is cleaving the Sn-C on the phenyl ring as opposed to the desired Co-Sn bond cleavage and that by substituting onto the para position of the phenyl ring may change the donor strength enough to promote Co-Sn cleavage. To test this hypothesis, tetraaryltin compounds were synthesized with $-\mathrm{CH}_{3},-\mathrm{OCH}_{3}$, and -tBu substituted in the para position of the phenyl ring. The next step was to perform a redistribution reaction to obtain the substituted chloro triaryl tin compounds which were then reacted with (4-t-BuPy) $\mathrm{Co}(\mathrm{DH})_{2} \mathrm{Cl}$ to form the desired cobaloximes. The cobaloximes then underwent halogen cleavage reactions and their products analyzed.

\subsection{Experimental}

\subsection{Materials and Methods}

All reactions were carried out under a nitrogen atmosphere using Schlenk techniques, unless otherwise noted. The $\mathrm{Co}(\mathrm{DH})\left(\mathrm{DH}_{2}\right) \mathrm{Cl}_{2}{ }^{36}$, $(\mathrm{Py}) \mathrm{Co}(\mathrm{DH})_{2} \mathrm{SnPh}_{3}$, (4-t-BuPy)Co(DH$)_{2} \mathrm{Cl}^{36}$, and (4-t$\mathrm{BuPy}) \mathrm{Co}(\mathrm{DH})_{2} \mathrm{SnPh}_{3}{ }^{32,37}$ were prepared using literature methods. The cobaloxime (4$\mathrm{CNPy}) \mathrm{Co}(\mathrm{DH})_{2} \mathrm{SnPh}_{3}$ was previously synthesized by a member of the Stolzenberg group. The cobalt ammine complex, $\left[\mathrm{Co}\left(\mathrm{NH}_{3}\right)_{5} \mathrm{Cl}\right] \mathrm{Cl}_{2}$, was synthesized in the Inorganic Synthesis lab (Chem 423) at West Virginia University, but is available commercially. All solvents and 
compounds used in the syntheses were reagent grade or the best available. All commercially available compounds were used as received. Deuterated solvents, $\mathrm{CDCl}_{3}, \mathrm{C}_{6} \mathrm{D}_{6}$, DMSO and $\mathrm{CD}_{3} \mathrm{CN}$, were passed through a column of activated alumina prior to use. ${ }^{1} \mathrm{H}$ NMR spectra were recorded on a JEOL Eclipse $270 \mathrm{MHz}$, Agilent $400 \mathrm{MHz}$, and Varian INOVA $600 \mathrm{MHz}$ NMR spectrometers. The chemical shifts $(\delta)$ are given in parts per million and referenced to internal TMS (0 ppm) or residual protio solvent (7.26 for $\mathrm{CDCl}_{3}, 7.16$ for $\mathrm{C}_{6} \mathrm{D}_{6}, 2.50$ for DMSO and 1.94 for $\mathrm{CD}_{3} \mathrm{CN}$ ). The GC/MS samples were run in benzene and the commercial compounds 1bromo-4-tertbutylbenzene, 4-bromotoluene, and 4-iodotoluene were run under the same conditions to compare the retention times to our compounds.

\subsection{Syntheses}

\subsubsection{Synthesis of tetraaryltin complexes, $\mathrm{SnAr}_{4}$}

The tetraaryltin complexes have four para-substituted phenyl rings attached to a tin center. The substituents used on the phenyl rings are $p$-tolyl $\left(-\mathrm{CH}_{3}\right), p$-anisole $\left(-\mathrm{OCH}_{3}\right)$, and $p$ tertbutyl (-t-Bu). The three compounds were synthesized using the same procedure and ${ }^{1} \mathrm{H}$ NMR shifts and melting points of the recrystallized compounds were consistent with literature values. The following procedure was used for the synthesis of $\mathrm{Sn}\left(\mathrm{C}_{6} \mathrm{H}_{4}-p \text {-tolyl }\right)_{4}$.

This synthesis was carried out under nitrogen using Schlenk techniques and the glassware and magnesium turnings were oven dried overnight to limit moisture exposure during the Grignard reaction. A combination of $12.26 \mathrm{~g}$ of 4-bromotoluene and $1.77 \mathrm{~g}$ of magnesium turnings were added to $105 \mathrm{~mL}$ of THF. An addition funnel attached to the reaction flask contained a portion of the 4-bromotoluene and $25 \mathrm{~mL}$ of THF. The reaction was brought up to reflux and the contents of the addition funnel were added slowly, along with two crystals of $I_{2}$. 
Upon addition of the iodine, the solution turned orange-brown, then slowly lightened in color as the reaction heated up until the color finally dissipated and a colorless solution remained. The solution was held at reflux for three hours. The procedure calls for the solution to be transferred under nitrogen away from any unreacted magnesium, but there was no unreacted magnesium at this point. The flask was cooled in an ice bath and $1.26 \mathrm{~mL}$ of $\mathrm{SnCl}_{4}$ was added through the top of the reflux condenser. Some white smoke was observed upon addition, along with some white solid $\left(\mathrm{MgCl}_{2}\right)$ on the top of the liquid when the ice bath was removed. The flask was heated back to reflux and allowed to reflux. After 20 hours of reflux, an amber colored liquid was observed. Upon addition of $35 \mathrm{~mL}$ of $1 \mathrm{M} \mathrm{HCl}$, the solution turned white and then heated slightly. The white solid dissolved and left an amber colored liquid layer on top and a colorless clear layer on the bottom of the flask. The flask was placed in ice and after about 20 minutes, a white solid began to form at the interface between the two liquid layers. As the flask remained in the ice longer, more solid began to form. The flask was placed in the freezer overnight to facilitate product formation. The solution was filtered and the filtrate saved for a second crop. The filtered solid was washed with $25 \mathrm{~mL}$ of methanol, followed by $50 \mathrm{~mL}$ of $1 \mathrm{M} \mathrm{HCl}$ and another $25 \mathrm{~mL}$ of methanol. $1.65 \mathrm{~g}$ of white solid was collected for crop 1. From the second crop, another $1.88 \mathrm{~g}$ of white solid was obtained. Crop 1 was recrystallized from warm toluene layered with ethanol. Its melting point was $235.3-236.4^{\circ} \mathrm{C}$, which is consistent with literature. The ${ }^{1} \mathrm{H}$ NMR is also consistent with literature values. (67\% yield) ${ }^{1} \mathrm{H}$ NMR $\left(\mathrm{CDCl}_{3}\right)$ : $\delta 2.37$ (s, $\left.12 \mathrm{H}\right), 7.21$ (dd, $8 \mathrm{H}$ ), 7.49 (dd, 8 H)

$\mathrm{Sn}\left(\mathrm{C}_{6} \mathrm{H}_{4}-\mathrm{p}-\mathrm{OCH}_{3}\right)_{4}:(39 \%$ yield $){ }^{1} \mathrm{H}$ NMR $\left(\mathrm{CDCl}_{3}\right): \delta 3.80(\mathrm{~s}, 12 \mathrm{H}), 6.87(\mathrm{dd}, 8 \mathrm{H})$, and 7.39 (dd, $8 \mathrm{H}$ ) 
$\mathrm{Sn}\left(\mathrm{C}_{6} \mathrm{H}_{4}-\mathrm{p}-\mathrm{tBu}\right)$ : $(47 \% \text { yield })^{1} \mathrm{H}$ NMR $\left(\mathrm{C}_{6} \mathrm{D}_{6}\right): \delta 1.23$ (s, $\left.27 \mathrm{H}\right), 7.33$ (dd, $8 \mathrm{H}$ ), and 7.75 (dd, 8

H)

\subsubsection{Synthesis of chlorotriaryltin complexes, $\mathrm{ClSnAr}_{3}$}

The tetraaryltin complexes undergo a redistribution in order to obtain the chlorotriaryltins. The following procedure details the synthesis of $\mathrm{ClSn}\left(\mathrm{C}_{6} \mathrm{H}_{4}-p-t-\mathrm{Bu}\right)_{3}$. The same procedure was used to synthesize $\mathrm{ClSn}\left(\mathrm{C}_{6} \mathrm{H}_{4} \text {-p-tolyl }\right)_{3}$ with similar observations, but redistribution attempts of $\mathrm{ClSn}\left(\mathrm{C}_{6} \mathrm{H}_{4}-p-\mathrm{OCH}_{3}\right)_{3}$ were unsuccessful.

$\mathrm{ClSn}\left(\mathrm{C}_{6} \mathrm{H}_{4}-p-t-\mathrm{Bu}\right)_{3}$ was synthesized using $1 / 20$ of the quantities from the Jolly procedure. ${ }^{38}$ A mass of $1.60 \mathrm{~g}(0.0025 \mathrm{~mol}) \mathrm{Sn}\left(\mathrm{C}_{6} \mathrm{H}_{4}-p-t-\mathrm{Bu}\right)_{4}$ was combined with $0.1 \mathrm{~mL}(0.00085 \mathrm{~mol})$ $\mathrm{SnCl}_{4}$ in the reaction tube and placed in an oil bath. The temperature was raised to $230{ }^{\circ} \mathrm{C}$ over a 45-minute period. The temperature remained at $233^{\circ} \mathrm{C}$ for three hours. After this time, the mixture in the reaction tube had dissolved. The temperature was dropped to $100{ }^{\circ} \mathrm{C}$ and the solution was poured into a beaker and allowed to cool to room temperature. The tan solid was broken up after cooling and stirred with $200 \mathrm{~mL}$ of ethanol at $\sim 50{ }^{\circ} \mathrm{C}$. About $500 \mathrm{~mL}$ of water was added slowly to the ethanolic solution and a white solid crashed out of solution. The flask was placed in a refrigerator for 30 minutes to promote solid formation. The solid was filtered and a relatively pure compound was obtained. (67\% yield) ${ }^{1} \mathrm{H}$ NMR $\left(\mathrm{C}_{6} \mathrm{D}_{6}\right): \delta 1.19(\mathrm{~s}, 27 \mathrm{H}), 7.30$ (dd, 6 H), and 7.70 (dd, 6 H)

ClSn $\left(\mathrm{C}_{6} \mathrm{H}_{4}-p \text {-tolyl }\right)_{3}$ : (61\% yield) ${ }^{1} \mathrm{H}$ NMR $\left(\mathrm{C}_{6} \mathrm{D}_{6}\right): \delta 2.04$ (s, $\left.9 \mathrm{H}\right), 7.02$ (dd, $\left.6 \mathrm{H}\right), 7.62$ (dd, $\left.6 \mathrm{H}\right)$ 


\subsubsection{Synthesis of $\left(\mathrm{NH}_{3}\right) \mathrm{Co}(\mathrm{DH})_{2} \mathrm{Cl}$}

In an Erlenmeyer flask, $4.00 \mathrm{~g}$ of dimethylglyoxime (DMG), $5.02 \mathrm{~g}\left[\mathrm{Co}\left(\mathrm{NH}_{3}\right)_{5} \mathrm{Cl}\right] \mathrm{Cl} 2,40$ $\mathrm{mL}$ of water and $15.04 \mathrm{~g}$ of ammonium acetate were combined and stirred. Approximately $2 \mathrm{~mL}$ of concentrated acetic acid was added to the flask. The flask was then heated in a water bath, keeping the temperature below $100{ }^{\circ} \mathrm{C}$. After five minutes, the solution turned brown and $\mathrm{NH}_{3}$ gas was detected by litmus paper. More acetic acid was added to the flask, about $8 \mathrm{~mL}$ in total, until no more ammonia gas was able to be detected. The flask continued to heat to dissolve the DMG. After 10 minutes, the solution was filtered and the filtrate was reduced to a small volume. The filtrate was filtered and the solid was combined with the previous crop of solid and washed with cold distilled water. The solid was then heated in $25 \mathrm{~mL}$ of ethanol to remove the undissolved DMG. The solution was filtered, and the crude solid was allowed to air dry. The crude product was then recrystallized from hot water with a drop of acetic acid. Crop one resulted in $3.00 \mathrm{~g}$ of product and the ${ }^{1} \mathrm{H}$ NMR was obtained. Crop two resulted in $0.75 \mathrm{~g}$ of brown needles. (55\% yield) ${ }^{1} \mathrm{H}$ NMR (DMSO): $\delta 1.92$ (s,3 H), 2.27 (s, $12 \mathrm{H}$ ), and 18.46 (s, $2 \mathrm{H}$ )

\subsubsection{Synthesis of Cobaloximes Using One-Step Synthesis}

The one-step cobaloxime procedure was used to synthesize $\left(\mathrm{NH}_{3}\right) \mathrm{Co}(\mathrm{DH})_{2} \mathrm{SnPh}_{3}$ and (4$t$-BuPy)Co(DH $)_{2} \mathrm{Bn}^{39}$ For the synthesis of the benzyl cobaloxime, benzyl chloride was used instead of $\mathrm{ClSnPh}_{3}$.

In a Schlenk flask $1.0 \mathrm{~g}\left(\mathrm{NH}_{3}\right) \mathrm{Co}(\mathrm{DH})_{2} \mathrm{Cl}, 1.0 \mathrm{~g} \mathrm{ClSnPh}_{3}$ and $20 \mathrm{~mL}$ of a 1:1 (v:v) methanol and water solution were combined and stirred. The flask was degassed and backfilled with nitrogen. Over a period of 15 minutes, $0.52 \mathrm{~g}$ of $\mathrm{NaBH}_{4}$ was added to the flask in 3 portions. Upon addition of the $\mathrm{NaBH}_{4}$, the solution turned a reddish brown color. After 10 
minutes, the solution was filtered and washed with methanol and the filtrate set aside. The solid was washed with ether and hexanes and $0.58 \mathrm{~g}$ of orange solid product was obtained in crop one. The second crop crashed out of the filtrate upon sitting and was filtered, washed with ether and hexanes, and the $0.43 \mathrm{~g}$ of lighter orange solid product was obtained. (50 \% yield) ${ }^{1} \mathrm{H}$ NMR ( $\left.\mathrm{C}_{6} \mathrm{D}_{6}\right): \delta 0.13$ (s, 3 H), 1.66 (s, 12 H), 7.13 (m, 4 H), 7.60 (m, 2 H), 7.78 (dd, 6 H), 19.20 (br., 2 H)

(4-t-BuPy)Co(DH) $)_{2} \mathrm{Bn}:\left(62 \%\right.$ yield), ${ }^{1} \mathrm{H}$ NMR $\left(\mathrm{C}_{6} \mathrm{D}_{6}\right): \delta 0.64$ (s, $\left.9 \mathrm{H}\right), 1.73$ (s, $\left.12 \mathrm{H}\right), 3.32$ (s, 2 H), 6.55 (dd, 2 H), 6.98 (t, 2 H), 7.03 (dd, 1 H), 7.39 (dd, 2 H), 8.83 (dd, 2 H), 19.52 (s, 2 H)

\subsubsection{Synthesis of Cobaloximes Using Regular Synthesis ${ }^{32,36-37}$}

These compounds were synthesized using the same procedure as the previously reported (4-t$\mathrm{BuPy}) \mathrm{Co}(\mathrm{DH})_{2} \mathrm{SnPh}_{3}{ }^{32,37}$ using (4-t-BuPy)Co(DH $)_{2} \mathrm{Cl}^{36}$ synthesized from literature methods and the $\mathrm{ClSn}\left(\mathrm{C}_{6} \mathrm{H}_{4}-p \text {-tolyl }\right)_{3}$ and $\mathrm{ClSn}\left(\mathrm{C}_{6} \mathrm{H}_{4}-p-t-\mathrm{Bu}\right)_{3}$ obtained from the redistribution procedure outlined in the above section.

(4-t-BuPy)Co(DH) $2 \mathrm{Sn}\left(\mathrm{C}_{6} \mathrm{H}_{4}-p \text {-tolyl) }\right)_{3}$ ( $\left(56 \%\right.$ yield) ${ }^{1} \mathrm{H}$ NMR $\left(\mathrm{CDCl}_{3}\right): \delta 1.25$ (s, $\left.9 \mathrm{H}\right), 1.72$ (s, 12 H), 2.30 (s, 9 H), 7.09 (dd, 6 H), 7.25 (dd, 2 H), 7.39 (dd, 6 H), 8.40 (dd, 2 H), 18.56 (br, 2 H) (4-t-BuPy)Co(DH) $2 \mathrm{Sn}\left(\mathrm{C}_{6} \mathrm{H}_{4}-p-t-\mathrm{Bu}\right)_{3}:\left(59 \%\right.$ yield) ${ }^{1} \mathrm{H}$ NMR $\left(\mathrm{C}_{6} \mathrm{D}_{6}\right): \delta 0.64(\mathrm{~s}, 9 \mathrm{H}), 1.22$ (s, 36 H), 1.63 (s, 12 H), 6.56 (dd, 2 H), 7.28 (dd, 6 H), 7.95 (dd, 6 H), 8.92 (dd, 2 H), 19.74 (br, 2 H) 2.3 X-ray Structure Analysis

\subsubsection{Analysis for (4-t-BuPy) $\mathrm{Co}(\mathrm{DH})_{2} \mathrm{Sn}\left(\mathrm{C}_{6} \mathrm{H}_{4}-p \text {-tolyl }\right)_{3}$}

A light orange crystal of (4-t-BuPy) $\mathrm{Co}(\mathrm{DH})_{2} \mathrm{Sn}\left(\mathrm{C}_{6} \mathrm{H}_{4}-p \text {-tolyl }\right)_{3}$ was washed with the perfluoropolyether PFO-XR75 (Lancaster) and wedged in a glass capillary. The sample was 
optically aligned on a Bruker AXS D8 Venture fixed-chi X-ray diffractometer equipped with a Triumph monochromator, a Mo K $\alpha$ radiation source $(\lambda=0.71073 \AA$ ), and a PHOTON 100 CMOS detector. Two sets of 12 frames each were collected using the omega scan method with a $10 \mathrm{~s}$ exposure time. Integration of these frames followed by reflection indexing and leastsquares refinement produced a crystal orientation matrix for the triclinic crystal lattice.

Data collection consisted of the measurement of a total of 1840 frames in five runs using omega scans with the detector held at $5.00 \mathrm{~cm}$ from the crystal. The total exposure time was 10.22 hours. Frame scan parameters are summarized in Table 1 below:

Table 1: Data collection details for (4-t-BuPy)Co(DH $)_{2} \mathrm{Sn}\left(\mathrm{C}_{6} \mathrm{H}_{4}-p \text {-tolyl }\right)_{3}$.

\begin{tabular}{cccccccc}
\hline Run & $2 \theta$ & $\omega$ & $\varphi$ & $\chi$ & Scan Width $\left(^{\circ}\right)$ & Frames & $\begin{array}{c}\text { Exposure Time } \\
(\mathrm{sec})\end{array}$ \\
1 & 11.01 & -170.99 & 144.00 & 54.74 & 0.50 & 368 & 20.00 \\
2 & 11.01 & -170.99 & 0.00 & 54.74 & 0.50 & 368 & 20.00 \\
3 & 11.01 & -170.99 & -144.00 & 54.74 & 0.50 & 368 & 20.00 \\
4 & 11.01 & -170.99 & -72.00 & 54.74 & 0.50 & 368 & 20.00 \\
5 & 11.01 & -170.99 & 72.00 & 54.74 & 0.50 & 368 & 20.00 \\
\hline
\end{tabular}

The APEX2 software program (version 2014.1-1) ${ }^{40}$ program was used for diffractometer control, preliminary frame scans, indexing, orientation matrix calculations, least-squares refinement of cell parameters, and the data collection. The frames were integrated with the Bruker SAINT software package using a narrow-frame algorithm. The integration of the data using a triclinic unit cell yielded a total of 97231 reflections to a maximum $\theta$ angle of $27.50^{\circ}(0.77 \AA$ resolution), of which 17647 were independent (average redundancy 5.510, completeness $=99.0 \%$, 
$\left.\mathrm{R}_{\text {int }}=5.76 \%, \mathrm{R}_{\text {sig }}=5.79 \%\right)$ and $11275(63.89 \%)$ were greater than $2 \sigma\left(\mathrm{F}^{2}\right)$. The final cell constants of $\underline{a}=13.2949(5) \AA, \underline{b}=17.7508(7) \AA, \underline{c}=18.2240(7) \AA, \alpha=107.1983(13)^{\circ}, \beta=91.6597(13)^{\circ}, \gamma$ $=107.6992(12)^{\circ}$, volume $=3880.5(3) \AA^{3}$, are based upon the refinement of the XYZ-centroids of 9877 reflections above $20 \sigma(\mathrm{I})$ with $4.703^{\circ}<2 \theta<54.95^{\circ}$. Data were corrected for absorption effects using the multi-scan method (SADABS). The ratio of minimum to maximum apparent transmission was 0.701 . The calculated minimum and maximum transmission coefficients (based on crystal size) are 0.659 and 0.885 .

The structure was solved by direct methods and difference Fourier analysis using the programs provided by SHELXL-2013. ${ }^{41}$ The crystallographic asymmetric unit contains two independent molecules of the cobalt complex. Idealized positions for the hydrogen atoms were included as fixed contributions using a riding model with isotropic temperature factors set at 1.2 times (aromatic hydrogens) or 1.5 (methyl hydrogens) times that of the adjacent carbon atom. The positions of the methyl hydrogen atoms were optimized by a rigid rotating group refinement with idealized angles. The fractional coordinates and the isotropic thermal parameters of the two Obound hydrogen atoms in each molecule were refined. The t-butyl substituent containing carbon atoms, C52-C55, suffers from a two-site Star-of-David disorder. The fractional coordinates and anisotropic thermal parameters for C53, C54, and C55 in both sites were independently refined with the six C52-C(methyl) distances restrained to $1.52 \pm 0.01 \AA$. Full-matrix least-squares refinement, based upon the minimization of $\Sigma \mathrm{w}_{\mathrm{i}}\left|\mathrm{F}_{\mathrm{o}}{ }^{2}-\mathrm{F}_{\mathrm{c}}{ }^{2}\right|^{2}$, with weighting $\mathrm{w}_{\mathrm{i}}^{-1}=\left[\sigma^{2}\left(\mathrm{~F}_{\mathrm{o}}^{2}\right)+\right.$ $\left.(0.0160 \mathrm{P})^{2}+6.5059 \mathrm{P}\right]$, where $\mathrm{P}=\left(\operatorname{Max}\left(\mathrm{F}_{0}^{2}, 0\right)+2 \mathrm{~F}_{\mathrm{c}}{ }^{2}\right) / 3 .{ }^{2}$ The final anisotropic full-matrix least-squares refinement on $\mathrm{F}^{2}$ with 950 variables converged at $\mathrm{R}_{1}=6.47 \%$, for the observed data and $\mathrm{wR}_{2}=9.56 \%$ for all data. The goodness-of-fit was 1.103 . The values of $\mathrm{R}_{1}, \mathrm{wR}_{2}$, and the goodness-of-fit (GOF) were determined using the following equations: $\mathrm{R}_{1}=\Sigma\left(|| \mathrm{F}_{\mathrm{O}}|-| \mathrm{F}_{\mathrm{C}} \|\right) / \Sigma\left|\mathrm{F}_{\mathrm{O}}\right|$, 
$\mathrm{wR}_{2}=\left[\Sigma\left[\mathrm{w}\left(\mathrm{F}_{\mathrm{O}}^{2}-\mathrm{F}_{\mathrm{C}}^{2}\right)^{2}\right] / \Sigma\left[\mathrm{w}\left(\mathrm{F}_{\mathrm{O}}^{2}\right)^{2}\right]\right]^{1 / 2}$, and GOF $=\left[\Sigma\left[\mathrm{w}\left(\mathrm{F}_{\mathrm{O}}^{2}-\mathrm{F}_{\mathrm{C}}^{2}\right)^{2}\right] /(\mathrm{n}-\mathrm{p})\right]^{1 / 2}$, where $\mathrm{n}$ is the number of reflections and $\mathrm{p}$ is the total number of parameters which were varied during the last refinement cycle.

A correction for secondary extinction was not applied. The largest peak in the final difference electron density synthesis was $1.054 \mathrm{e}^{-} / \AA^{3}$ and the largest hole was $-0.657 \mathrm{e}^{-} / \AA^{3}$ with an RMS deviation of $0.091 \mathrm{e}^{-} / \AA^{3}$. The linear absorption coefficient, atomic scattering factors, and anomalous dispersion corrections were calculated from values found in the International Tables of X-ray Crystallography. ${ }^{42}$

\subsubsection{Preliminary X-ray Analysis for $\left(\mathrm{NH}_{3}\right) \mathrm{Co}(\mathrm{DH})_{2} \mathrm{SnPh}_{3}$}

An X-ray structural analysis was also performed to confirm the molecular structure and composition of $\left(\mathrm{NH}_{3}\right) \mathrm{Co}(\mathrm{DH})_{2} \mathrm{SnPh}_{3}$. However, the quality of the structural analysis was limited by the presence of unidentified disordered solvent molecules in the lattice. The analysis was sufficient to establish the atom connectivity and coordination of $\mathrm{NH}_{3}$.

\subsection{Halogen Cleavage Titrations}

Halogen cleavage titration reactions were completed for the following compounds: (Py)Co(DH) $)_{2} \mathrm{SnPh}_{3},(4-t-\mathrm{BuPy}) \mathrm{Co}(\mathrm{DH})_{2} \mathrm{SnPh}_{3},\left(\mathrm{NH}_{3}\right) \mathrm{Co}(\mathrm{DH})_{2} \mathrm{SnPh}_{3},(4-\mathrm{CNPy}) \mathrm{Co}(\mathrm{DH})_{2} \mathrm{SnPh}_{3}$, (4-t-BuPy)Co(DH $)_{2} \mathrm{Sn}\left(\mathrm{C}_{6} \mathrm{H}_{4}-p \text {-tolyl }\right)_{3}$, and (4-t-BuPy)Co(DH $)_{2} \mathrm{Sn}\left(\mathrm{C}_{6} \mathrm{H}_{4}-p-t-\mathrm{Bu}\right)_{3}$. A former group member also ran a halogen cleavage titration with (4-t-BuPy)Co(DH$)_{2} \mathrm{Sn}(n-\mathrm{Bu})_{3}$. In general, the halogen used was either $\mathrm{I}_{2}$ or $\mathrm{Br}_{2}$.

The first step was to determine how many equivalents of halogen would be desired for each sample (for example 0, 0.25, 0.5, 0.75, 1 and 2 equivalents of halogen) and calculate the amount 
of cobaloxime required to end up with approximately $5 \mathrm{mg}$ of sample in each NMR tube. The cobaloxime was dissolved in a deuterated solvent and diluted to a known volume in a volumetric flask. This gave the known concentration of the cobaloxime and $1 \mathrm{~mL}$ of this solution was placed in every test tube. The sample of the bromine or iodine was prepared in deuterated solvent and diluted to a known volume in a volumetric flask. The amount of halogen sample for 0.25 equivalents was calculated and the samples prepared by adding the necessary aliquots of halogen to the $1 \mathrm{~mL}$ cobaloxime samples to get $0,0.25,0.5,0.75,1$, and 2 equivalents of halogen in the test tubes. For each test tube, $100 \mu \mathrm{L}$ of solution was removed and used to prepare a GCMS sample. The remaining $900 \mu \mathrm{L}$ were transferred to an NMR tube and the proton spectra obtained for each titration sample. The ${ }^{1} \mathrm{H}$ NMR data was then analyzed to determine how many products arose as the titration of the halogen progressed to higher equivalents.

\subsection{Results and Discussion}

This section discusses the synthesis of the compounds used in this project, the X-ray structure analysis performed, and the results from the halogen cleavage titrations of the cobaloximes. The syntheses that are covered in this section include: Grignard synthesis of the tetraaryltin complexes, the successful and unsuccessful attempts at redistribution of the tetraaryltin species to obtain the chlorotriaryltin complexes, and the synthesis of the cobaloximes using the chlorotriaryltin complexes. It also discusses the basic synthesis of cobaloximes, the one step synthesis of the $\left(\mathrm{NH}_{3}\right) \mathrm{Co}(\mathrm{DH})_{2} \mathrm{SnPh}_{3}$ and (4-t-BuPy)Co(DH)$)_{2} \mathrm{Bn}$, and previously synthesized compounds. 


\subsection{Synthesis and Characterization of Compounds}

\subsubsection{Synthesis of Cobaloximes}

The Tada method for synthesis of cobaloximes was adapted for the synthesis of (4-tBuPy)Co(DH) ${ }_{2} \mathrm{SnPh}_{3}$ by Stolzenberg, et. al. ${ }^{32,37}$ The synthesis of this cobaloxime is described in Scheme 2. The procedure begins with the reaction of cobaltous chloride hexahydrate with dimethylglyoxime (DMG) in acetone under aerobic conditions, resulting in $\mathrm{Co}(\mathrm{DH})\left(\mathrm{DH}_{2}\right) \mathrm{Cl}_{2}$ crashing out as the major product. ${ }^{36}$ The dichloro cobaloxime is then suspended in methanol under aerobic conditions and heated to about $60{ }^{\circ} \mathrm{C}$ with stirring. This suspension is then mixed with tri-n-butyl amine that helps to dissolve the dichloro cobaloxime and deprotonate the cobaloxime before the base is added. The base, 4-t-butylpyridine (4-t-BuPy), is then added to the solution along with a little water. We chose to use 4-t-BuPy instead of the more common pyridine due to the improved solubility of these compounds with this base and the simplification
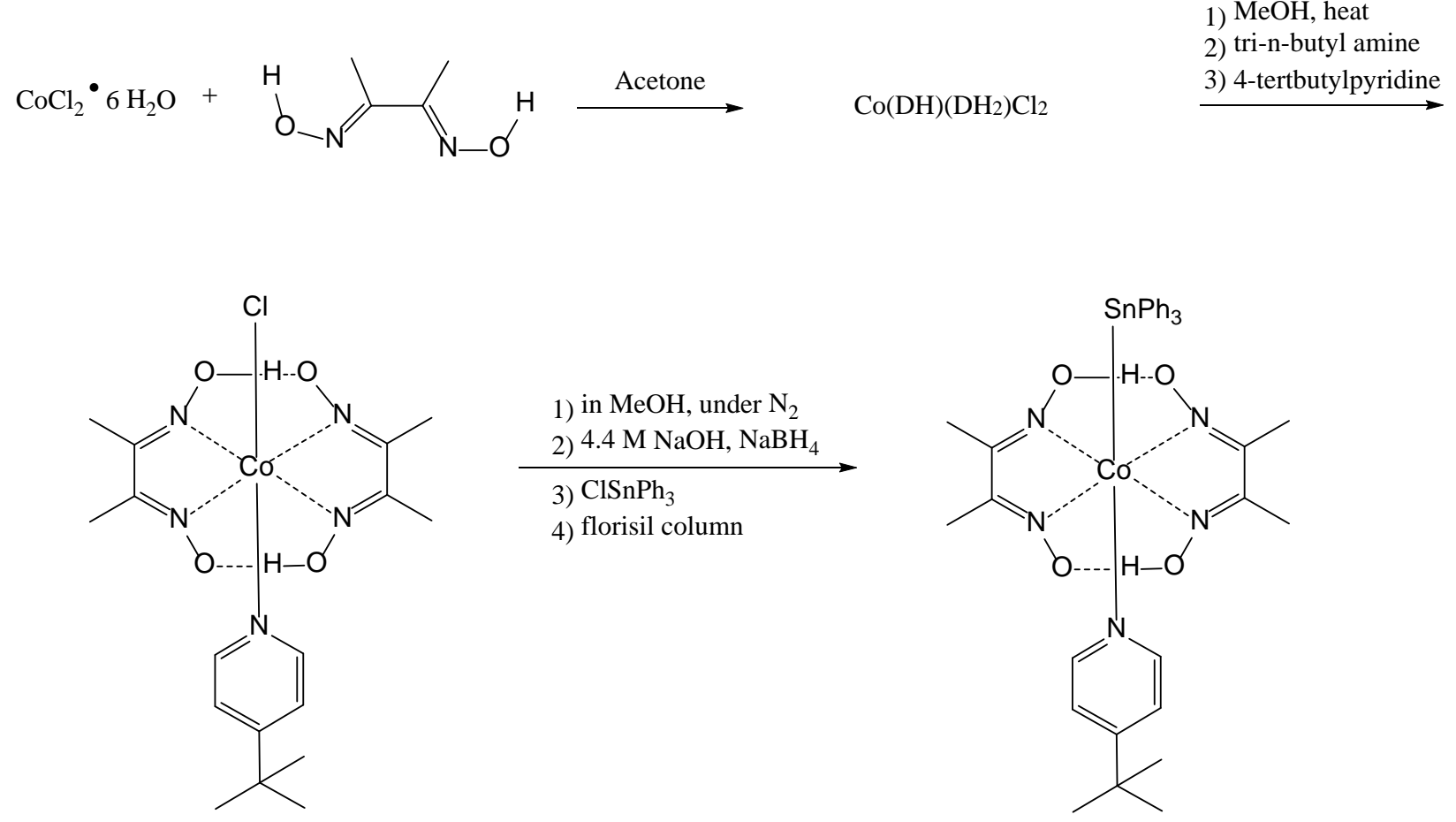

Scheme 2: Synthesis of (4-t-BuPy)Co(DH $)_{2} \mathrm{SnPh}_{3}$ 
of the ${ }^{1} \mathrm{H}$ NMR spectra. ${ }^{33-35}$ The product crashes out of solution slowly overnight and can then be recrystallized before the final step of the synthesis.

The (4-t-BuPy)Co(DH) ${ }_{2} \mathrm{Cl}$ is then dissolved in methanol under a nitrogen environment and placed in an ice bath. The solution of $4.4 \mathrm{M} \mathrm{NaOH}$ is added to help deprotonate the cobaloxime and reduce the amount of $\mathrm{NaBH}_{4}$ needed during the reaction. This smaller amount of sodium borohydride helps to prevent the production of hydrogen gas in the reaction. The cobalt center then reduces to $\mathrm{Co}(\mathrm{I})$ upon the addition of sodium borohydride and the chlorotriphenyl tin is then added. The reaction flask is covered in aluminum foil to exclude light during the reaction. After removing the ice bath, the flask is allowed to stir and come to room temperature overnight. During this time, the (4-t-BuPy)Co(DH) ${ }_{2} \mathrm{SnPh}_{3}$ is formed. The compound is extracted in dichloromethane, dried and the solvent removed by vacuum to obtain the crude product. The crude product is then run through a florisil column using a 4:1 dichloromethane: ethyl acetate eluting solvent system. The product is obtained as orange-red crystals. About $60 \%$ yield is expected based on the limiting chlorotriphenyltin.

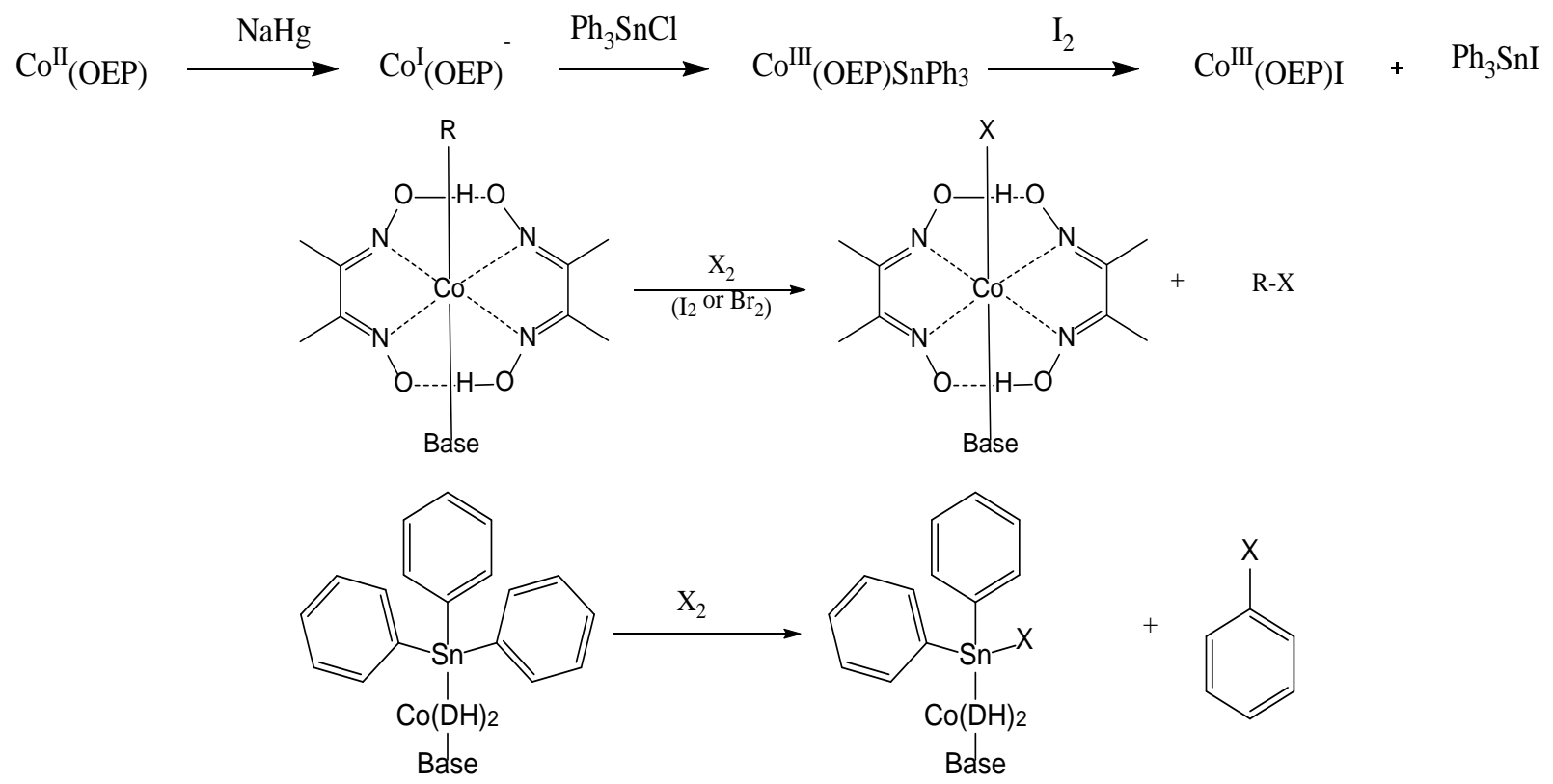

Scheme 3: Halogen cleavage of $\mathrm{Co}(\mathrm{OEP}) \mathrm{SnPh}_{3}$ versus (base)Co(DH) $\mathrm{SnPh}_{3}$ 
Upon reaction with halogen ( $\mathrm{I}_{2}$ or $\left.\mathrm{Br}_{2}\right)$, (4-t-BuPy)Co(DH $)_{2} \mathrm{SnPh}_{3}$ formed multiple products in the ${ }^{1} \mathrm{H}$ NMR. This means that the cobaloxime is not reacting the same way as the porphyrin in regards to Co-Sn bond cleavage with halogen. The halogen cleaves the Co-Sn bond of the $\mathrm{Co}(\mathrm{OEP}) \mathrm{SnPh}_{3}$ cleanly, as seen in Scheme 3, but the triphenyl tin cobaloxime does not. The halogen is cleaving the Sn-C bond through electrophilic aromatic substitution instead of homolytically cleaving the desired Co-Sn bond.

The project then progressed to explore modifying the coordination environment of the cobalt. One way that this was explored was through attempts to change the group 14 element from tin to germanium, silicon, or lead. The lead analogue was previously synthesized and characterized in the group, but the germanium and silicon analogues are inaccessible in our hands. In attempts to obtain the germanium analogue, benzyl cobaloxime was synthesized in order to react with $\mathrm{HGePh}_{3}$ to form toluene and (4-t-BuPy)Co(DH$)_{2} \mathrm{GePh}_{3}$. The synthesis of benzyl cobaloxime, (4-t-BuPy)Co(DH)$)_{2} \mathrm{Bn}$, and the proposed synthesis of (4-t-

$\mathrm{BuPy}) \mathrm{Co}(\mathrm{DH})_{2} \mathrm{GePh}_{3}$ is seen in Scheme 4. The benzyl cobaloxime is synthesized through a onestep procedure. ${ }^{39}$ The (4-t-BuPy)Co(DH $)_{2} \mathrm{Cl}$ and benzyl chloride are mixed in a methanol and water solution under nitrogen. The cobaloxime is reduced by $\mathrm{NaBH}_{4}$ which is added slowly in several portions over about 15 minutes. The solution is allowed to stir and react for a few more minutes and then can be isolated through vacuum filtration and washed with ether and hexanes. The orange product is obtained in approximately $50 \%$ yield. The ${ }^{1} \mathrm{H}$ NMR is consistent with the structure. Although reactions of benzyl cobaloxime and $\mathrm{HGePh}_{3}$ were unable to produce isolable (4-t-BuPy)Co(DH $)_{2} \mathrm{GePh}_{3}$, the procedure seems like a promising avenue to explore in the future. 

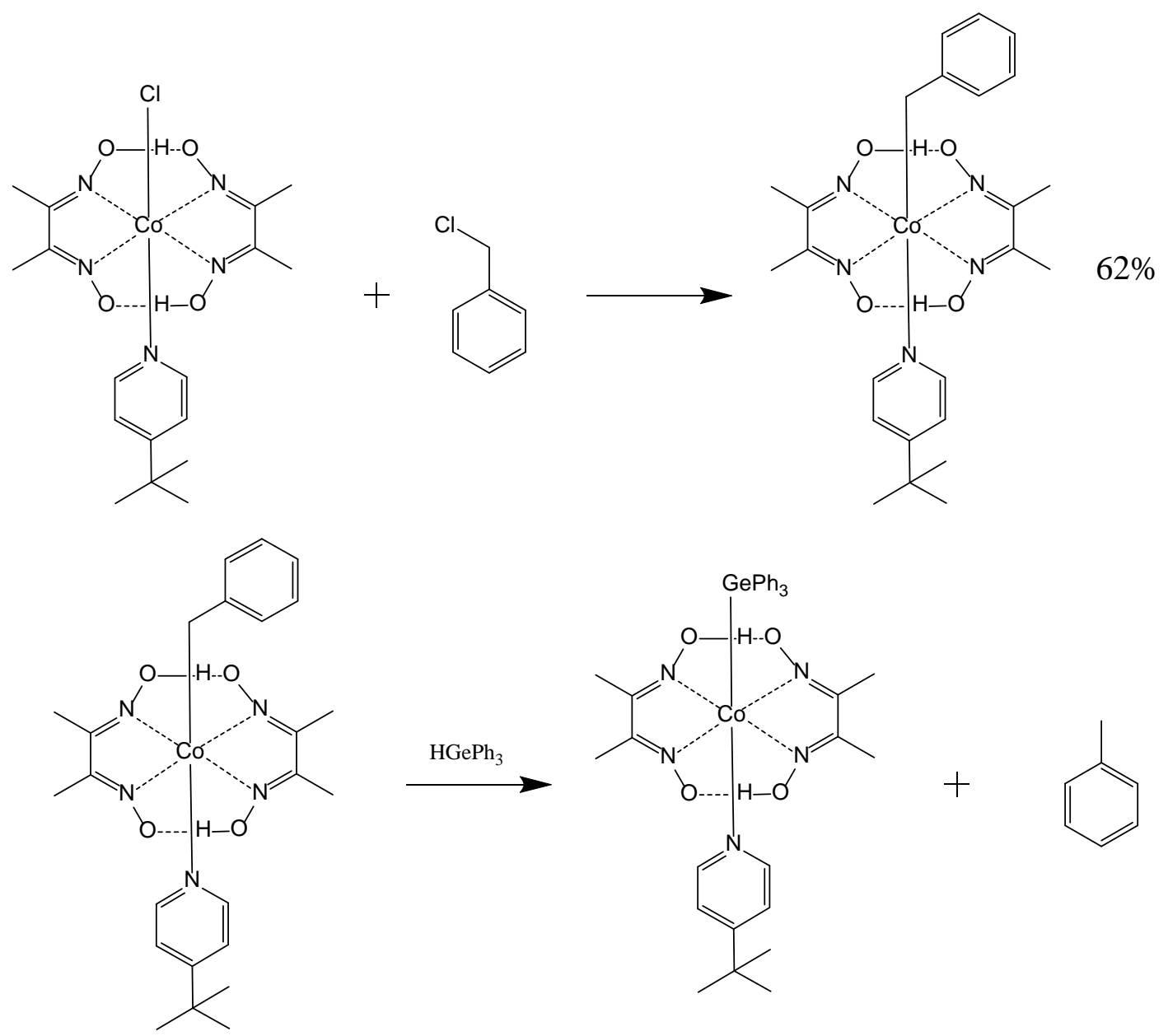

Scheme 4: Synthesis of benzyl cobaloxime and synthetic attempt to synthesize (4-t$\mathrm{BuPy}) \mathrm{Co}(\mathrm{DH})_{2} \mathrm{GePh}_{3}$

Another modification to the coordination environment of the cobalt that was explored was altering the Lewis base. Attempts to synthesize (2-MePy)Co(DH) $)_{2} \mathrm{Cl},(4-\mathrm{MePy}) \mathrm{Co}(\mathrm{DH})_{2} \mathrm{Cl}$, and (2,6-dimethylpyridine) $\mathrm{Co}(\mathrm{DH})_{2} \mathrm{Cl}$ were unsuccessful, but the synthesis of $\left(\mathrm{NH}_{3}\right) \mathrm{Co}(\mathrm{DH})_{2} \mathrm{Cl}$ was successful. This compound was then used to synthesize $\left(\mathrm{NH}_{3}\right) \mathrm{Co}(\mathrm{DH})_{2} \mathrm{SnPh}_{3}$ which was explored as a route to a five coordinate cobaloxime to compare to the five coordinate alkyl cobalt porphyrin complex. Attempts to drive off the ammonia group by heating were unsuccessful, but should be revisited in the future. The ammonia cobaloxime was synthesized through the same one-step procedure as benzyl cobaloxime and a preliminary crystal structure analysis was 
performed. The synthesis of both $\left(\mathrm{NH}_{3}\right) \mathrm{Co}(\mathrm{DH})_{2} \mathrm{Cl}$ and $\left(\mathrm{NH}_{3}\right) \mathrm{Co}(\mathrm{DH})_{2} \mathrm{SnPh}_{3}$ is seen in Scheme 5.<smiles>CC(=NO)C(C)=NO</smiles>

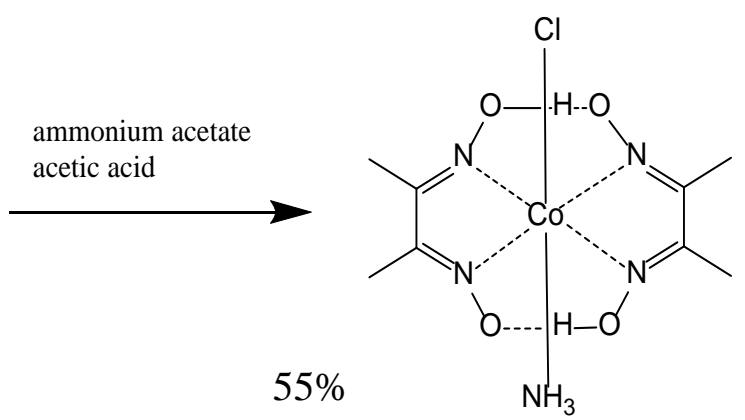

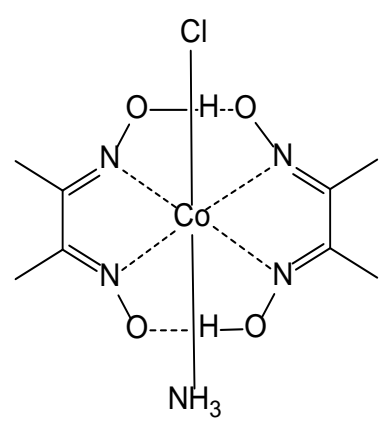

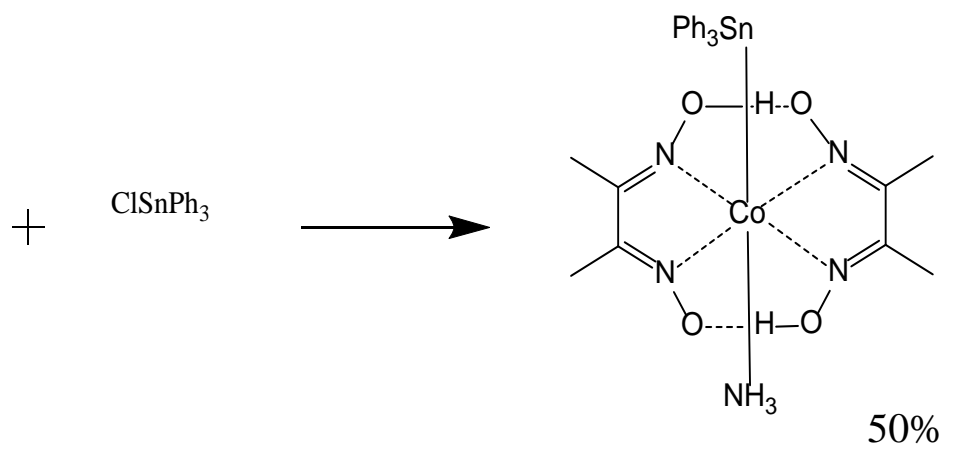

Scheme 5: Synthesis of $\left(\mathrm{NH}_{3}\right) \mathrm{Co}(\mathrm{DH})_{2} \mathrm{SnPh}_{3}$

The $\left(\mathrm{NH}_{3}\right) \mathrm{Co}(\mathrm{DH})_{2} \mathrm{Cl}$ was synthesized by reacting dimethylglyoxime, $\left[\mathrm{Co}\left(\mathrm{NH}_{3}\right)_{5} \mathrm{Cl}\right] \mathrm{Cl}_{2}$, and ammonium acetate in water and acetic acid. The reaction was heated to $100^{\circ} \mathrm{C}$ and acetic acid was added periodically until no ammonia gas was detectible by litmus. The solid was collected by vacuum filtration and obtained in $55 \%$ yield. The $\left(\mathrm{NH}_{3}\right) \mathrm{Co}(\mathrm{DH})_{2} \mathrm{Cl}$ was then reacted in a one-step procedure with $\mathrm{ClSnPh}_{3}$ and $\mathrm{NaBH}_{4}$ in degassed methanol. The reaction flask was allowed to stir for several minutes and the solid was collected by vacuum filtration and washed with ether and hexanes. The product was an orange solid obtained in 50\% yield. Its ${ }^{1} \mathrm{H}$ NMR was consistent with the structure. 


\subsubsection{Synthesis of Tetraaryltin Compounds}

The hypothesis of this project is that sterically hindering access to the Sn-C bond through substitution on the para position of the phenyl ring will promote Co-Sn bond cleavage. In order to test this hypothesis, aryl para-substituted cobaloximes are required. These aryl parasubstituted cobaloximes are achieved through the synthesis of chlorotriaryltin complexes that are then reacted with (4-t-BuPy)Co(DH$)_{2} \mathrm{Cl}$ to produce the desired product.
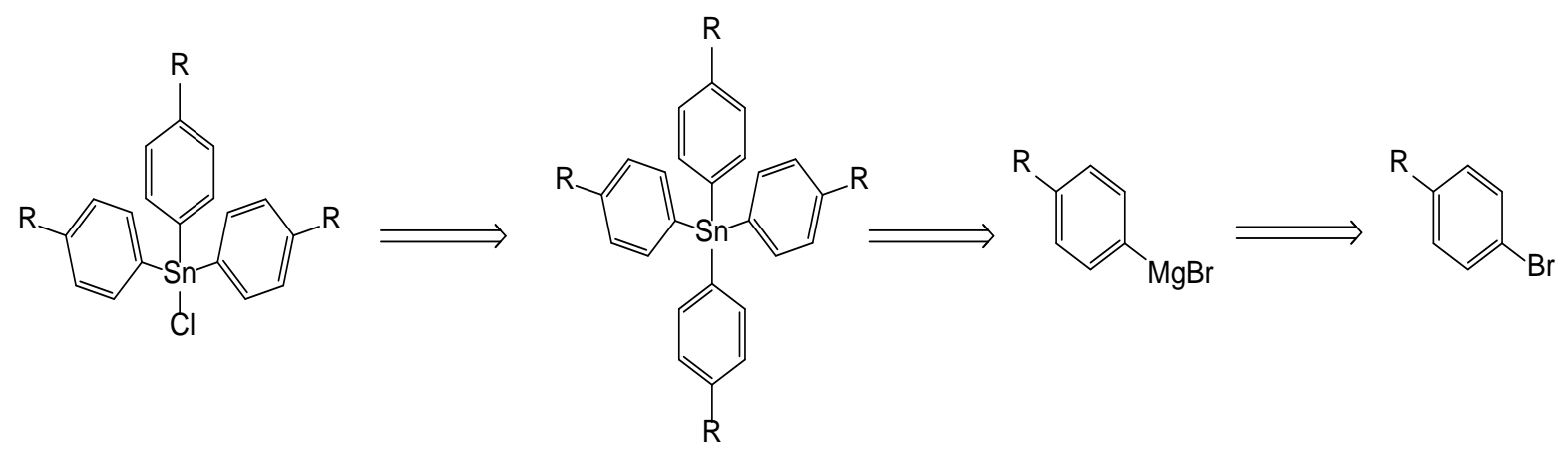

Scheme 6: Retrosynthesis of para-substituted chlorotriaryltin species

The retrosynthetic analysis for the synthesis of these chlorotriaryltin compounds is represented in Scheme 6. The chlorotriaryltin complex is formed from the redistribution reaction of the corresponding tetraaryltin compound. This tetraaryltin compound is synthesized from a Grignard reaction of the bromophenyl compound. 

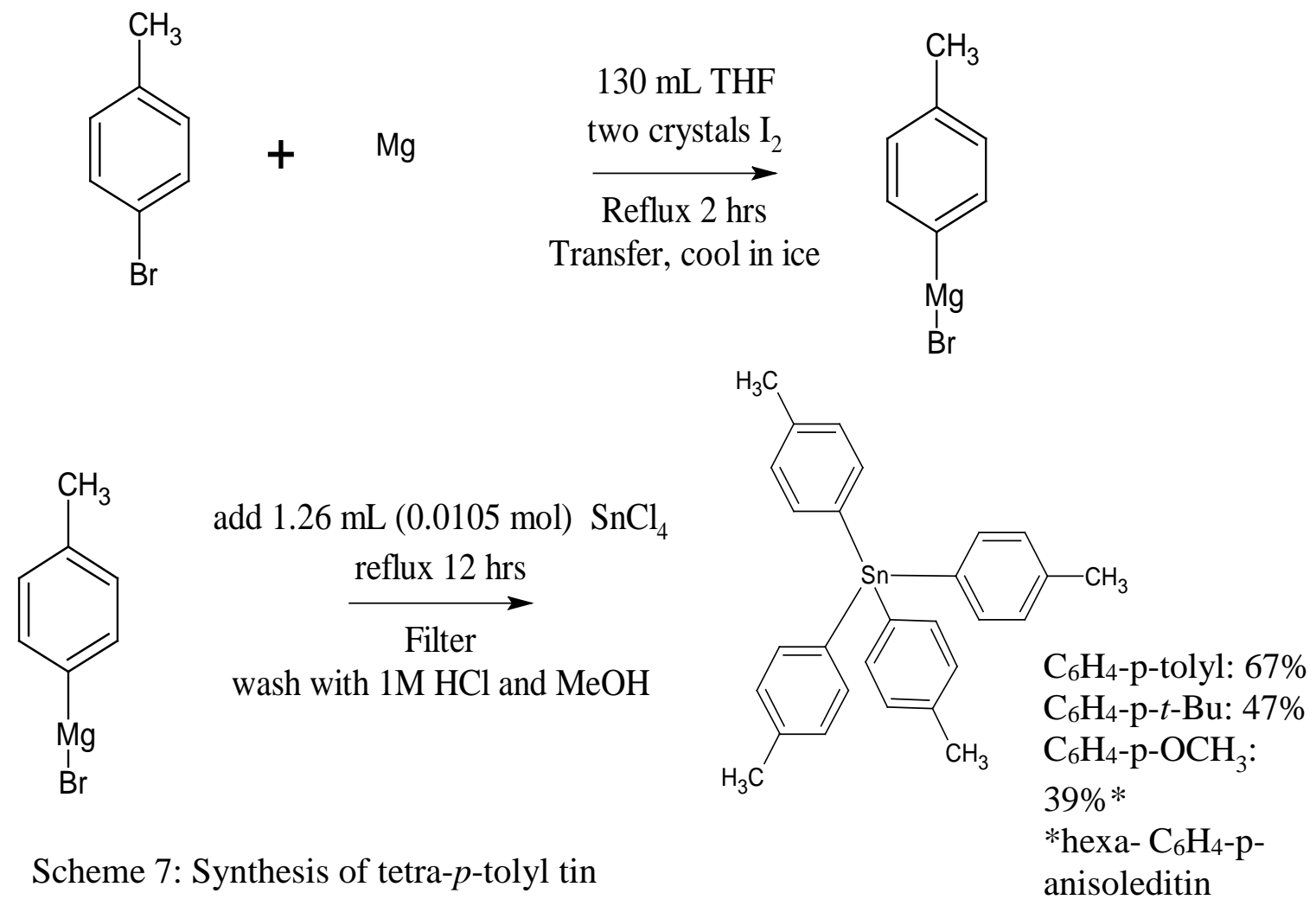

The first step to this synthetic route is to perform the Grignard reaction. The reaction for tetra-p-tolyl tin shown in Scheme $7 .{ }^{43}$ The tetraaryltin compounds that are synthesized from this step include tetra- $\mathrm{C}_{6} \mathrm{H}_{4}-p$-tolyl tin, tetra- $\mathrm{C}_{6} \mathrm{H}_{4}-p$-anisole tin, and tetra- $\mathrm{C}_{6} \mathrm{H}_{4}-p$-t-butyl tin represented by the formulas $\mathrm{Sn}\left(\mathrm{C}_{6} \mathrm{H}_{4}-p \text {-tolyl }\right)_{4}$, $\mathrm{Sn}\left(\mathrm{C}_{6} \mathrm{H}_{4}-p-\mathrm{OCH}_{3}\right)_{4}$, and $\mathrm{Sn}\left(\mathrm{C}_{6} \mathrm{H}_{4}-p \text {-tBu }\right)_{4}$ respectively. The synthesis is carried out under nitrogen and begins with the mixing of 4bromotoluene and magnesium turnings in THF. Two crystals of $\mathrm{I}_{2}$ are added to help initiate the reaction and the flask is brought to reflux for two hours. After the reflux period is complete, the grayish solution is transferred under nitrogen to another flask and away from any unreacted magnesium. The flask is then cooled in an ice bath and tin tetrachloride $\left(\mathrm{SnCl}_{4}\right)$ is added slowly to the Grignard reagent. The mixture is brought back up to reflux for another twelve hours. At this point the white solid should form and be able to be filtered out. At times, there was no solid 
and the washing of the solution with $1 \mathrm{M} \mathrm{HCl}$ produced a yellow solution. The yellow solution was then cooled in a freezer for several hours and a white solid product formed and was obtained through filtration. The solid was rinsed with methanol and $1 \mathrm{M} \mathrm{HCl}$. Several crops of crystals can be obtained from the solution. The product can be recrystallized by dissolving the solid in warm toluene and layering with ethanol. The melting point and ${ }^{1} \mathrm{H}$ NMR of the product are consistent with literature. The synthesis of $\mathrm{Sn}\left(\mathrm{C}_{6} \mathrm{H}_{4}-p-\mathrm{OCH}_{3}\right)_{4}$ and $\mathrm{Sn}\left(\mathrm{C}_{6} \mathrm{H}_{4}-p-t-\mathrm{Bu}\right)_{4}$ follow the same procedure and result in white crystalline solids in good yield that have NMR spectra consistent with their structures. During the preparation of $\mathrm{Sn}\left(\mathrm{C}_{6} \mathrm{H}_{4}-p-\mathrm{OCH}_{3}\right)_{4}$ one of the crops of solid that crashed out was hexa- $\mathrm{C}_{6} \mathrm{H}_{4}-p$-anisole ditin, as determined by ${ }^{1} \mathrm{H}$ NMR and melting point. An attempt to cleave this using halogen to obtain the chlorotriaryltin species was unsuccessful.

\subsubsection{Synthesis of TriaryltinCl Compounds}

With the tetraaryl tin species in hand, the redistribution reaction to form the chlorotriaryltin complexes was attempted. Several unsuccessful methods (Kocheshkov, Chambers and Scherer, Krause, and a 3:1 Grignard reaction) were explored before a successful procedure (Jolly) for the redistribution reaction was found. ${ }^{38,43-45}$ All attempts at redistribution were made first using $\mathrm{Sn}\left(\mathrm{C}_{6} \mathrm{H}_{4}-p \text {-tolyl }\right)_{4}$ and if successful the other two tetraaryl tin complexes were investigated. 


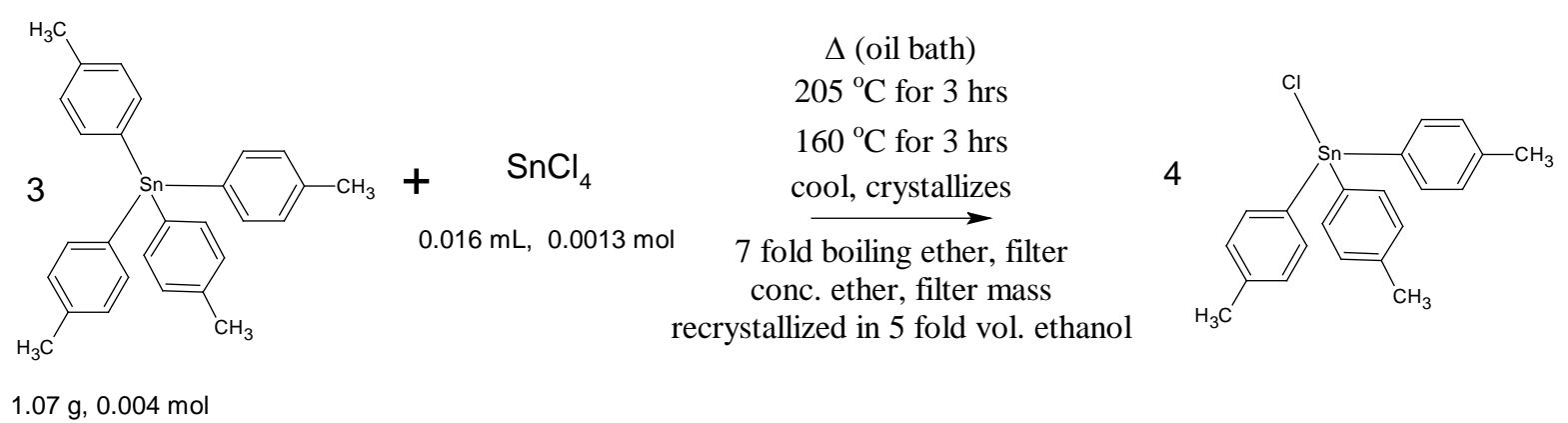

Scheme 8: Kocheshkov redistribution synthesis attempt

The first attempt at redistribution involved the Kocheshkov reaction, shown in Scheme $8 .{ }^{38}$ In a 3:1 mole ratio of $\mathrm{Sn}\left(\mathrm{C}_{6} \mathrm{H}_{4}-p \text {-tolyl }\right)_{4}$ to $\mathrm{SnCl}_{4}$, these two compounds are mixed in a test tube and heated in an oil bath at $205^{\circ} \mathrm{C}$ for three hours. The temperature is then dropped to 160 ${ }^{\circ} \mathrm{C}$ for another three hours and the solution is then cooled. Upon cooling, a solid should crystallize and can then be rinsed in boiling ether and filtered. The ether washings are then concentrated under vacuum and the resulting solid mass filtered. The solid can then be recrystallized using ethanol. After cooling the solution following its heating to $160{ }^{\circ} \mathrm{C}$, little product was observed. After proceeding through with the washings in ether very little product remained. The ${ }^{1} \mathrm{H}$ NMR showed very little compound and was overwhelmed by mainly solvent peaks and some impurities. Attempts were also made using $\mathrm{SnI}_{4}$ instead of $\mathrm{SnCl}_{4}$ due to the ease of handling of the iodide compound, but these attempts were also unsuccessful. 

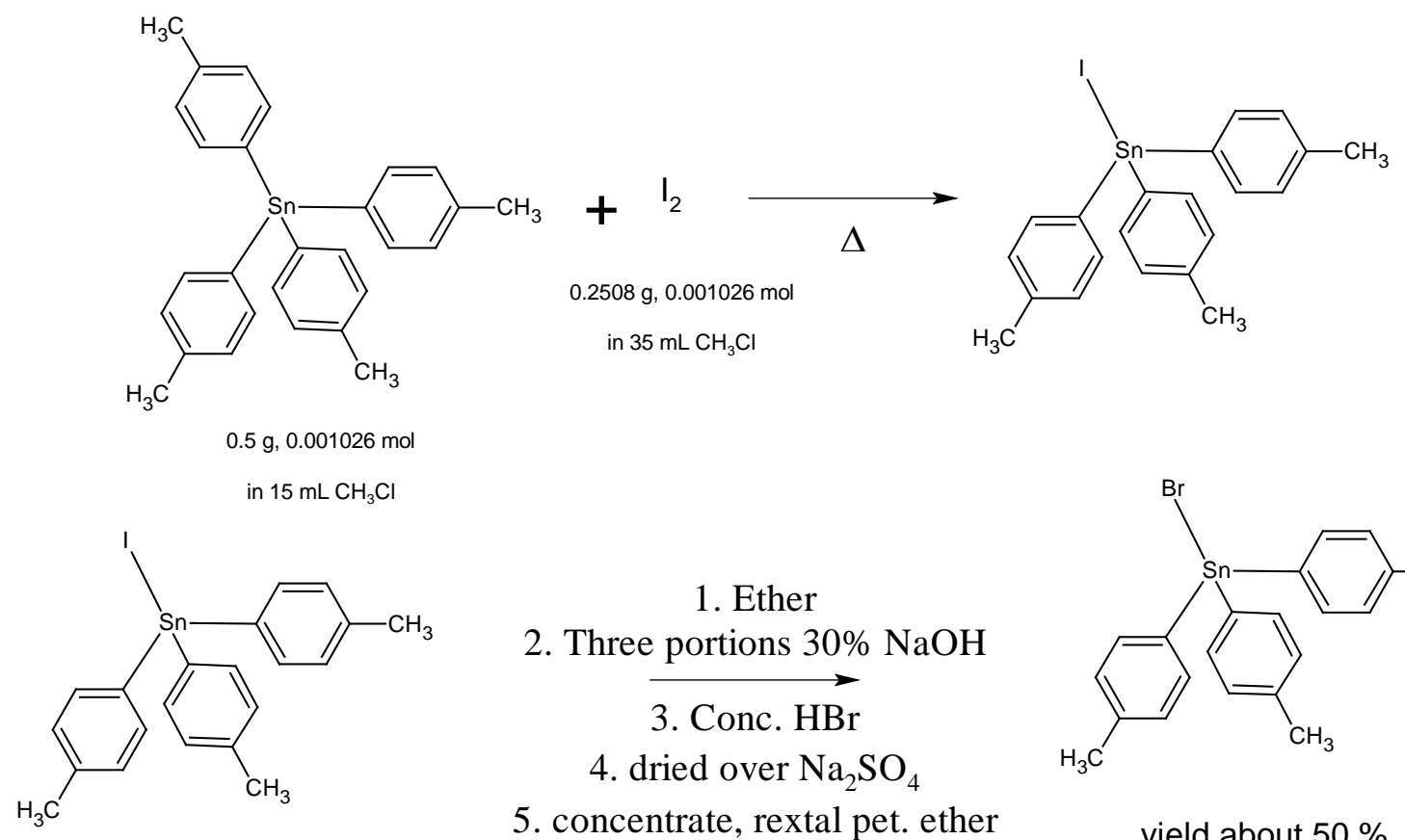

\section{Ether \\ 2. Three portions $30 \% \mathrm{NaOH}$ \\ 3. Conc. $\mathrm{HBr}$ \\ 4. dried over $\mathrm{Na}_{2} \mathrm{SO}_{4}$ \\ 5. concentrate, rextal pet. ether}

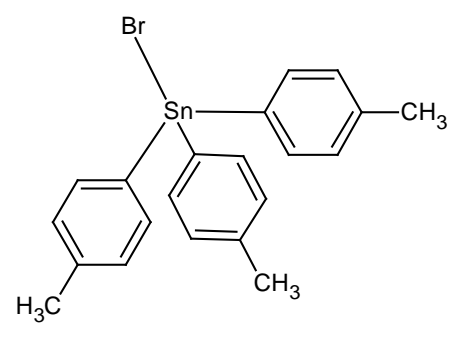

yield about $50 \%$

Scheme 9: Chambers and Scherer redistribution synthetic attempt

The next attempt at the redistribution reaction involved a method from Chambers and Scherer, seen in Scheme 9. ${ }^{44}$ This synthetic approach involved a 1:1 mole ratio of $\mathrm{Sn}\left(\mathrm{C}_{6} \mathrm{H}_{4}-p\right.$ tolyl) $)_{4}$ to iodine. Each reagent was dissolved in chloroform, combined and heated to produce the iodotriaryltin species. This step never resulted in a pure isolable product. From this step, one could convert it to the bromotriaryltin complex by dissolving in ether and adding three portions of $30 \% \mathrm{NaOH}$ and concentrated $\mathrm{HBr}$. The solutions are dried using sodium sulfate, filtered and the solvent concentrated using rotary evaporation. The product could be recrystallized from petroleum ether resulting in about 50\% yield.

The third attempt at redistribution involved the Krause method, seen in Scheme $10 .^{45}$ This method began by dissolving $\mathrm{Sn}\left(\mathrm{C}_{6} \mathrm{H}_{4}-p \text {-tolyl }\right)_{4}$ in hot pyridine and stirring. The solution is then cooled in ice and the solid recrystallizes into fine small crystals that are then reacted with 
$\mathrm{Br}_{2}$ in pyridine added in six aliquots over a few hours. The pyridine and bromobenzene is removed by vacuum and a brown residue remains. This residue is dissolved in ether and then reacted with concentrated $\mathrm{HCl}$. The ether solution is filtered and the solvent was removed with a rotary evaporator to yield the crude chlorotriaryltin product. This crude product is then dissolved in ether and washed with $30 \% \mathrm{NaOH}$. It is then washed with concentrated $\mathrm{HCl}$ and purified in warm ether to yield $\mathrm{ClSn}\left(\mathrm{C}_{6} \mathrm{H}_{4}-p \text {-tolyl }\right)_{4}$. The crude product was never obtained through multiple attempts of this procedure. This is not a viable option for the redistribution of the substituted phenyl tin compounds.
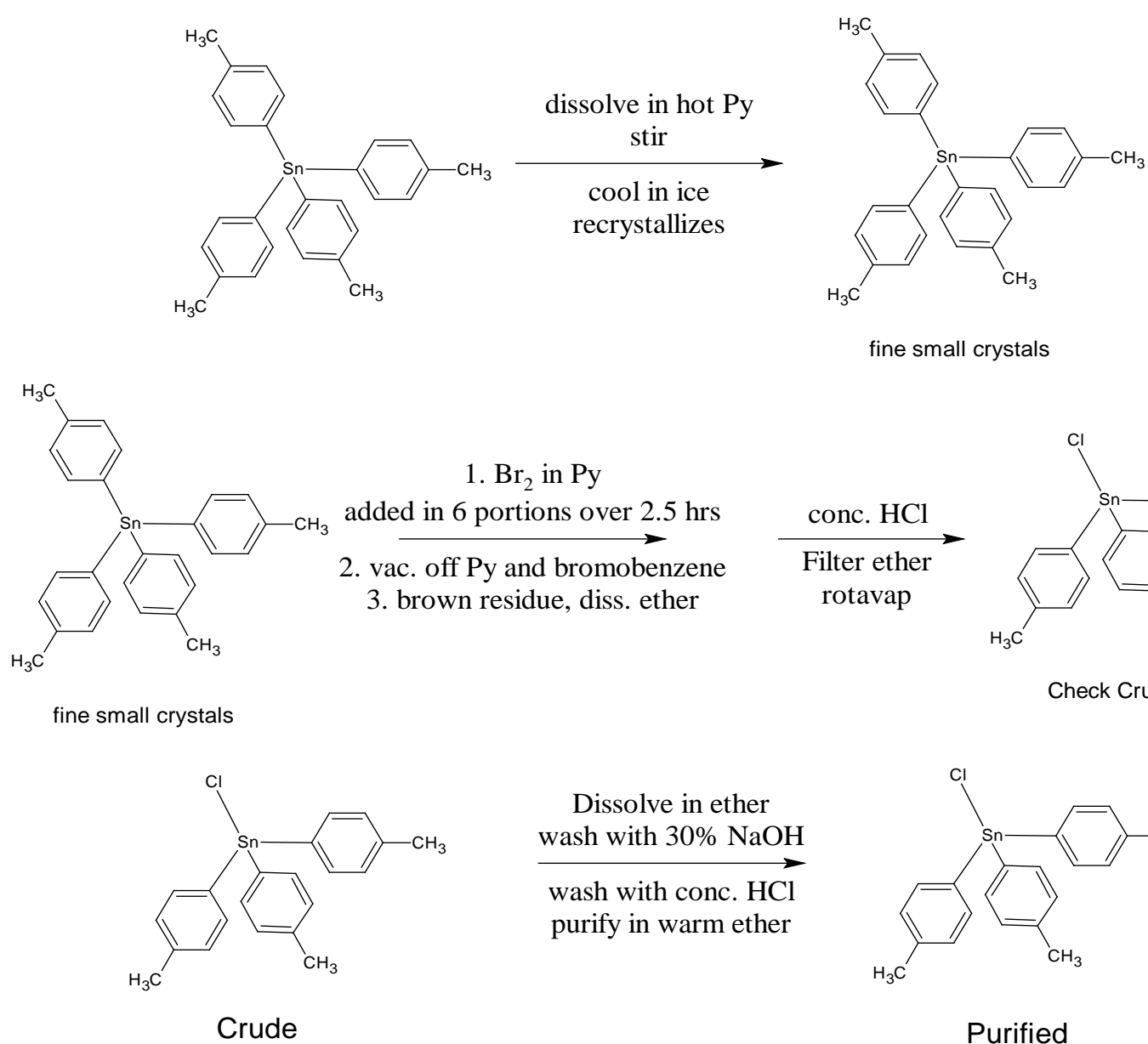

1. $\mathrm{Br}_{2}$ in $\mathrm{Py}$ 2. vac. off Py and bromobenzene 3. brown residue, diss. ether

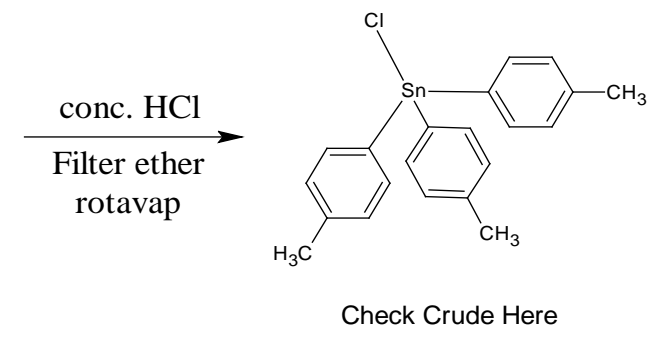

Scheme 10: Krause method for redistribution synthetic attempt 
The next synthetic route investigated was a 3:1 Grignard reaction, seen in Scheme $11 .^{43}$ The ratio was expected to limit the available Grignard reagent in hopes of leading to only three of the chlorines being displaced from the $\mathrm{SnI}_{4}$ and producing $\mathrm{ISn}\left(\mathrm{C}_{6} \mathrm{H}_{4}-p \text {-tolyl }\right)_{3}$ which can then be used to synthesize the substituted cobaloxime. The synthesis of the Grignard reagent follows the same procedure as used in the tetraaryltin syntheses. The next step in the synthesis is similar as well, except the ratio of the Grignard reagent to the $\mathrm{SnI}_{4}$ has been altered to 1:3. This synthesis produced many products that were not easily isolated. The main product was still the tetraaryltin species. This method is not a feasible route to obtain the chlorotriaryltin compounds.

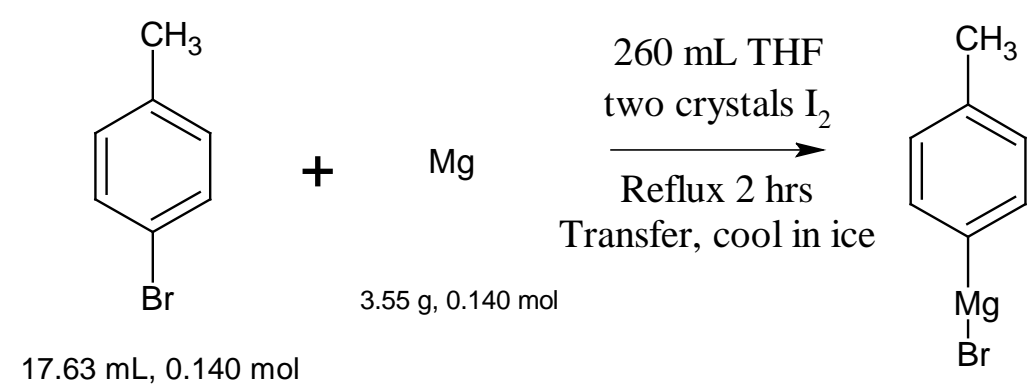<smiles>Cc1ccc([Al]Br)cc1</smiles>
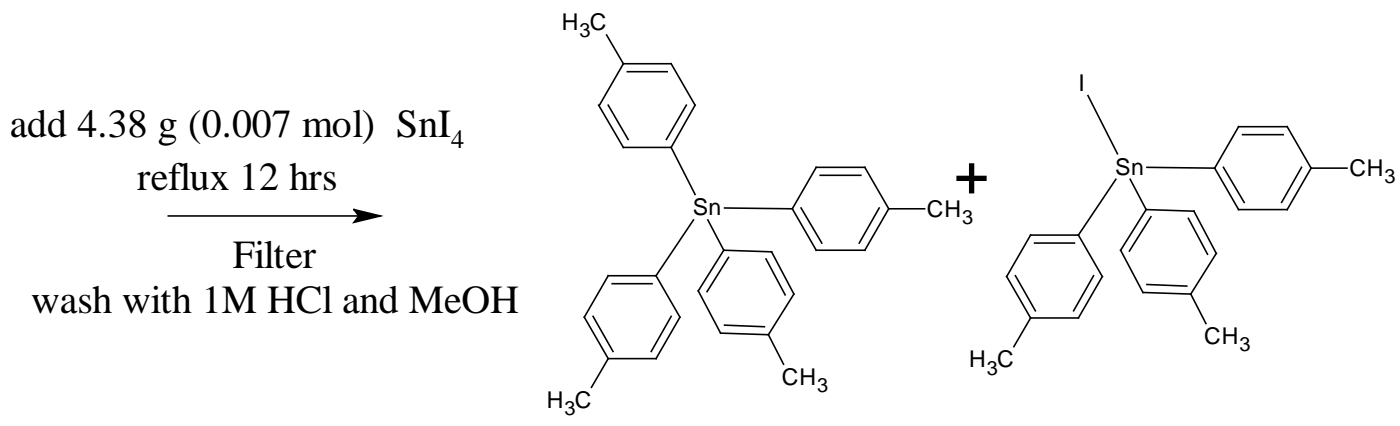

Scheme 11: 3:1 Grignard in an attempt to synthesize $\mathrm{ClSn}\left(\mathrm{C}_{6} \mathrm{H}_{4}-p \text {-tolyl }\right)_{3}$

The final redistribution method was developed by Jolly and led to the successful synthesis of $\mathrm{ClSn}\left(\mathrm{C}_{6} \mathrm{H}_{4}-p \text {-tolyl }\right)_{3}$ and $\mathrm{ClSn}\left(\mathrm{C}_{6} \mathrm{H}_{4}-p-t-\mathrm{Bu}\right)_{3}$, as seen in Scheme $12 .{ }^{38}$ The $\mathrm{ClSn}\left(\mathrm{C}_{6} \mathrm{H}_{4}-p-\mathrm{OCH}_{3}\right)_{3}$ was not successfully synthesized by this method or any other methods. It is believed that the methoxy group is being cleaved and other side reactions are occurring, 
preventing the redistribution of the phenyl group. The Jolly procedure is a variation on the Kocheshkov procedure, but the reaction is done at higher temperatures and the work up of the solid product is handled differently. The $\mathrm{Sn}\left(\mathrm{C}_{6} \mathrm{H}_{4}-p \text {-tolyl }\right)_{4}$ is added to a reaction tube along with $\mathrm{SnCl}_{4}$ and the tube is heated to $230{ }^{\circ} \mathrm{C}$ slowly over a period of 1.5 hours. The temperature is held for three hours and then cooled to $100{ }^{\circ} \mathrm{C}$. When this temperature is reached, the solution is poured into a beaker and cooled to room temperature. The solid mass is broken up and stirred with warm ethanol at about $50{ }^{\circ} \mathrm{C}$. Water is added slowly to crash out the desired product. The white solid is then filtered and allowed to air dry. This procedure leads to a reasonably pure product in decent yield, but can be recrystallized to improve the purity of the sample. This procedure afforded us the desired chlorotriaryltins, $\mathrm{ClSn}\left(\mathrm{C}_{6} \mathrm{H}_{4}-p \text {-tolyl }\right)_{3}$ and $\mathrm{ClSn}\left(\mathrm{C}_{6} \mathrm{H}_{4}-p-t-\mathrm{Bu}\right)_{3}$. From here the substituted chlorotriaryltin compounds were reacted using a procedure analogous to the synthesis of (4-t-BuPy)Co(DH $)_{2} \mathrm{SnPh}_{3}$ discussed above. The reaction of both of these compounds with (4-t-BuPy)Co(DH) $)_{2} \mathrm{Cl}$ afforded the desired products of (4-t$\mathrm{BuPy}) \mathrm{Co}(\mathrm{DH})_{2} \mathrm{Sn}\left(\mathrm{C}_{6} \mathrm{H}_{4}-p \text {-tolyl }\right)_{3}$ and (4-t-BuPy)Co(DH) $)_{2} \mathrm{Sn}\left(\mathrm{C}_{6} \mathrm{H}_{4}-p-t-\mathrm{Bu}\right)_{3}$. The reactivity of these substituted cobaloximes was examined through NMR titrations with halogen, described in the next section.
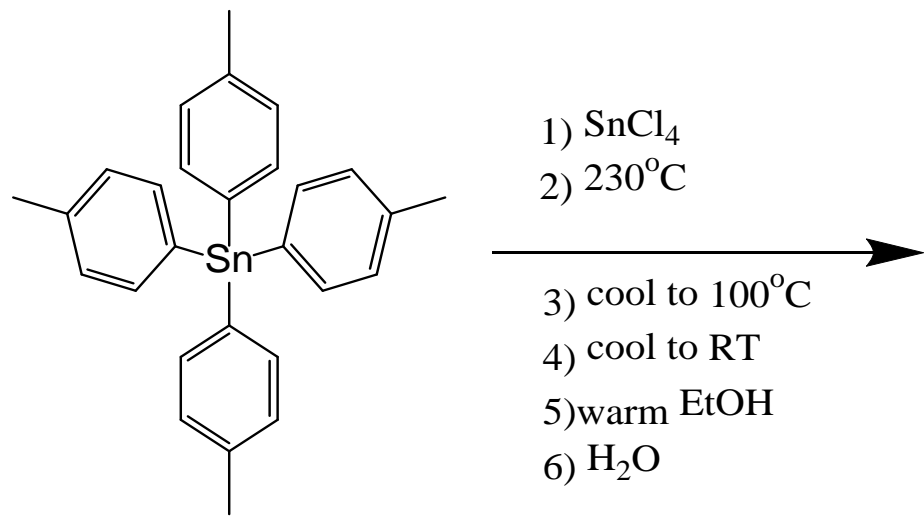

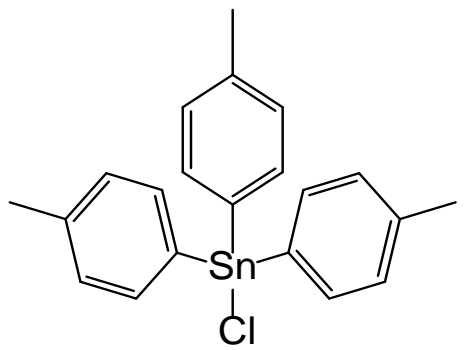

$\mathrm{C}_{6} \mathrm{H}_{4}$-p-tolyl: $61 \%$ $\mathrm{C}_{6} \mathrm{H}_{4}-\mathrm{p}-\mathrm{t}-\mathrm{Bu}: 67 \%$

Scheme 12: Jolly procedure for the successful redistribution of $\mathrm{Sn}\left(\mathrm{C}_{6} \mathrm{H}_{4}-p\right.$ tolyl $)_{4}$ to $\mathrm{ClSn}\left(\mathrm{C}_{6} \mathrm{H}_{4}-p \text {-tolyl }\right)_{3}$ 


\subsection{X-ray Structure Analysis of Cobaloxime Tin Complexes}

\subsubsection{X-ray Analysis of (4-t-BuPy) $\mathrm{Co}(\mathrm{DH})_{2} \mathrm{Sn}\left(\mathrm{C}_{6} \mathrm{H}_{4}-p \text {-tolyl }\right)_{3}$}

A crystal structure of (4-t-BuPy)Co(DH $)_{2} \mathrm{Sn}\left(\mathrm{C}_{6} \mathrm{H}_{4}-p \text {-tolyl }\right)_{3}$ was determined. An ORTEP drawing of the structure is shown in Figure 4. The crystal data is represented in Table 2. Table 3 contains the data collection and structure refinement parameters and Table 4 contains selected interatomic distances and bond angles for (4-t-BuPy)Co(DH $)_{2} \mathrm{Sn}\left(\mathrm{C}_{6} \mathrm{H}_{4}-p \text {-tolyl }\right)_{3}$. The compound crystallizes in the centrosymmetric triclinic space group $P-1$ with two compounds in the unit cell. The cobalt is a six coordinate octahedral atom that is connected to the four donor nitrogen atoms

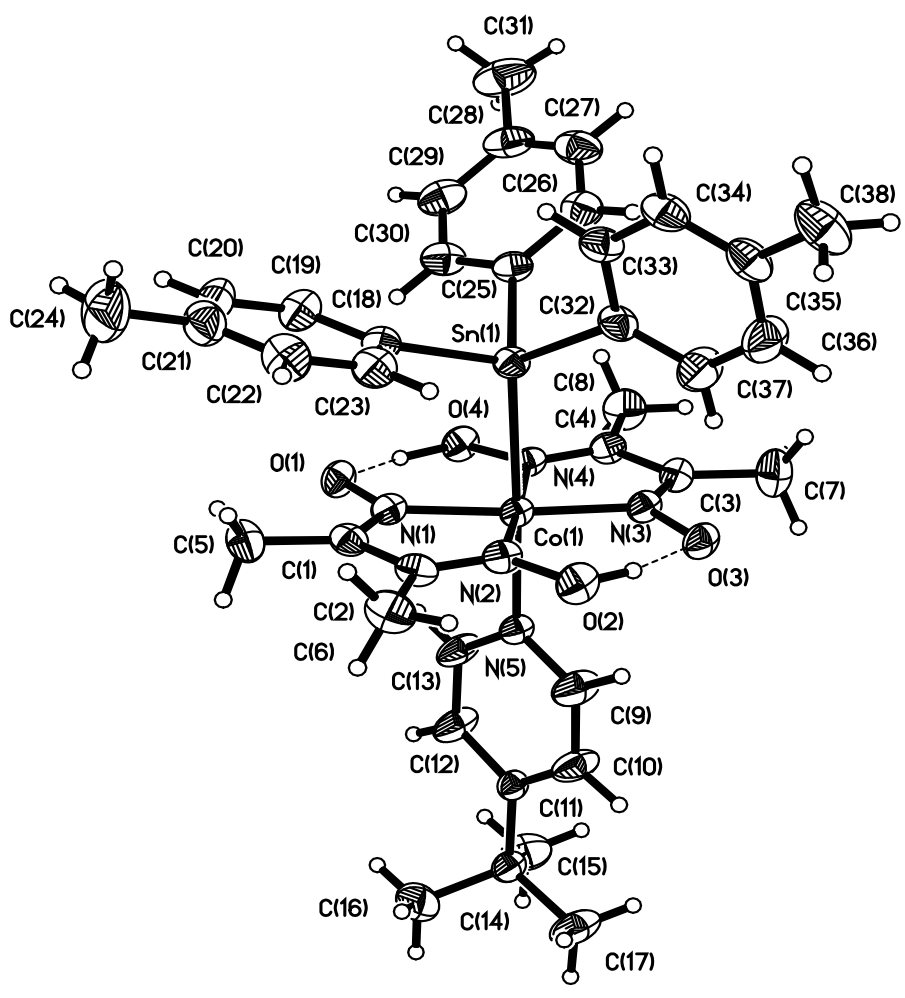

Figure 4. ORTEP drawing of (4-t-BuPy) $\mathrm{Co}(\mathrm{DH})_{2} \mathrm{Sn}\left(\mathrm{C}_{6} \mathrm{H}_{4}-p \text {-tolyl }\right)_{3}$. Perspective view of the molecular structure of one of the two crystallographic independent molecules of (4-t$\mathrm{BuPy}) \mathrm{Co}(\mathrm{DH})_{2} \mathrm{Sn}\left(\mathrm{C}_{6} \mathrm{H}_{4}-p \text {-tolyl }\right)_{3}$ with the atom labeling scheme for the non-hydrogen atoms. The thermal ellipsoids are scaled to enclose 30\% probability. 
from dimethylglyoxime (DMG) in the equatorial plane and to the tin and nitrogen of the 4-tBupyridine in the axial positions. Each of the DMG ligands is chelated in a bidentate fashion through the donor nitrogen atoms to the cobalt center. The DMG ligands are connected to each other through two bridging $\mathrm{O}-\mathrm{H} \cdots \mathrm{O}$ hydrogen bonds.

The equatorial Co-N bonds have interatomic distances that range from 1.874(3) - 1.880(3) $\AA$. This is comparable to the equatorial Co-N interatomic distances for the coenzyme $\mathrm{B}_{12}(\sim 1.90 \AA)$, vitamin $\mathrm{B}_{12}(\sim 1.92 \AA)$, and alkyl cobaloxime $(\sim 1.88 \AA) .{ }^{7,14}$ The alkyl cobaloxime that is referenced is the first alkyl cobaloxime studied by Lenhert in 1967, $\mathrm{PyCo}(\mathrm{DH})_{2} \mathrm{CH}_{2} \mathrm{COOCH}_{3}$. The equatorial Co-N bonds for $\mathrm{Co}^{\mathrm{III}}(\mathrm{OEP}) \mathrm{SnPh}_{3}$ are slightly longer $(1.962-1.975 \AA)$ than (4tBuPy $) \mathrm{Co}(\mathrm{DH})_{2} \mathrm{Sn}\left(\mathrm{C}_{6} \mathrm{H}_{4}-\mathrm{p} \text {-tolyl }\right)_{3 .}{ }^{26}$

The axial Co-N bond for the 4-t-BuPy is 2.063(3) $\AA$. This is similar to the bond distances in vitamin $\mathrm{B}_{12}(1.97-2.06 \AA)$ and alkyl cobaloxime $(\sim 2.04 \AA)$, but is shorter than the axial Co-N bond in coenzyme $B_{12}(2.24 \AA) .{ }^{7}, 14$ The increased length in the axial Co-N bond in the coenzyme is believed to come from the cobaloxime having a slightly greater positive charge on the cobalt center than in the coenzyme.

The axial Co-Sn bond for the $\mathrm{Sn}(\mathrm{p} \text {-tolyl) })_{3}$ is 2.5746(6) $\AA$. It is slightly longer than the axial Co-Sn bond from $\mathrm{Co}^{\mathrm{III}}(\mathrm{OEP}) \mathrm{SnPh}_{3}(2.510 \AA)$, and is much longer than the axial Co-C bonds from coenzyme $\mathrm{B}_{12}(2.03 \AA)$, vitamin $\mathrm{B}_{12}(1.92 \AA)$, and alkyl cobaloxime (2.04 $\left.\AA\right)$. large bond distance for $\mathrm{Co}-\mathrm{Sn}$ in $(4-t-\mathrm{BuPy}) \mathrm{Co}(\mathrm{DH})_{2} \mathrm{Sn}\left(\mathrm{C}_{6} \mathrm{H}_{4}-p \text {-tolyl }\right)_{3}$ likely arises from the trans effect of the pyridine. ${ }^{32}$ 
Table 2. Crystal data for (4-t-BuPy)Co(DH $)_{2} \mathrm{Sn}\left(\mathrm{C}_{6} \mathrm{H}_{4}-p \text {-tolyl }\right)_{3}$

\begin{tabular}{lll} 
Chemical formula & $\mathrm{C}_{38} \mathrm{H}_{48} \mathrm{CoN}_{5} \mathrm{O}_{4} \mathrm{Sn}$ & \\
Formula weight & 816.43 & \\
Temperature & $296(2) \mathrm{K}$ & \\
Wavelength & $0.71073 \AA$ & \\
Crystal size & $0.112 \times 0.156 \times 0.408 \mathrm{~mm}$ \\
Crystal system & triclinic & \\
Space group & $\mathrm{P}-1(\mathrm{No} .2)$ & \\
Unit cell dimensions & $\mathrm{a}=13.2949(5) \AA$ & $\alpha=107.1983(13)^{\circ}$ \\
& $\mathrm{b}=17.7508(7) \AA$ & $\beta=91.6597(13)^{\circ}$ \\
& $\mathrm{c}=18.2240(7) \AA$ & $\gamma=107.6992(12)^{\circ}$ \\
Volume & $3880.5(3) \AA^{3}$ & \\
Z & 4 & \\
Density (calculated) & $1.397 \mathrm{~g} / \mathrm{cm}^{3}$ & \\
Absorption coefficient & $1.115 \mathrm{~mm}^{-1}$ & \\
F(000) & 1680 & \\
\hline
\end{tabular}

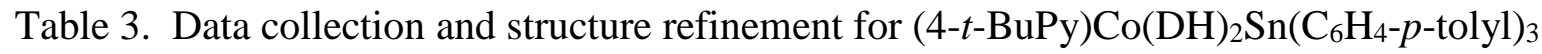

\begin{tabular}{|c|c|c|}
\hline Theta range for data collection & \multicolumn{2}{|l|}{2.75 to $27.50^{\circ}$} \\
\hline Index ranges & \multicolumn{2}{|c|}{$-17 \leq \mathrm{h} \leq 16,-23 \leq \mathrm{k} \leq 23,-23 \leq 1 \leq 23$} \\
\hline Reflections collected & \multicolumn{2}{|c|}{97231} \\
\hline Independent reflections & \multicolumn{2}{|c|}{$17647[\mathrm{R}$ (int) $=0.0576]$} \\
\hline $\begin{array}{l}\text { Coverage of independent } \\
\text { reflections }\end{array}$ & \multicolumn{2}{|l|}{$99.0 \%$} \\
\hline Absorption correction & \multicolumn{2}{|l|}{ multi-scan } \\
\hline Max. and min. transmission & \multicolumn{2}{|l|}{0.885 and 0.659} \\
\hline Refinement method & \multicolumn{2}{|c|}{ Full-matrix least-squares on $\mathrm{F}^{2}$} \\
\hline Refinement program & \multicolumn{2}{|c|}{ SHELXL-2013 (Sheldrick, 2013) } \\
\hline Data / restraints / parameters & \multicolumn{2}{|l|}{17647 / 6 / 950} \\
\hline Goodness-of-fit on $\mathrm{F}^{2}$ & \multicolumn{2}{|l|}{1.103} \\
\hline \multirow[t]{2}{*}{ Final $\mathrm{R}$ indices } & 11275 data; $\mathrm{I}>2 \sigma(\mathrm{I})$ & $\mathrm{R} 1=0.0647, \mathrm{wR} 2=0.0880$ \\
\hline & all data & $\mathrm{R} 1=0.1061, \mathrm{wR} 2=0.0956$ \\
\hline Largest diff. peak and hole & \multicolumn{2}{|l|}{1.054 and $-0.657 \mathrm{e}^{-} / \AA^{3}$} \\
\hline
\end{tabular}


Table 4: Selected interatomic distances $(\AA)$ and bond angles $\left(^{\circ}\right)$ for $(4-t-\mathrm{BuPy}) \mathrm{Co}(\mathrm{DH})_{2} \mathrm{Sn}\left(\mathrm{C}_{6} \mathrm{H}_{4-}\right.$ -tolyl $)_{3}$

\begin{tabular}{|c|c|c|c|}
\hline \multicolumn{4}{|c|}{ Selected Interatomic Distances } \\
\hline Sn1-C25 & $2.153(4)$ & Sn1-C32 & $2.163(4)$ \\
\hline Sn1-C18 & $2.170(4)$ & Sn1-Co1 & $2.5746(6)$ \\
\hline Co1-N4 & $1.874(3)$ & Co1-N2 & $1.875(3)$ \\
\hline Co1-N3 & $1.875(3)$ & Co1-N1 & $1.880(3)$ \\
\hline Co1-N5 & $2.063(3)$ & & \\
\hline \multicolumn{4}{|c|}{ Selected Bond Angles } \\
\hline C25-Sn1-C32 & 105.99(17) & C25-Sn1-C18 & $106.08(17)$ \\
\hline C32-Sn1-C18 & 101.28(16) & C25-Sn1-Co1 & $112.52(11)$ \\
\hline C32-Sn1-Co1 & 119.39(12) & C18-Sn1-Co1 & $110.32(11)$ \\
\hline N4-Co1-N2 & $175.45(14)$ & N4-Co1-N3 & $81.44(15)$ \\
\hline N2-Co1-N3 & $99.20(15)$ & N4-Co1-N1 & $98.24(14)$ \\
\hline N2-Co1-N1 & $80.77(15)$ & N3-Co1-N1 & $175.54(14)$ \\
\hline N4-Co1-N5 & 92.56(13) & N2-Co1-N5 & 91.92(13) \\
\hline N3-Co1-N5 & 91.78(13) & N1-Co1-N5 & $92.68(13)$ \\
\hline N4-Co1-Sn1 & $89.28(10)$ & N2-Co1-Sn1 & $86.22(10)$ \\
\hline N3-Co1-Sn1 & $90.13(10)$ & N1-Co1-Sn1 & $85.42(10)$ \\
\hline N5-Co1-Sn1 & 177.52(9) & & \\
\hline
\end{tabular}

\subsubsection{Preliminary X-ray Analysis of $\left(\mathrm{NH}_{3}\right) \mathrm{Co}(\mathrm{DH})_{2} \mathrm{SnPh}_{3}$}

The crystal structure was also obtained for the cobaloxime with ammonia as a labile base, $\mathrm{NH}_{3} \mathrm{Co}(\mathrm{DH})_{2} \mathrm{SnPh}_{3}$. This compound was synthesized in an effort to obtain a five coordinate cobaloxime through the dissociation of the ammonia. The goal of this synthesis was to develop a cobaloxime with the same coordination environment as the organotin porphyrin complexes to see if this change in the structure of the cobaloxime would result in clean cleavage of the Co-Sn bond by oxidation with halogen. This compound was synthesized by a one-step cobaloxime 
procedure described in the experimental, but efforts to obtain the five coordinate cobaloxime by heating to $60-70{ }^{\circ} \mathrm{C}$ to drive off the $\mathrm{NH}_{3}$ have been unsuccessful.

The quality of the crystal structure analysis of this complex, although limited, was sufficient to verify the atom connectivity of this ammonia adduct. The cobalt complex, as depicted in Figure 5, is six coordinate with the octahedral coordination sphere containing ammonia, tin and four donor nitrogens from the two dimethylglyoxime ligands. The ammonia and tin are located in the axial positions with the four donor nitrogens of the dimethylglyoxime ligands in the equatorial plane. The analysis showed that the lattice contained a disordered solvent. The bridging hydrogens that connect the two dimethylglyoxime ligands through O-H-O hydrogen bonds were unable to be resolved in this structure. The crystal structure is not resolved well enough for publication, but is sufficient to demonstrate the connectivity of the $\mathrm{NH}_{3} \mathrm{Co}(\mathrm{DH})_{2} \mathrm{SnPh}_{3}$.

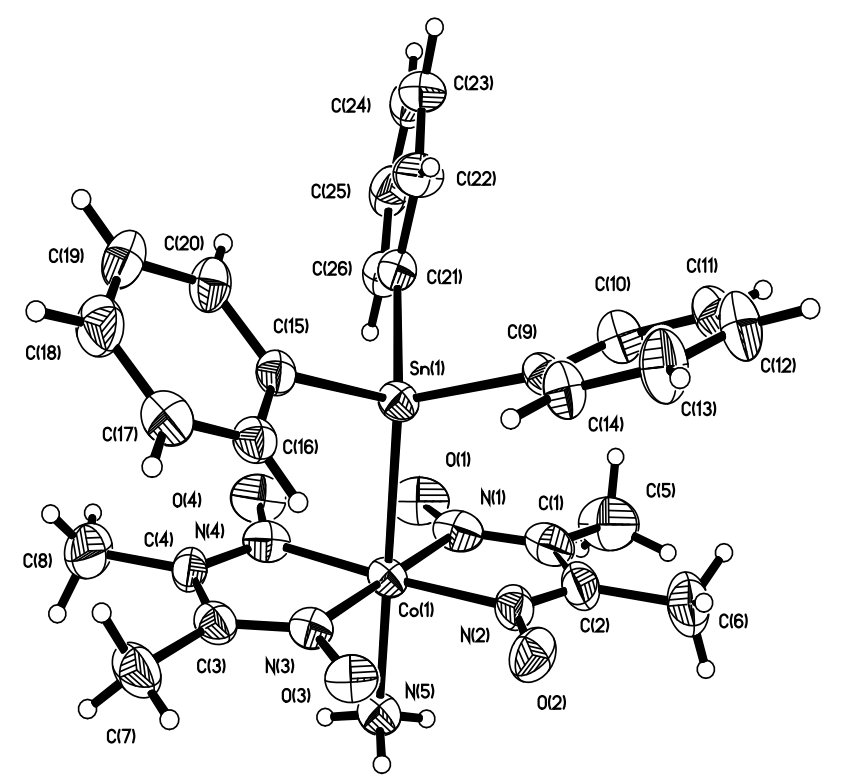

Figure 5: ORTEP drawing of $\left(\mathrm{NH}_{3}\right) \mathrm{Co}(\mathrm{DH})_{2} \mathrm{SnPh}_{3}$. Perspective view of the molecular structure of $\left(\mathrm{NH}_{3}\right) \mathrm{Co}(\mathrm{DH})_{2} \mathrm{SnPh}_{3}$, where $\mathrm{DH}=$ $\mathrm{ONC}(\mathrm{Me})=\mathrm{C}(\mathrm{Me}) \mathrm{NOH}$, with the atom labeling scheme for the nonhydrogen atoms. The thermal ellipsoids are scaled to enclose 30\% 


\subsection{Halogen Cleavage Titrations}

This section discusses the halogen cleavage reactions of the synthesized cobaloximes. The $\mathrm{Co}(\mathrm{OEP}) \mathrm{SnPh}_{3}$ cleaves the Co-Sn bond cleanly upon addition of halogen, as seen in Scheme $3 .^{26}$ The (4-t-BuPy)Co(DH) $)_{2} \mathrm{SnPh}_{3}$ was seen to form multiple products upon the addition of halogen and did not cleave the Co-Sn bond cleanly. Instead, the cleavage of the Sn-C bond of the phenyl ring through electrophilic aromatic substitution was observed, as seen in Scheme 3. The purpose of this project is to develop a system for the cobaloxime, through tuning its environment, that will allow it to exhibit clean homolytic Co-Sn bond cleavage. If this is achieved, the system may help us to understand the differences in reactivity of the porphyrins and cobaloximes. The hypothesis of this project was that substitution on the para position of the phenyl rings attached to the tin could change the donor strength and may promote Co-Sn bond cleavage. The para substituted cobaloximes were successfully synthesized and the halogen cleavage reactions discussed in this section will test this hypothesis.

The following halogen cleavage reactions have been performed to date: $(\mathrm{Py}) \mathrm{Co}(\mathrm{DH})_{2} \mathrm{SnPh}_{3}$, (4-t-BuPy)Co(DH $)_{2} \mathrm{SnPh}_{3},\left(\mathrm{NH}_{3}\right) \mathrm{Co}(\mathrm{DH})_{2} \mathrm{SnPh}_{3},(4-\mathrm{CNPy}) \mathrm{Co}(\mathrm{DH})_{2} \mathrm{SnPh}_{3}$, (4-tBuPy) $\mathrm{Co}(\mathrm{DH})_{2} \mathrm{Sn}\left(\mathrm{C}_{6} \mathrm{H}_{4}-p \text {-tolyl }\right)_{3}$, and (4-t-BuPy)Co(DH $)_{2} \mathrm{Sn}\left(\mathrm{C}_{6} \mathrm{H}_{4}-p-t-\mathrm{Bu}\right)_{3}$. A former group member also ran a halogen cleavage titration with $(4-t-\mathrm{BuPy}) \mathrm{Co}(\mathrm{DH})_{2} \mathrm{Sn}(n-\mathrm{Bu})_{3}$. The halogen cleavage titrations were performed on the NMR scale using $\mathrm{I}_{2}$ or $\mathrm{Br}_{2}$ and measuring the ${ }^{1} \mathrm{H} \mathrm{NMR}$ spectra for every determined amount of equivalents. The (4-t-BuPy)Co(DH $)_{2} \mathrm{Sn}(n-\mathrm{Bu})_{3}$ did exhibit clean cleavage of the Sn-Co bond, but may not provide enough information about the differences in the porphyrin and cobaloxime system since it is an alkyl tin ligand and not an aryltin ligand attached to the cobalt center. The alkyl tin does not translate well to the lead analogue due to toxicity issues, so comparison across group 14 elements is better served by the 
aryl tin ligand cobaloximes. All of the triaryltin cobaloximes exhibited cleavage of the Sn-C bond instead of clean cleavage of the Co-Sn bond. Although all of these cobaloximes showed multiple products developing in the NMR as the halogen was added, the halogen titration of (4-t$\mathrm{BuPy}) \mathrm{Co}(\mathrm{DH})_{2} \mathrm{Sn}\left(\mathrm{C}_{6} \mathrm{H}_{4}-p-t-\mathrm{Bu}\right)_{3}$ had less overlap due to the $\mathrm{p}-t-\mathrm{Bu}$ group. To provide an example of the nature of the halogen cleavage reactions for the cobaloxime tin complexes, the experimental results are described for the bromine titration and the corresponding ${ }^{1} \mathrm{H}$ NMR spectra at room temperature for (4-t-BuPy) $\mathrm{Co}(\mathrm{DH})_{2} \mathrm{Sn}\left(\mathrm{C}_{6} \mathrm{H}_{4}-p-t-\mathrm{Bu}\right)_{3}$ are displayed in Figures 615. 


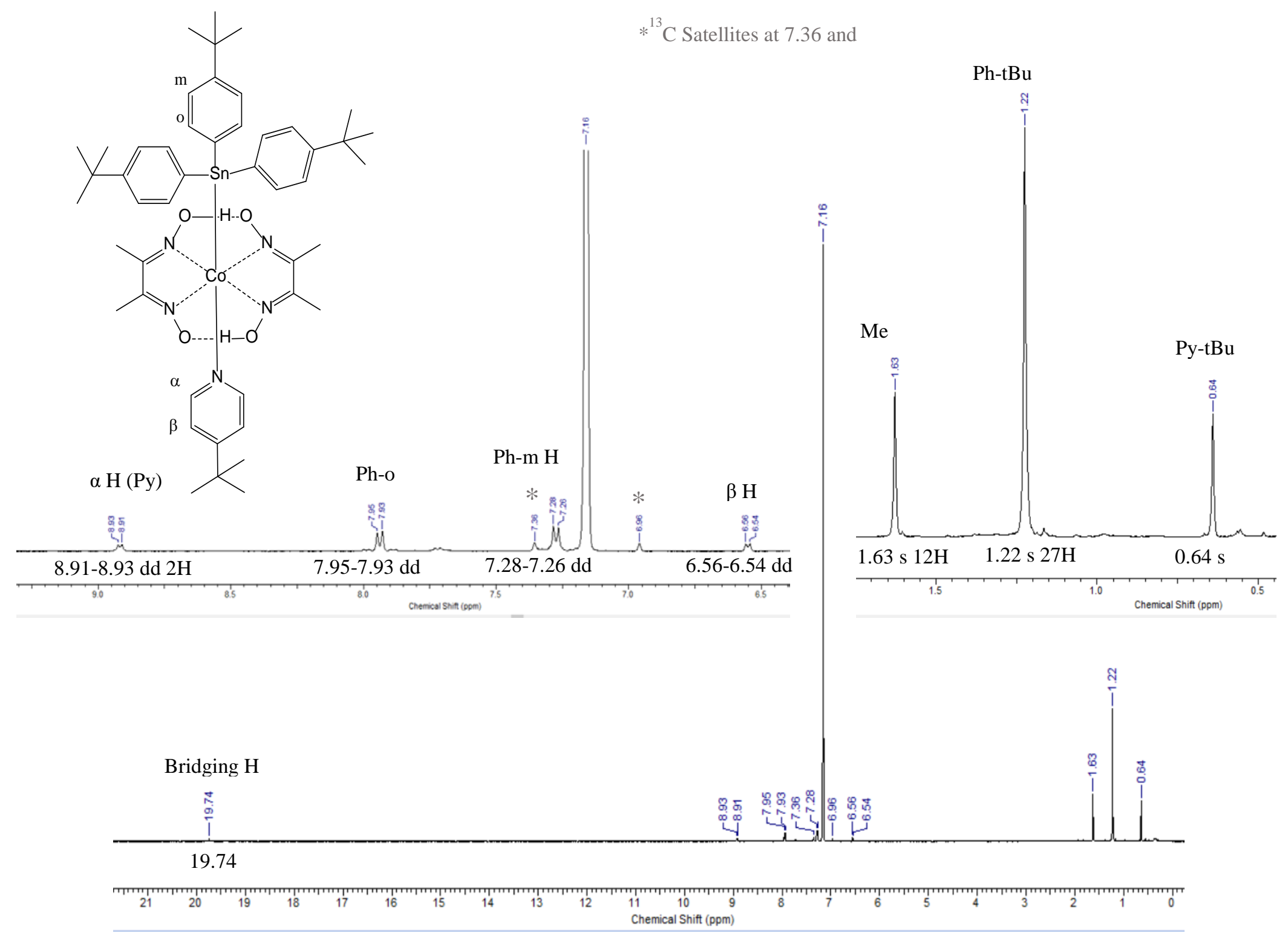

Figure 6: Initial ${ }^{1} \mathrm{H}$ NMR bromine cleavage of (4-t-BuPy)Co(DH $)_{2} \mathrm{Sn}\left(\mathrm{C}_{6} \mathrm{H}_{4}-p-t-\mathrm{Bu}\right)_{3}$ in $\mathrm{C}_{6} \mathrm{D}_{6}$ 

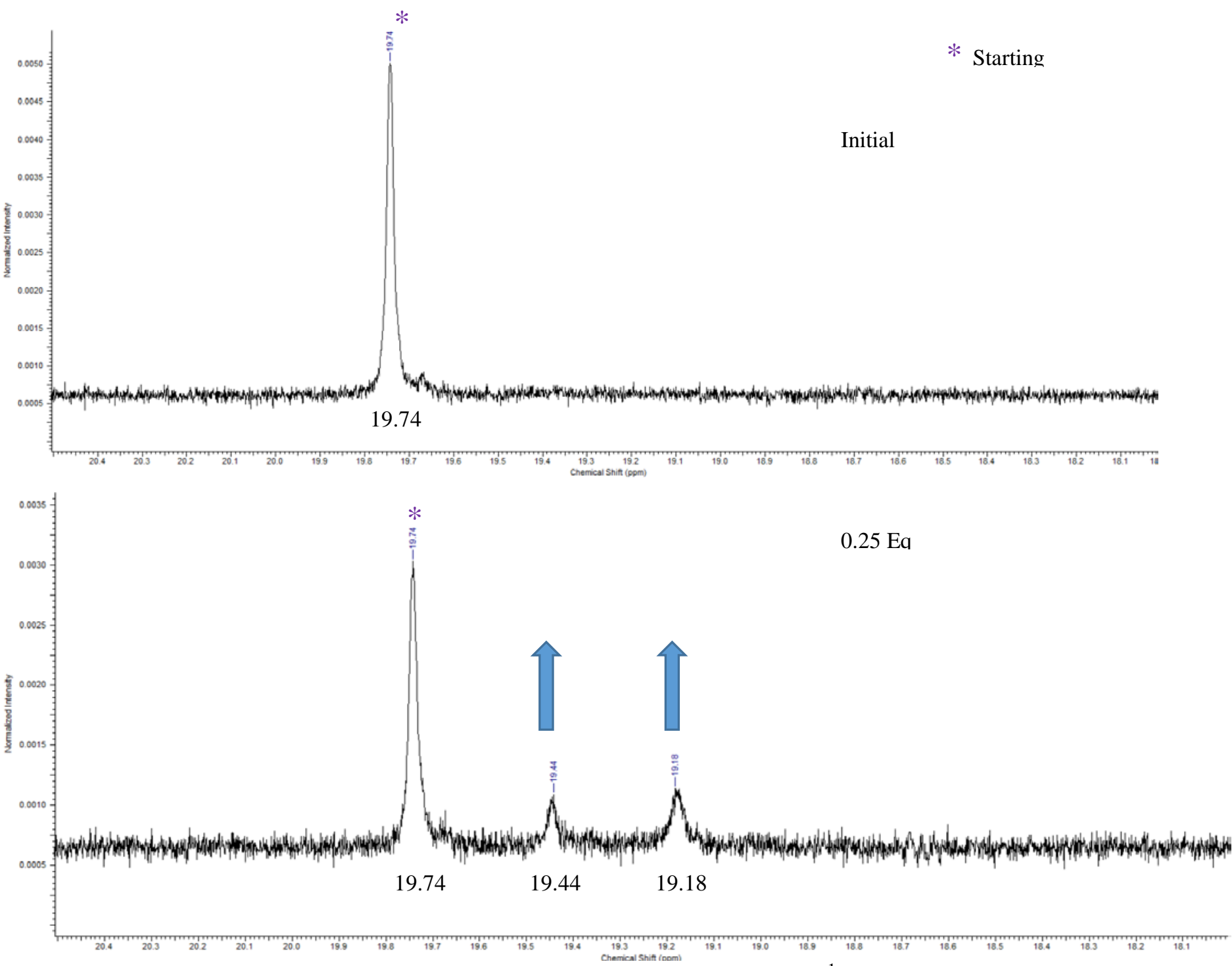

Figure 7: Bromine Cleavage of (4-t-BuPy)Co(DH $)_{2} \mathrm{Sn}\left(\mathrm{C}_{6} \mathrm{H}_{4}-p-t-\mathrm{Bu}\right)_{3}{ }^{1} \mathrm{H}$ NMR in $\mathrm{C}_{6} \mathrm{D}_{6}$. The O$\mathrm{H} \cdots \mathrm{O}$ bridging region for 0 and 0.25 equivalents of $\mathrm{Br}_{2}$. 

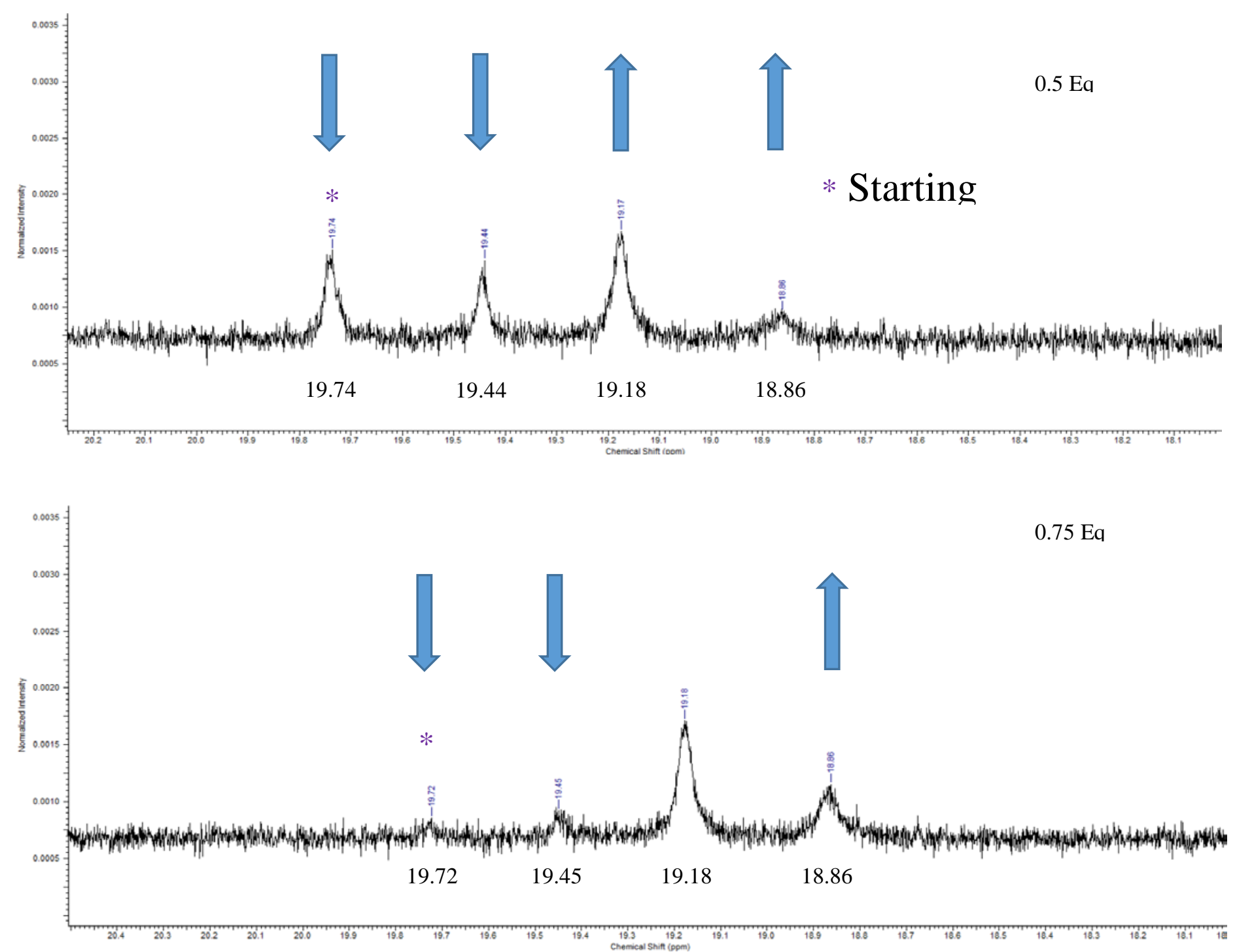

Figure 8: Bromine Cleavage of (4-t-BuPy) $\mathrm{Co}(\mathrm{DH})_{2} \mathrm{Sn}\left(\mathrm{C}_{6} \mathrm{H}_{4}-p-t-\mathrm{Bu}\right)_{3}{ }^{1} \mathrm{H}$ NMR in $\mathrm{C}_{6} \mathrm{D}_{6}$. The $\mathrm{O}-\mathrm{H} \cdots \mathrm{O}$ bridging region for 0.5 and 0.75 equivalents of $\mathrm{Br}_{2}$. 


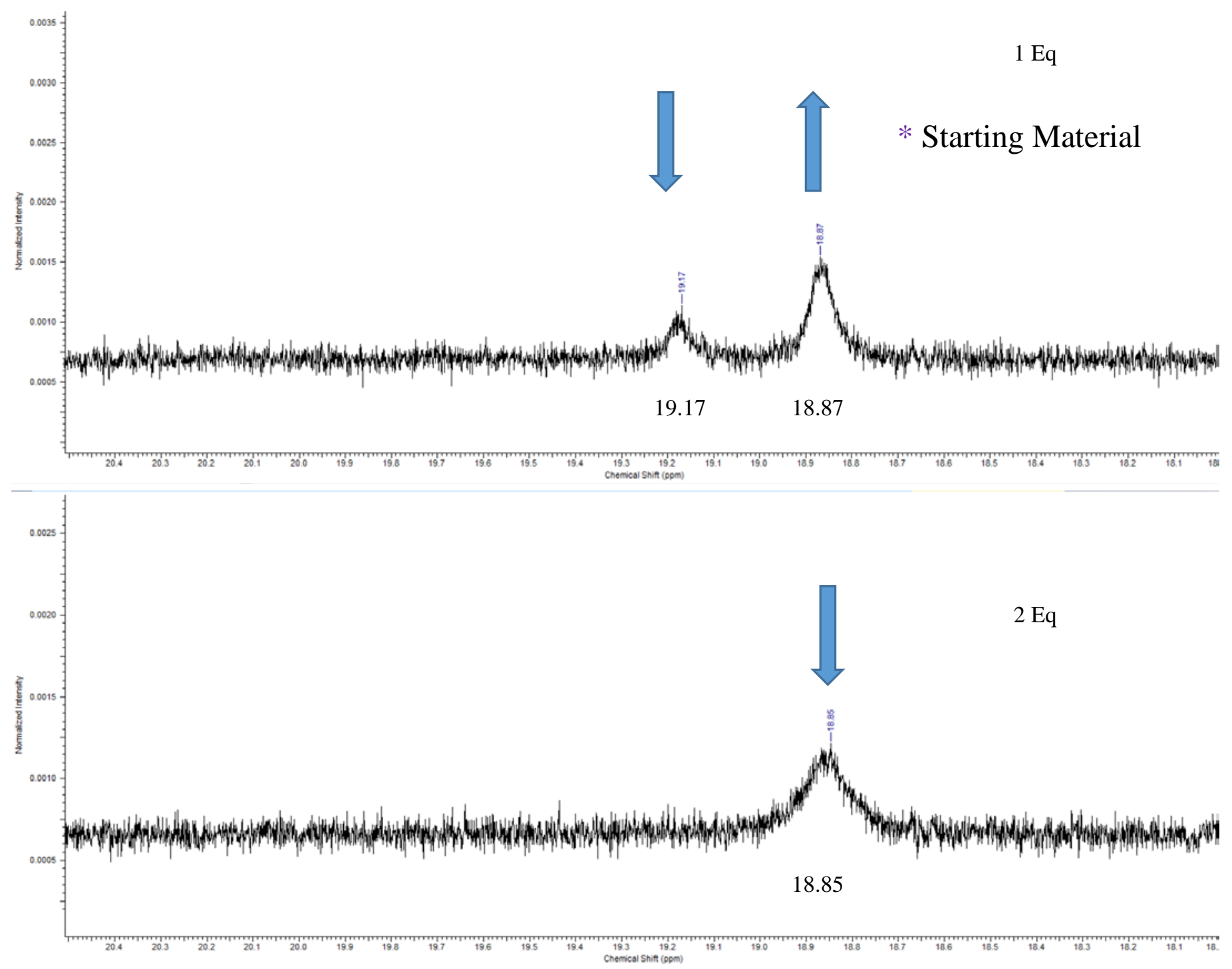

Figure 9: Bromine Cleavage of (4-t-BuPy)Co(DH) $)_{2} \mathrm{Sn}\left(\mathrm{C}_{6} \mathrm{H}_{4}-p-t-\mathrm{Bu}\right)_{3}{ }^{1} \mathrm{H}$ NMR in $\mathrm{C}_{6} \mathrm{D}_{6}$. The $\mathrm{O}-\mathrm{H} \cdots \mathrm{O}$ bridging region for 1 and 2 equivalents of $\mathrm{Br}_{2}$. 


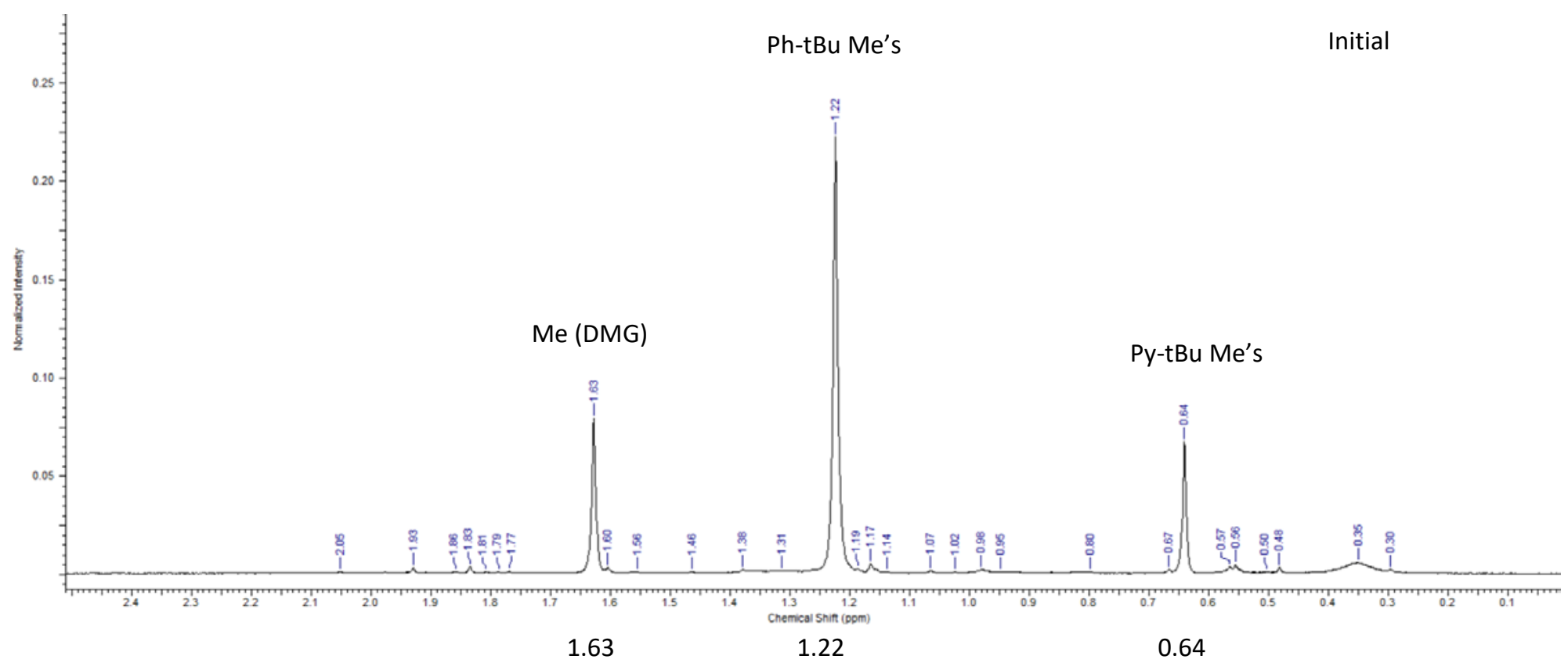

Figure 10: Bromine Cleavage of (4-t-BuPy)Co(DH) $)_{2} \mathrm{Sn}\left(\mathrm{C}_{6} \mathrm{H}_{4}-p-t-\mathrm{Bu}\right)_{3}{ }^{1} \mathrm{H}$ NMR in $\mathrm{C}_{6} \mathrm{D}_{6}$. The alkyl region 0 eq $\mathrm{Br}_{2}$. 


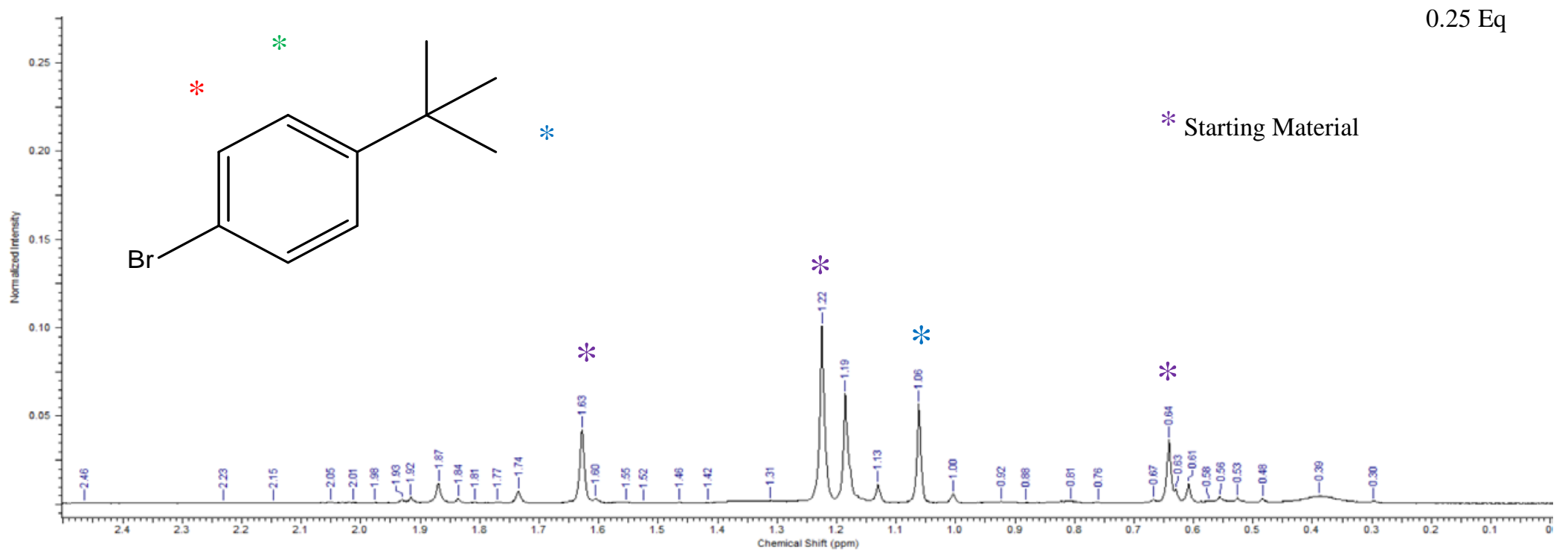

Figure 11: Bromine Cleavage of (4-t-BuPy)Co(DH) $)_{2} \mathrm{Sn}\left(\mathrm{C}_{6} \mathrm{H}_{4}-p-t-\mathrm{Bu}\right)_{3}{ }^{1} \mathrm{H}$ NMR in $\mathrm{C}_{6} \mathrm{D}_{6}$. The alkyl region 0.25 eq $\mathrm{Br}_{2}$. 


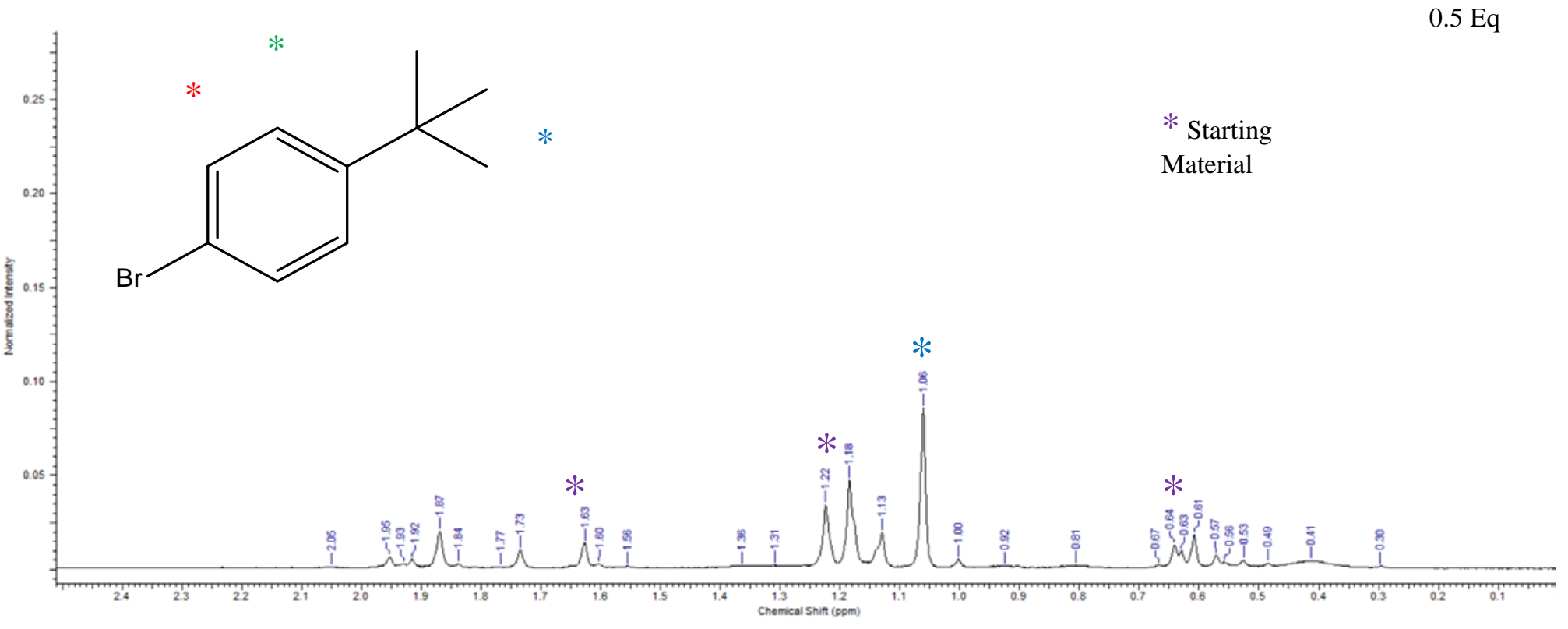

Figure 12: Bromine Cleavage of (4-t-BuPy) $\mathrm{Co}(\mathrm{DH})_{2} \mathrm{Sn}\left(\mathrm{C}_{6} \mathrm{H}_{4}-p-t-\mathrm{Bu}\right)_{3}{ }^{1} \mathrm{H}$ NMR in $\mathrm{C}_{6} \mathrm{D}_{6}$. The alkyl region 0.5 eq $\mathrm{Br}_{2}$. 


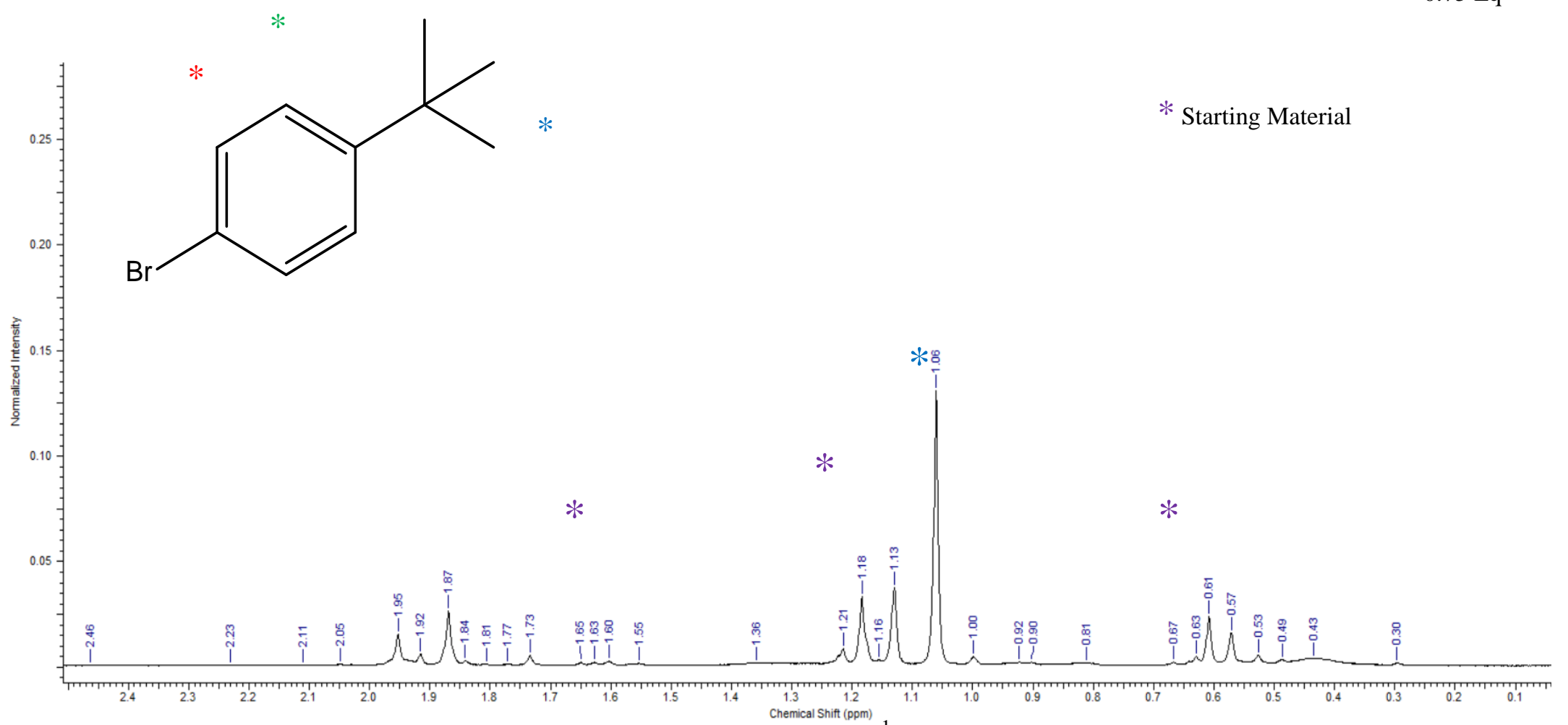

Figure 13: Bromine Cleavage of (4-t-BuPy)Co(DH $)_{2} \mathrm{Sn}\left(\mathrm{C}_{6} \mathrm{H}_{4}-p-t-\mathrm{Bu}\right)_{3}{ }^{1} \mathrm{H}$ NMR in $\mathrm{C}_{6} \mathrm{D}_{6}$. The alkyl region 0.75 eq $\mathrm{Br}_{2}$. 


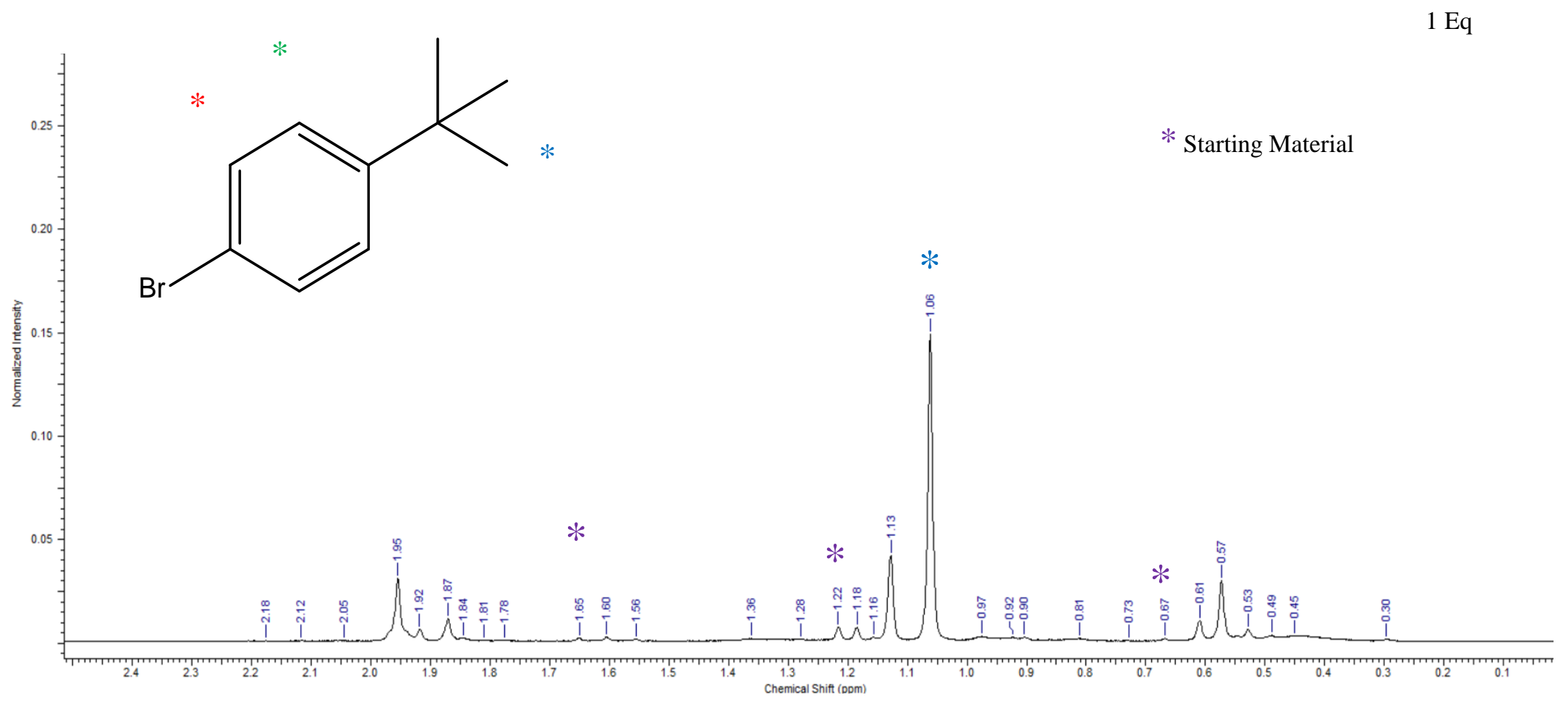

Figure 14: Bromine Cleavage of (4-t-BuPy)Co(DH) $)_{2} \mathrm{Sn}\left(\mathrm{C}_{6} \mathrm{H}_{4}-p-t-\mathrm{Bu}\right)_{3}{ }^{1} \mathrm{H}$ NMR in $\mathrm{C}_{6} \mathrm{D}_{6}$. The alkyl region 1 eq $\mathrm{Br}_{2}$. 


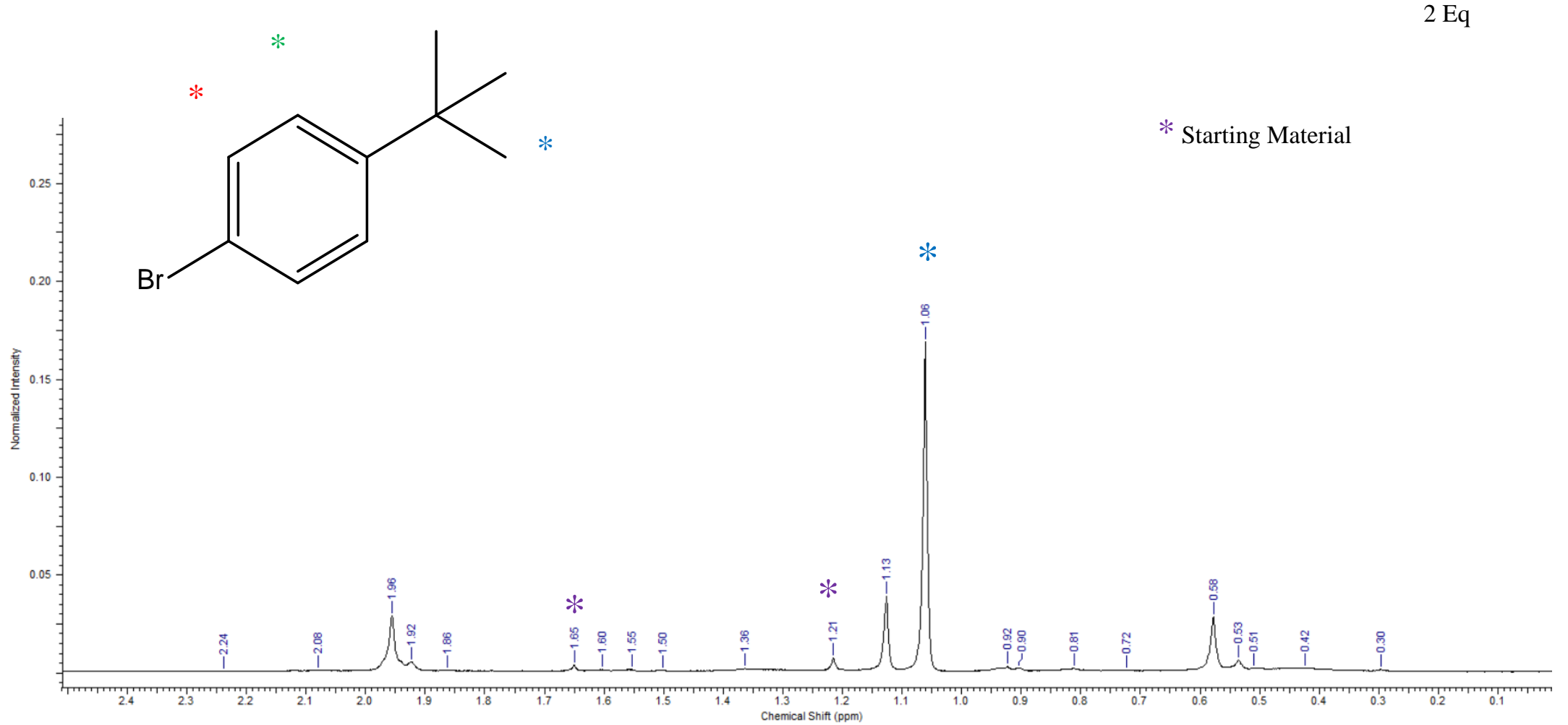

Figure 15: Bromine Cleavage of (4-t-BuPy)Co(DH $)_{2} \mathrm{Sn}\left(\mathrm{C}_{6} \mathrm{H}_{4}-p-t-\mathrm{Bu}\right)_{3}{ }^{1} \mathrm{H}$ NMR in $\mathrm{C}_{6} \mathrm{D}_{6}$. The alkyl region 2 eq $\mathrm{Br}_{2}$. 


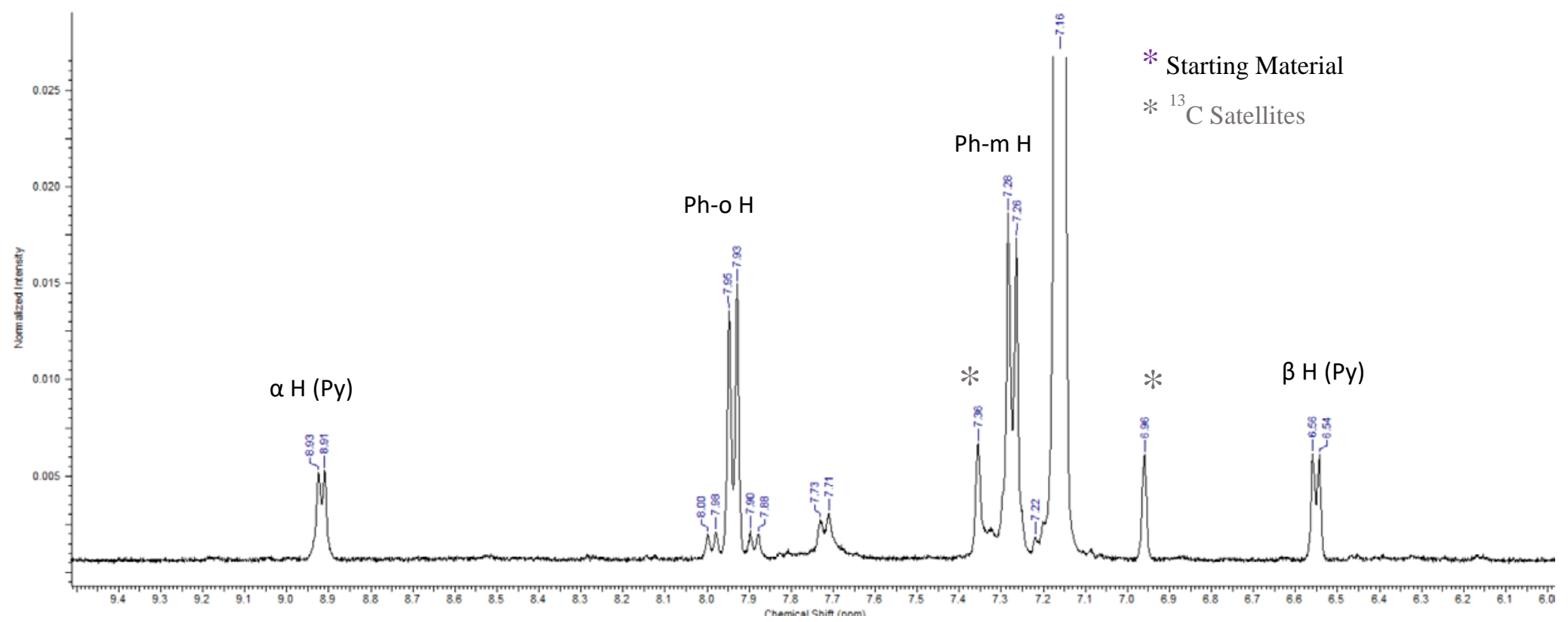

Figure 16: Bromine Cleavage of $(4-t-\mathrm{BuPy}) \mathrm{Co}(\mathrm{DH})_{2} \mathrm{Sn}\left(\mathrm{C}_{6} \mathrm{H}_{4}-p-t-\mathrm{Bu}\right)_{3}{ }^{1} \mathrm{H}$ NMR in $\mathrm{C}_{6} \mathrm{D}_{6}$. The aromatic region for 0 equivalents of $\mathrm{Br}_{2}$. 


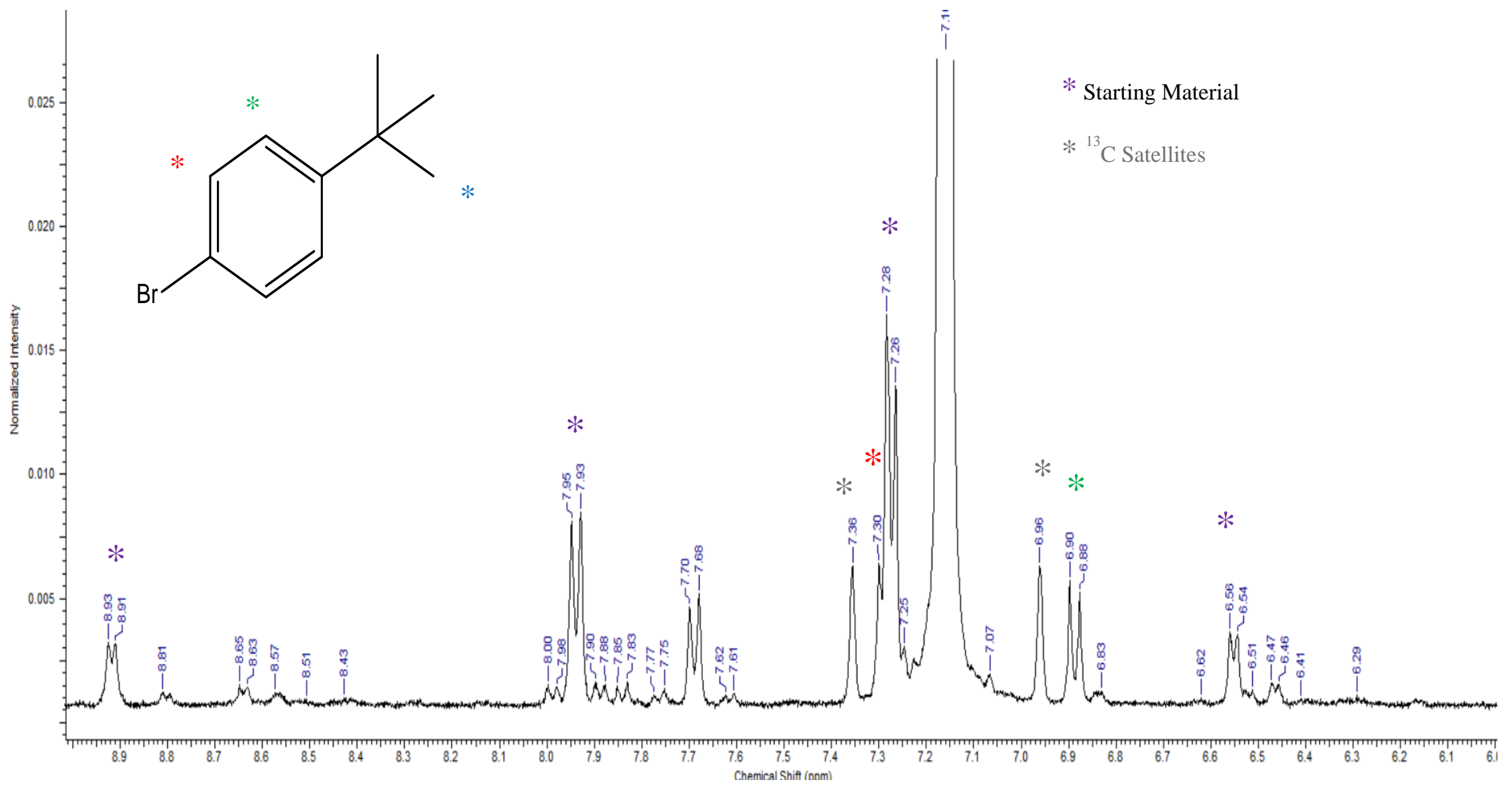

Figure 17: Bromine Cleavage of (4-t-BuPy)Co(DH) $)_{2} \mathrm{Sn}\left(\mathrm{C}_{6} \mathrm{H}_{4}-p-t-\mathrm{Bu}\right)_{3}{ }^{1} \mathrm{H}$ NMR in $\mathrm{C}_{6} \mathrm{D}_{6}$. The aromatic region for 0.25 equivalents of $\mathrm{Br}_{2}$. 


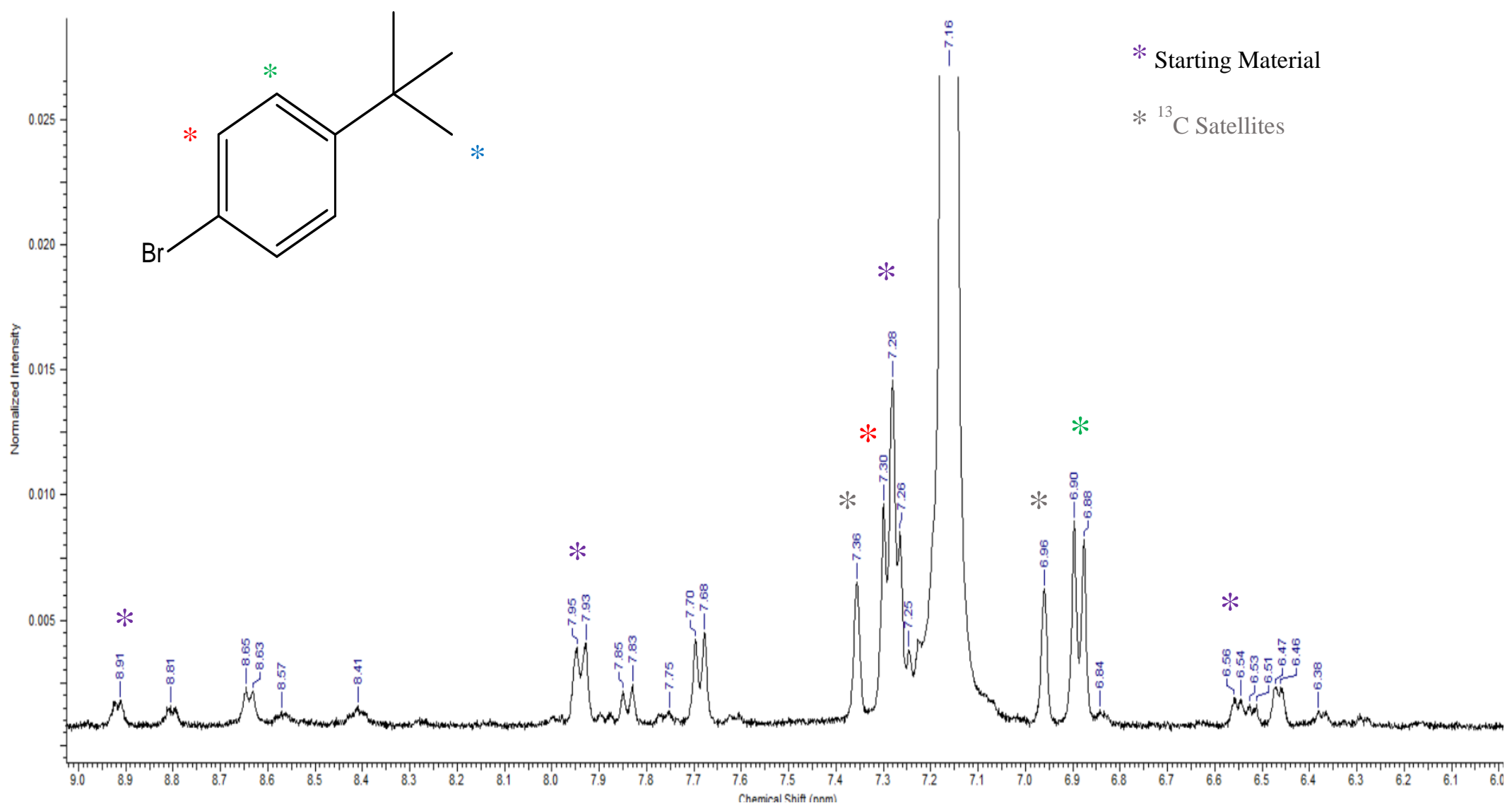

Figure 18: Bromine Cleavage of (4-t-BuPy) $\mathrm{Co}(\mathrm{DH})_{2} \mathrm{Sn}\left(\mathrm{C}_{6} \mathrm{H}_{4}-p-t-\mathrm{Bu}\right)_{3}{ }^{1} \mathrm{H}$ NMR in $\mathrm{C}_{6} \mathrm{D}_{6}$. The aromatic region for 0.5 equivalents of $\mathrm{Br}_{2}$. 


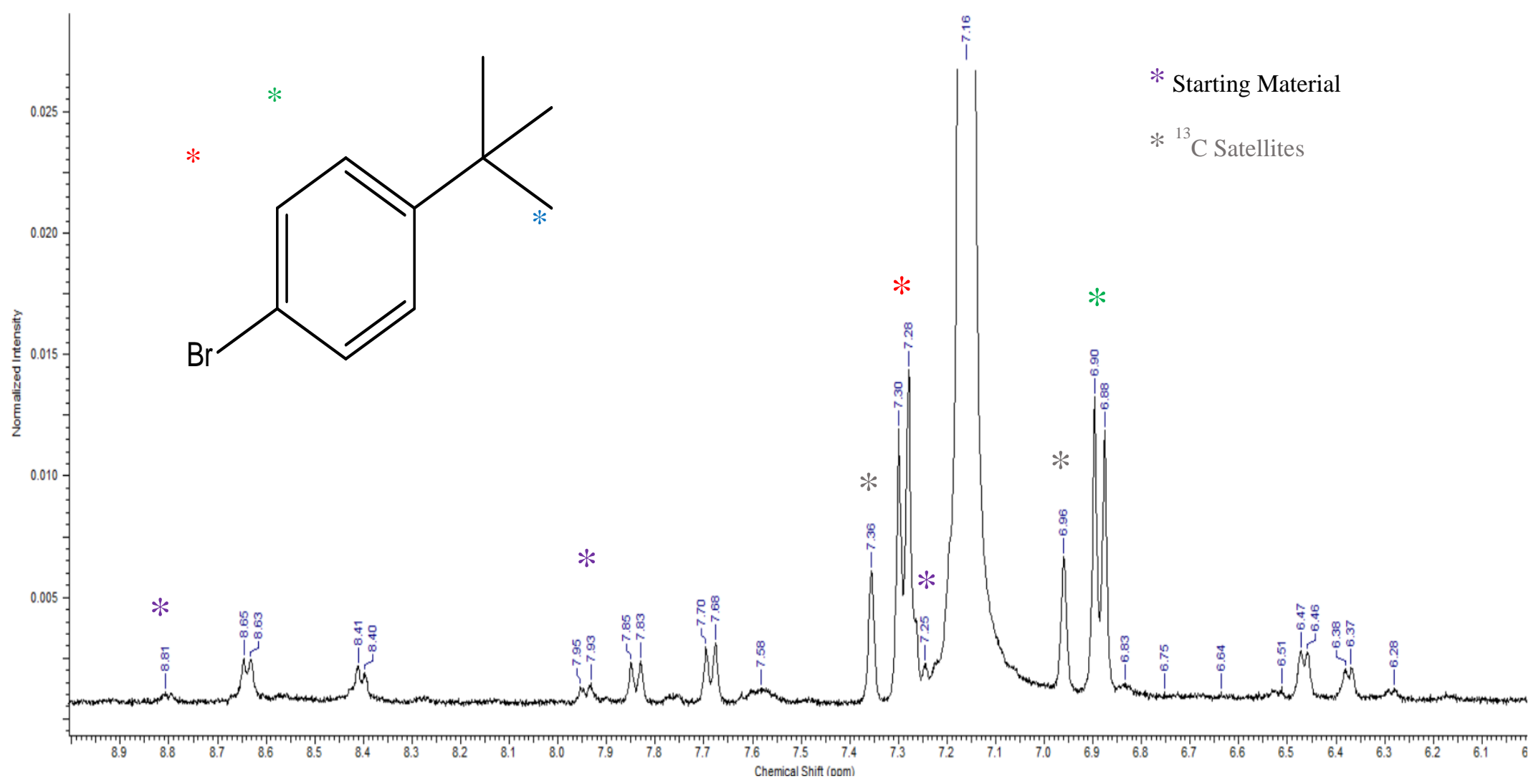

Figure 19: Bromine Cleavage of (4-t-BuPy)Co(DH $)_{2} \mathrm{Sn}\left(\mathrm{C}_{6} \mathrm{H}_{4}-p-t-\mathrm{Bu}\right)_{3}{ }^{1} \mathrm{H}$ NMR in $\mathrm{C}_{6} \mathrm{D}_{6}$. The aromatic region for 0.75 equivalents of $\mathrm{Br}_{2}$. 


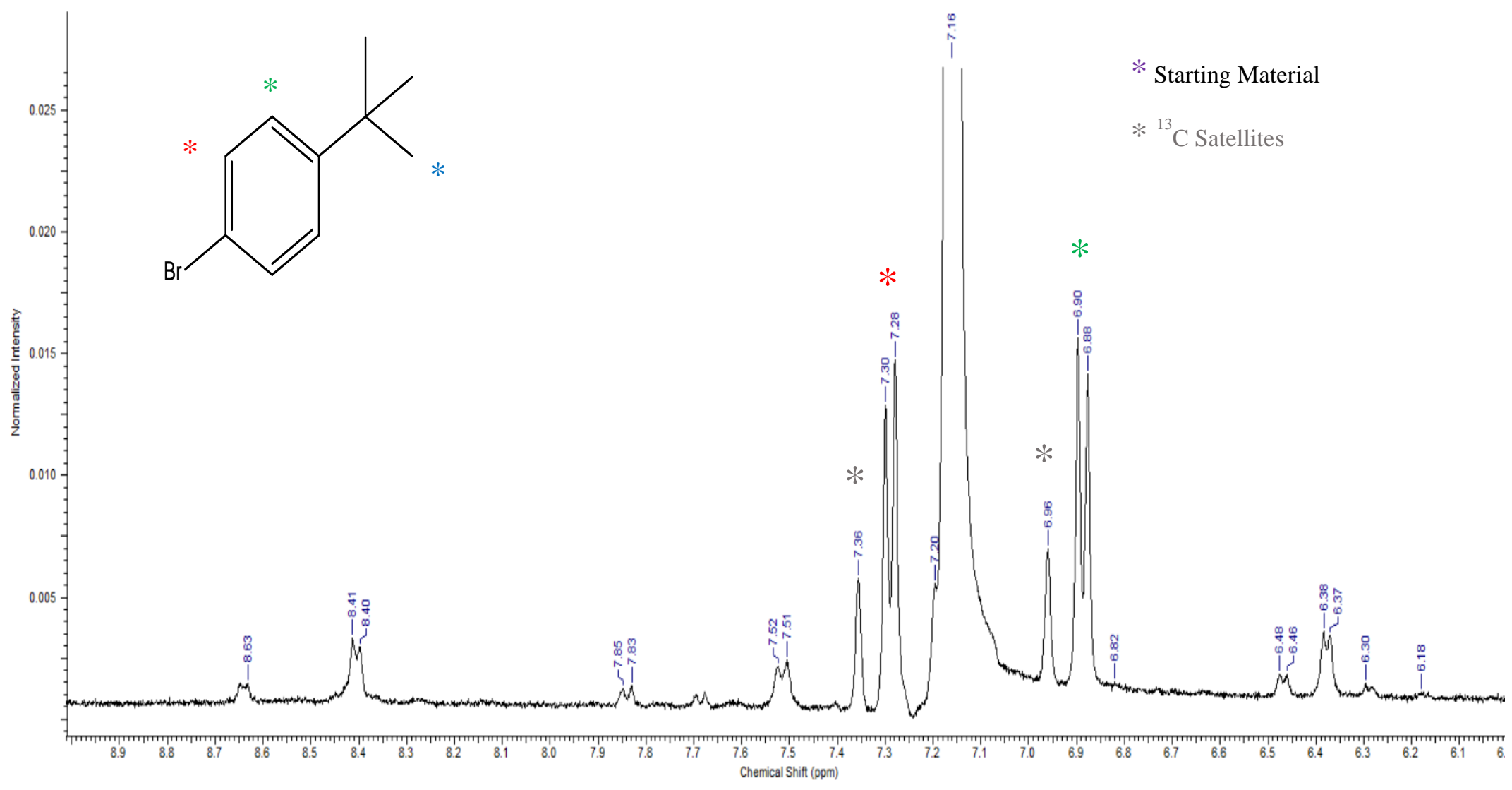

Figure 20: Bromine Cleavage of (4-t-BuPy)Co(DH $)_{2} \mathrm{Sn}\left(\mathrm{C}_{6} \mathrm{H}_{4}-p-t-\mathrm{Bu}\right)_{3}{ }^{1} \mathrm{H}$ NMR in $\mathrm{C}_{6} \mathrm{D}_{6}$. The aromatic region for 1 equivalent of $\mathrm{Br}_{2}$. 


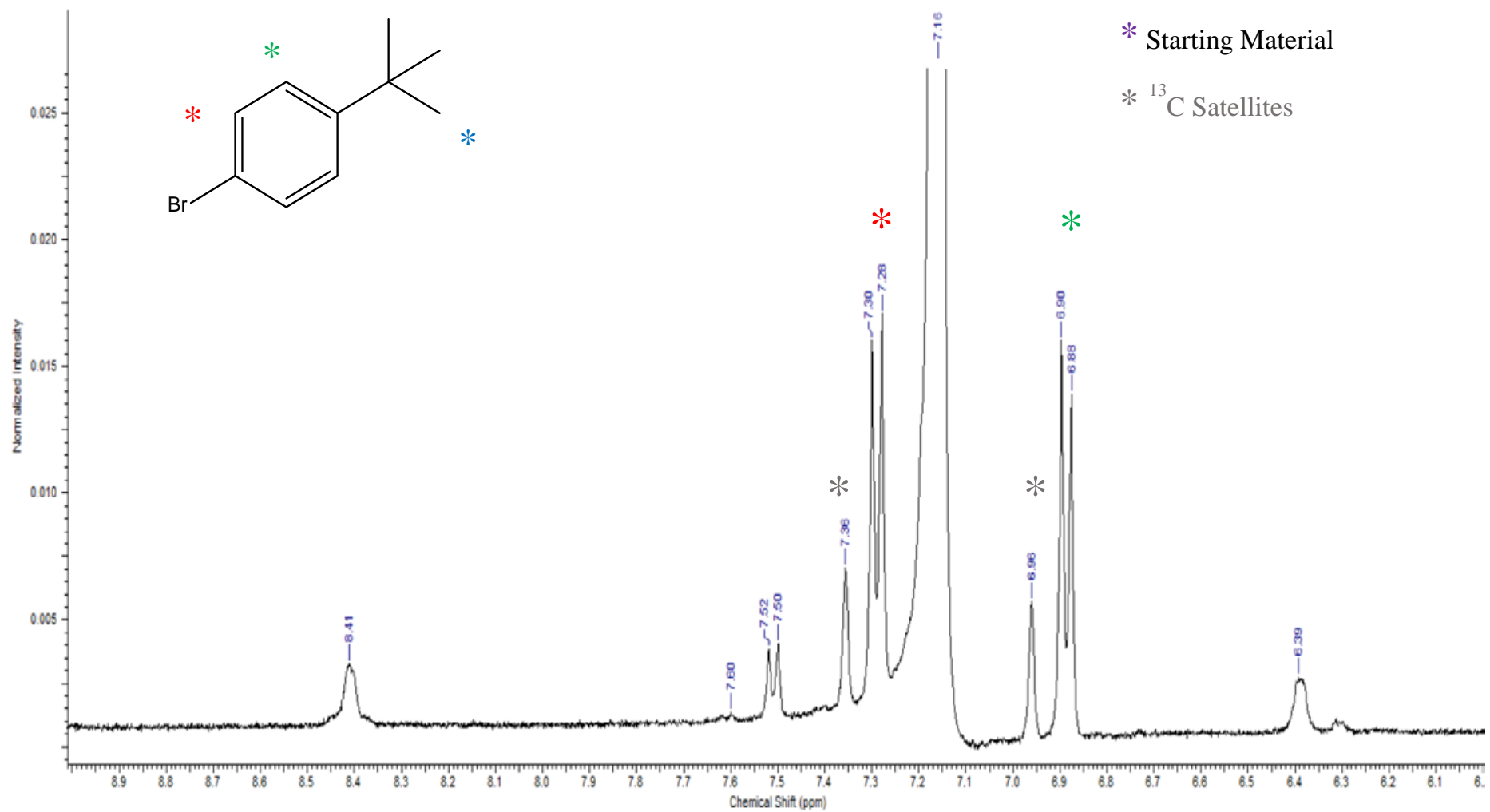

Figure 21: Bromine Cleavage of (4-t-BuPy)Co(DH $)_{2} \mathrm{Sn}\left(\mathrm{C}_{6} \mathrm{H}_{4}-p-t-\mathrm{Bu}\right)_{3}{ }^{1} \mathrm{H}$ NMR in $\mathrm{C}_{6} \mathrm{D}_{6}$. The aromatic region for 2 equivalents of $\mathrm{Br}_{2}$. 
The (4-t-BuPy)Co(DH $)_{2} \mathrm{Sn}\left(\mathrm{C}_{6} \mathrm{H}_{4}-p-t-\mathrm{Bu}\right)_{3}$ was dissolved in $\mathrm{C}_{6} \mathrm{D}_{6}$ and the concentration determined. Seven test tubes received $1 \mathrm{~mL}$ of the cobaloxime solution and bromine was added to the test tubes in order to obtain samples with $0,0.25,0.5,0.75,1$, and 2 eq. of bromine. An aliquot of $100 \mu \mathrm{L}$ was removed from each sample to prepare a GCMS sample in benzene. The remaining $900 \mu \mathrm{L}$ of solution went into an NMR tube and the proton spectra was obtained. The Figures 6-15 are broken into the different regions of the spectra for each equivalent of bromine. Figure 6 provides the overall structure (4-t-BuPy) $\mathrm{Co}(\mathrm{DH})_{2} \mathrm{Sn}\left(\mathrm{C}_{6} \mathrm{H}_{4}-p-t-\mathrm{Bu}\right)_{3}$ and the initial spectra for the compound. Figures $7-9$ cover the $\mathrm{O}-\mathrm{H} \cdots \mathrm{O}$ region around $19 \mathrm{ppm}$, Figures $10-$ 12 cover the alkyl region from $0-2.5$ ppm, and Figures $13-15$ cover the aromatic region from $6-9$ ppm.

Figure 6 displays the initial structure of $(4-t-\mathrm{BuPy}) \mathrm{Co}(\mathrm{DH})_{2} \mathrm{Sn}\left(\mathrm{C}_{6} \mathrm{H}_{4}-p-t-\mathrm{Bu}\right)_{3}$. This compound has very distinct peaks and is more resolved than some of the other cobaloximes that tend to have overlapping and crowding in the aromatic region. The compound has 8 distinct peaks corresponding to the 75 hydrogens in the structure. In the alkyl region, the three peaks correspond to the $t$-Bu group of the pyridine $(0.64 \mathrm{ppm}, \mathrm{s}, 9 \mathrm{H})$, the $t$-Bu groups on the phenyl rings attached to the tin $(1.22 \mathrm{ppm}, \mathrm{s}, 27 \mathrm{H})$, and the methyl groups on the DMG ligand (1.63 ppm, s, $12 \mathrm{H}$ ). In the aromatic region there are four peaks that correspond to the $\beta$ protons of the pyridine ring (6.56-6.54 ppm, dd, $2 \mathrm{H}$ ), the $m-\mathrm{H}$ of the phenyl rings (7.28-7.26 ppm, dd, $6 \mathrm{H}$ ), the $o-\mathrm{H}$ of the phenyl ring (7.95-7.93 ppm, dd, $6 \mathrm{H})$, and the $\alpha$ protons of the pyridine ring (8.93$8.91 \mathrm{ppm}, \mathrm{dd}, 2 \mathrm{H})$. The final region is the $\mathrm{O}-\mathrm{H} \cdots \mathrm{O}$ hydrogen bonds that appear at $19.74 \mathrm{ppm}$ as a broad singlet of $2 \mathrm{H}$. These NMR peaks, integrations and chemical shifts are consistent with the structure. There is also a strong solvent peak for $\mathrm{C}_{6} \mathrm{D}_{6}$ at $7.16 \mathrm{ppm}$ with ${ }^{13} \mathrm{C}$ satellites appearing at 7.36 and $6.96 \mathrm{ppm}$, but no other unexpected peaks are present. 

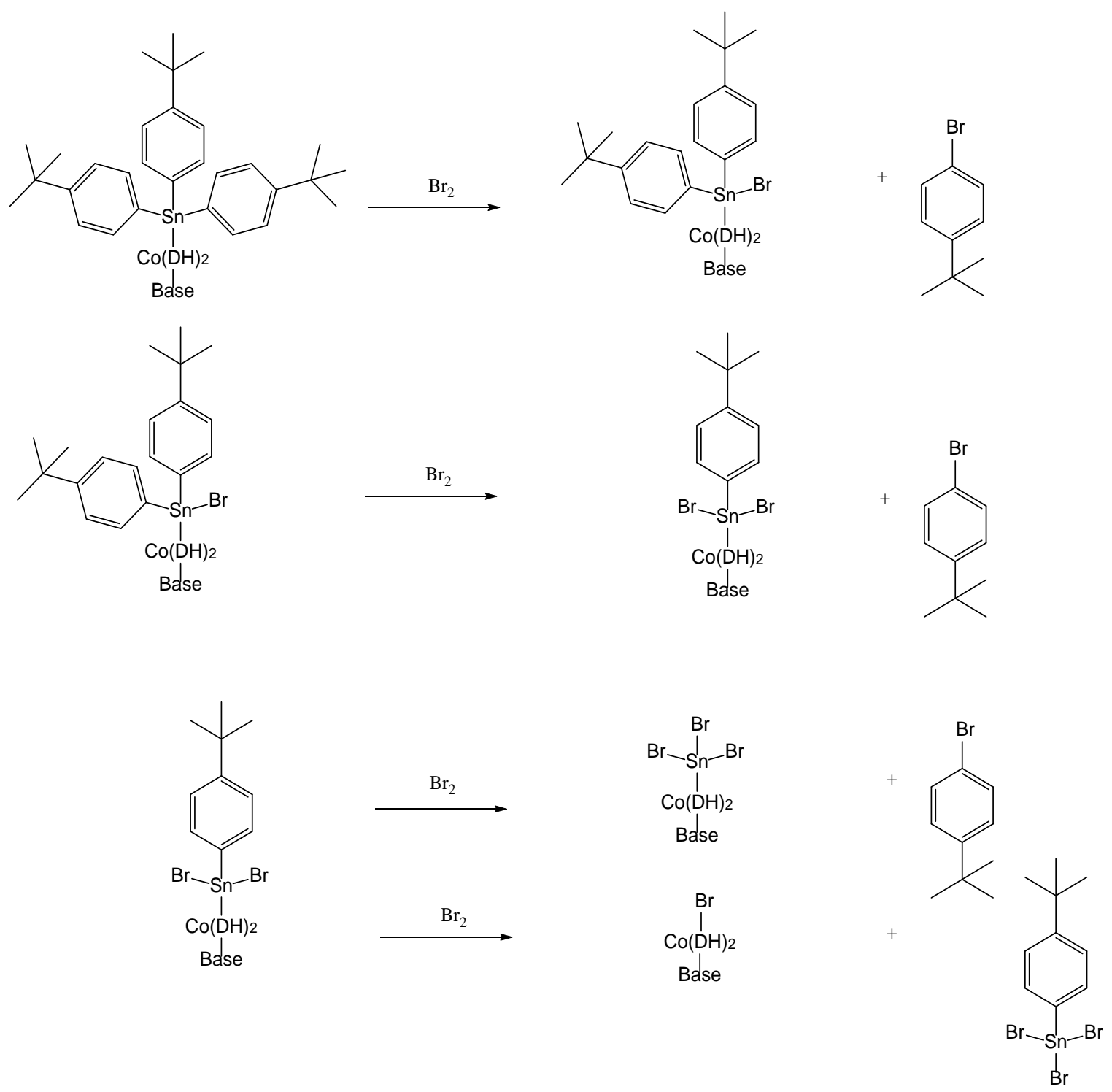

Scheme 13: Proposed Reaction of Halogen with Triaryltin Cobaloxime

Figures 7 through 9 contain the $\mathrm{O}-\mathrm{H} \cdots \mathrm{O}$ bonding region around $19.7 \mathrm{ppm}$ for $0,0.25,0.5$, $0.75,1$, and 2 equivalents of bromine. The initial peak for the bridging hydrogen is at $19.74 \mathrm{ppm}$. At 0.25 equivalents of bromine, two more bridging hydrogen peaks are present at 19.44 and $19.18 \mathrm{ppm}$. These new peaks correspond to a new cobaloxime being formed through cleavage of a C-Sn bond by the halogen. At 0.5 equivalents of bromine, the starting compound peak at 19.74 has decreased significantly and a new peak at $18.86 \mathrm{ppm}$ is present. At 0.75 equivalents of 
bromine, the 19.74 and $19.44 \mathrm{ppm}$ peaks have almost disappeared and the 19.18 and $18.86 \mathrm{ppm}$ peaks have increased. At 1 equivalent of bromine, the 19.74 and $19.44 \mathrm{ppm}$ peaks are completely gone and the 19.18 ppm peak has decreased in relation to the 18.86 ppm peak. At 2 equivalents of bromine, the only peak that remains is the $18.86 \mathrm{ppm}$ peak. The $19.74 \mathrm{ppm}$ corresponds to the initial cobaloxime and the new peaks 19.44, 19.18, and $18.86 \mathrm{ppm}$ correspond to the new cobaloxime products. Through GCMS studies it is determined that 1-bromo-4-t-butylbenzene is the main product formed upon addition of bromine and the concentration of the peak increases as the equivalents of bromine increase. This product would arise from the cleavage of the Sn-C bond by bromine as seen in Scheme 13 below. The peaks corresponding to 19.44, 19.18 and $18.86 \mathrm{ppm}$ arise from the Sn-C cleavage and production of $\mathrm{Ar}-\mathrm{Br}$ bonds.

Figures $10-15$ contain the ${ }^{1} \mathrm{H}$ NMR spectra for the alkyl region. The initial peaks are the $t$ Bu group of the pyridine ( $0.64 \mathrm{ppm}, \mathrm{s}, 9 \mathrm{H})$, the $t$-Bu groups on the phenyl rings attached to the tin (1.22 ppm, s, $36 \mathrm{H}$ ), and the methyl groups on the DMG ligand (1.63 ppm, s, $12 \mathrm{H}$ ). This region behaves similar to the bridging hydrogen region upon addition of bromine. The clearest example in this region is the $t$-butyl peak of the phenyl rings. The initial peak is at $1.22 \mathrm{ppm}$ and upon addition of 0.25 equivalents of bromine, three new peaks are observed $(1.19,1.13,1.06$ $\mathrm{ppm})$. For the $0.5,0.75$, and 1 equivalents of bromine spectra all four peaks are still visible, but the more downfield peaks have significantly decreased in intensity and the $1.06 \mathrm{ppm}$ peak is the most dominant. After 2 equivalents of bromine, the dominant peak is $1.06 \mathrm{ppm}$ and the initial peak of $1.22 \mathrm{ppm}$ and the $1.13 \mathrm{ppm}$ peaks are still observed, but the $1.18 \mathrm{ppm}$ peak has disappeared. The 1.06 ppm peak corresponds to the tert-butyl group of the 1-bromo-4-tbutylbenzene organic product that is formed from the Sn-C bond cleavage. This peak increases in intensity as the equivalents of bromine increase and can indicate that the three bonds of the Sn-C 
may be cleaved in succession upon addition of the bromine and lead to an increasing amount of BrAr cleavage product being present. A proposed set of reactions for this compound is seen in Scheme 13 with a focus on Sn-C cleavage. The three new cobaloxime products seen in the bridging region could be consistent with the formation of (4-t-BuPy)Co(DH $)_{2} \mathrm{SnAr}_{2} \mathrm{Br}$, (4-t$\mathrm{BuPy}) \mathrm{Co}(\mathrm{DH})_{2} \mathrm{SnArBr}_{2}$ and (4-t-BuPy)Co(DH $)_{2} \mathrm{SnBr}_{3}$ as the bromine titration progresses. Another option could be that Co-Sn bond cleavage may be possible after the cleavage of some of the Sn-C bonds due to changes in the electronic environment of the tin ligand. The exact products for these peaks can be suggested, but cannot be confirmed without the synthesis and characterization of the possible intermediates outlined in Scheme 13. One can infer that since the Sn-C bond is preferentially cleaved, the Sn-C bond cleavage with halogen is more facile than the Co-Sn bond with this set of compounds.

Figures 16 - 21 contain the aromatic region for the halogen cleavage titration. This spectral region gets more crowded, but the same behavior can be seen with the pyridine and phenyl peaks. Several new products are growing into the aromatic region of the cobaloxime as the bromine is added, but as the titration progresses some peaks are harder to resolve. Although this spectral region is not as clear as the bridging hydrogen and alkyl regions, we can still monitor the formation of the cleavage product 1-bromo-4-t-butylbenzene. The cleavage product has aromatic peaks 7.29-7.27 and 6.91-6.89 ppm. These peaks behave similarly to the t-Bu peak in the alkyl region and increase in intensity as the bromine is added in increasing equivalents. This preference for the Sn-C bond cleavage is demonstrated in this region as well and the changes in the spectra are consistent with the previously discussed proposed reaction Scheme 13. 


\subsection{Conclusions}

Several six-coordinate cobaloxime compounds containing a triaryltin ligand were synthesized and characterized. The susceptibility of these cobaloximes to halogen cleavage was investigated. The multiple products formed through these halogen cleavage reactions indicates that the Co-Sn bond is not readily cleaved cleanly for these cobaloximes, unlike the reactivity observed with the alkyl and tin porphyrin complexes. The cobaloximes react with the halogens to first cleave the Sn-C bonds through electrophilic aromatic substitution, which indicates that the Sn-C bond cleavage is more facile than the Co-Sn cleavage for this set of compounds. The alteration of the para substituent on the phenyl rings to change donor ability of the Sn-C bonds and alter the electronic environment in attempts to promote Co-Sn cleavage was unsuccessful. The ultimate goal of this work is to find a cobaloxime system, containing a triaryltin ligand, that will have clean cleavage of the Co-Sn bond so it can be compared to the porphyrin system to better understand the differences in reactivity between these two vitamin $\mathrm{B}_{12}$ analogues. 
5.0 References

1. Pratt, J. M., Inorganic Chemistry of Vitamin B B $_{12}$. Academic Press: London, 1972.

2. $\quad$ Smith, E. L.; Parker, L. F. J., Biochem. J. 1948, 43.

3. $\quad$ Smith, E. L., Nature 1948, 162.

4. Rickes, E. L.; Brink, N. G.; Koniuszy, F. R.; Wood, T. R.; Folkers, K., Science 1948, 107.

5. $\quad$ Barker, H. A.; Weissbach, H.; Smyth, R. D., Proc. Nat. Acad. Sci. 1958, 44.

6. Kaim, W.; Schwederski, B., Bioinorganic Chemistry: Inorganic Elements in the Chemistry of Life. John Wiley \& Sons: Chichester, 1994.

7. Dolphin, D., $B_{12}$ Volume I: Chemistry

John Wiley \& Sons: New York, 1982; Vol. 1.

8. Vitamin B 12 . https://en.wikipedia.org/wiki/Vitamin_B12\#/media/File:Cobalamin.png.

9. Porphyrin. https://en.wikipedia.org/wiki/Porphyrin\#/media/File:Porphyrin.svg.

10. Corrin. https://en.wikipedia.org/wiki/Corrin\#/media/File:Corrin.svg.

11. Schneider, Z.; Stroinski, A., Comprehensive B12. de Gruyter: Berlin, 1987.

12. Toscano, P. J.; Marzilli, L. G., Prop. Inorg. Chem. 1984, 31.

13. Schrauzer, G. N.; Kohnle, J., Chem. Ber. 1964, 97, 3056-3064.

14. Lenhert, P. G., Chem. Commun. 1967, 980-982.

15. Hegg, M. J.; Elder, R. C., Inorg. Chem. 1980, 19, 932-934.

16. Toscano, P. J.; Marzilli, L. G., Inorg. Chem. 1979, 18, 421-424.

17. Marzilli, L. G.; Epps, L. A.; Sorrell, T.; Kistenmacher, T. J., J. Am. Chem. Soc. 1975, 97, 3351-3358.

18. Elder, R. C.; P. E. Ellis, J., Inorg. Chem. 1978, 17, 870-874 
19. Elder, R. C.; Heeg, M. J.; Payne, M. D.; Trkula, M.; Deutsch, E., Inorg. Chem. 1978, 17, 431-440.

20. Elder, R. C.; Heeg, M. J.; Deutsch, E., Inorg. Chem. 1978, 17, 427-431.

21. Elder, R. C.; Trkula, M., J. Am. Chem. Soc. 1974, 96.

22. Elder, R. C.; Florian, L. R.; Lake, R. E.; Yacynych, A. M., Inorg. Chem. 1973, 12, 26902699.

23. Marzilli, L. G.; Toscano, P. J.; Randaccio, L.; Bresciani-Pahor, N.; Calligaris, M., J. Am. Chem. Soc. 1979, 101, 6754-6756.

24. Bresciani-Pahor, N.; Calligaris, M.; Randaccio, L., Inorg. Chim. Acta 1980, 39, 173-179.

25. Cao, Y.; Petersen, J. L.; Stolzenberg, A. M., Inorg. Chim. Acta 1997, (263), 139-148.

26. Cao, Y.; Petersen, J. L.; Stolzenberg, A. M., Inorg. Chem. 1998, 37 (20), 5173-5179.

27. Stolzenberg, A. M.; Cao, Y., J. Am. Chem. Soc. 2001, 123 (37), 9078-9090.

28. Stolzenberg, A. M.; Summers, J. S., Inorg. Chem. 2000, 39 (7), 1518-1524.

29. Summers, J. S.; Stolzenberg, A. M., J. Am. Chem. Soc. 1993, 115 (23), 10559-10567.

30. Schrauzer, G. N.; Kratel, G., Angew. Chem. Int. Ed. Engl. 1965, 4, 146-147.

31. Schrauzer, G. N.; Kratel, G., Chem. Ber. 1969, 102 (2392-2407).

32. Stolzenberg, A. M.; Workman, S. R.; Gutshall, J. E.; Petersen, J. L.; Akhmedov, N., Inorg. Chem. 2007, 46 (16), 6744-6754.

33. Chadha, P.; Gupta, B. D.; Mahata, K., Organometallics 2006, 25, 92-98.

34. Gupta, B. D.; Yamuna, R.; Singh, V.; Tiwari, U., Organometallics 2003, 22, 226-232.

35. Bulkowski, J.; Cutler, A.; Dolphin, D.; Silverman, R. B., Inorg. Synth. 1980, 20 (127134). 
36. Trogler, W. C.; Stewart, R. C.; Epps, L. A.; Marzilli, L. G., Inorg. Chem. 1974, 13, 15641570.

37. Tada, M.; Kaneko, K., J. Org. Chem. 1995, 60 (20), 6635-6636.

38. Kozeschkow, K. A.; Nadj, M. M.; Alexandrow, A. P., Chem. Ber. 1934, 67.

39. Dutta, Organometallics 2009, 28.

40. APEX2 is a Bruker AXS crystallographic software package for single crystal data collection, reduction and preparation.

41. Sheldrick, G. M., SHELXL-2013, Crystallographic software package, Bruker AXS, Inc., Madison, Wisconsin, USA.

42. International Tables for X-Ray Crystallography. Kynoch Press: Birmingham, 1974; Vol. IV.

43. Ng, M. C. C., Chem. Eur. J. 2009, 15, 6569-6572.

44. Chambers; Scherer, Phenyltin Compounds 1926, 48.

45. Krause, E., Berichte 1918, 51. 
Synthesis, Characterization, and Reactivity Studies of para-Substituted Triaryltin Cobaloximes

\section{Elizabeth Marie Ward}

Thesis submitted to the Eberly College of Arts and Sciences at West Virginia University in partial fulfillment of the requirements for the degree of

Masters of Science in Chemistry

C. Eugene Bennett Department of Chemistry

APPROVAL OF THE EXAMINING COMMITTEE
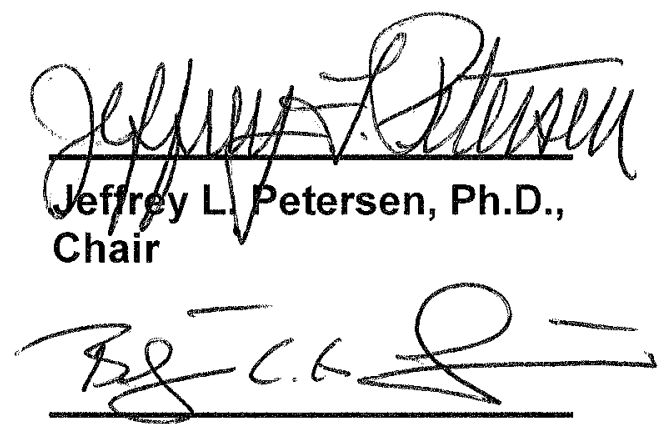

Björn C. G. Söderberg, Ph.D.

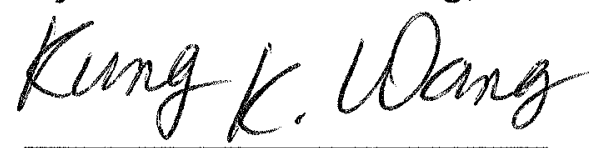

Kung K. Wang, Ph.D.

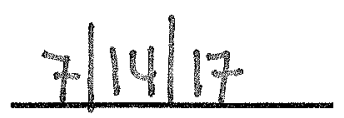

Date 